\title{
Certified Athletic Trainers' Abilities to Identify and Refer Athletes with Psychological Symptoms
}

Marc L. Cormier

West Virginia University

Follow this and additional works at: https://researchrepository.wvu.edu/etd

\section{Recommended Citation}

Cormier, Marc L., "Certified Athletic Trainers' Abilities to Identify and Refer Athletes with Psychological Symptoms" (2014). Graduate Theses, Dissertations, and Problem Reports. 239.

https://researchrepository.wvu.edu/etd/239

This Dissertation is protected by copyright and/or related rights. It has been brought to you by the The Research Repository @ WVU with permission from the rights-holder(s). You are free to use this Dissertation in any way that is permitted by the copyright and related rights legislation that applies to your use. For other uses you must obtain permission from the rights-holder(s) directly, unless additional rights are indicated by a Creative Commons license in the record and/ or on the work itself. This Dissertation has been accepted for inclusion in WVU Graduate Theses, Dissertations, and Problem Reports collection by an authorized administrator of The Research Repository @ WVU.

For more information, please contact researchrepository@mail.wvu.edu. 
Certified Athletic Trainers' Abilities to Identify and Refer Athletes with Psychological Symptoms

\author{
Marc L. Cormier, M.A.
}

Dissertation submitted to the College of Physical Activities and Sport Sciences at West Virginia University

in partial fulfillment of the requirements for the degree of

Doctor of Philosophy

In

Sport and Exercise Psychology

Sam Zizzi, Ed.D., Chair

Damien Clement, Ph.D., ATC

Edward F. Etzel, Ed.D.

Christine Schimmel, Ed.D.

Vanessa Shannon, Ph.D.

Department of Sport Sciences

\title{
Morgantown, West Virginia
}

2014

Keywords: psychology of injury, certified athletic trainers, psychological referral Copyright 2014 Marc L. Cormier 


\section{ABSTRACT \\ Certified Athletic Trainers' Abilities to Identify and Refer Athletes with Psychological Symptoms}

\section{Marc L. Cormier}

This study's purpose was to expand the literature based in the area of psychology of injury by assessing certified athletic trainers' (ATs') skills in symptom identification, intended course of action, and intervention identification with athletes experiencing psychological distress. Using a web-based survey protocol, data were collected from 326 (191 female and 132 male) ATs using three case vignettes. AT responses were compared to a panel of experts in psychology of injury and assessed for accuracy. Results indicated that ATs demonstrated high accuracy in symptom identification and making referral decision, but struggled in identifying appropriate interventions for athletes. Stepwise regression analyses revealed that as ATs reported more specific coursework in sport psychology, they were able to more accurately identify symptoms across all cases $(t=$ $3.01, p<.01)$ and those ATs with more experience reported lower scores in accurately choosing a course of action $(t=-2.25, p<.05)$. Overall, the results provide evidence of ATs' abilities to apply their knowledge of sport psychology within the athletic training realm while also raising some important questions regarding the structure of existing sport psychology coursework. Findings may emphasize the inclusion of coursework focusing more heavily on applied areas of sport psychology in the training of ATs. 


\section{TABLE OF CONTENTS}

\section{Table of Contents}

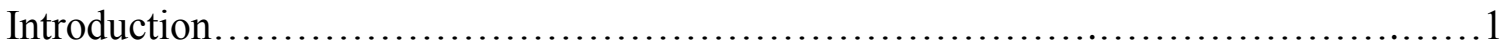

Methods........................................................................

Research Questions.................................................6

Participants and Recruitment.........................................

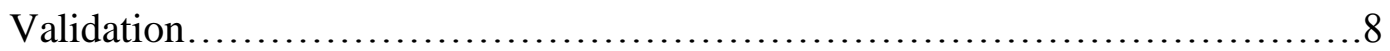

Pilot Testing................................................9

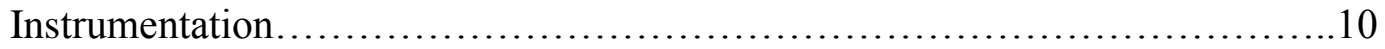

Case Vignettes..............................................10

Symptom Ratings......................................11

Recommendation for Best Course of Action ..................11

Recommendation for Referral..........................11

Implementing Psychological Interventions...................12

Perceived Roles of ATs........................................12

Perceived Competency Implementing Psychological Interventions.......13

Education and Training Relevant to PS...........................13

Referral Practices..............................................13

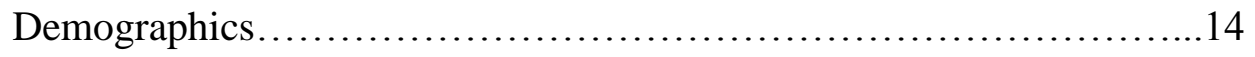

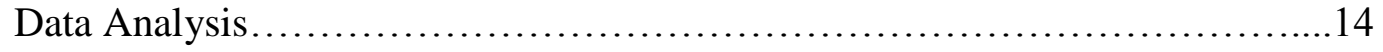

Results................................................................... 15

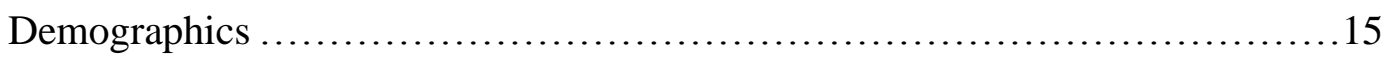


Perceptions about Psychosocial Competencies..............................15

Psychological Referrals................................................16

AT Accuracy in Symptom Identification, Referral Decisions, and Intervention

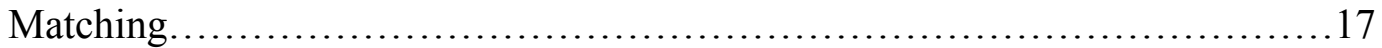

Predictors of Accuracy.................................................. 18

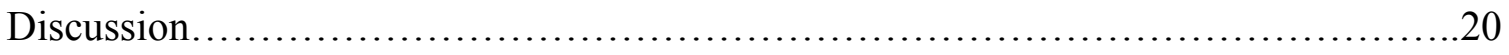

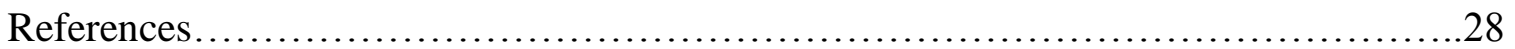

Appendix A - Web-Based Questionnaire ..........................................40

Appendix B - Email History .....................................................60

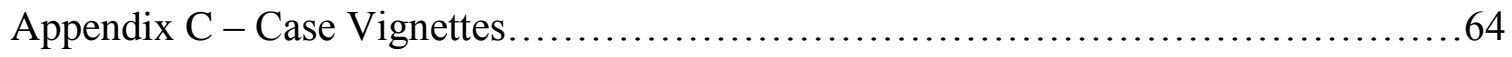

Appendix D - Results From Expert Panel...........................................66

Appendix E - Accuracy in Symptom Identification (Table 5).........................76

Appendix F - Accuracy in Intended Course of Action (Table 6) ........................78

Appendix G - Accuracy in Choosing Appropriate Interventions (Table 7)..............80

Appendix H - Review of the Literature......................................... 83 


\section{LIST OF TABLES}

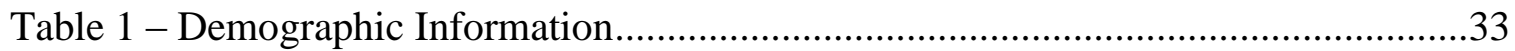

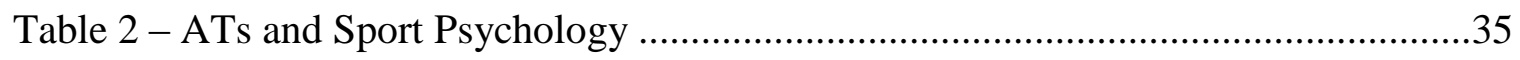

Table 3 - Post-Injury Concerns - Qualitative Analysis.......................................................36

Table 4 - Non-Injury-Related Concerns - Qualitative Analysis ........................................38 


\section{LIST OF FIGURES}

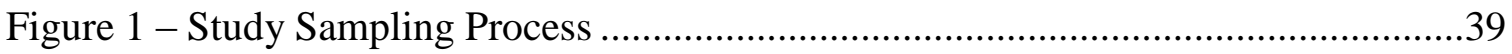




\section{ATs IDENTIFYING AND REFERRING PSYCHOLOGICAL SYMPTOMS}

\section{ACKNOWLEDGEMENTS}

I would like to express my gratitude to the following people without whom, the design and completion of this study would not have been possible. I couldn't have asked for a better group of Sherpa guides to help guide me up Research Mountain this past year.

First and foremost, I must express my everlasting gratitude to my wonderful teacher, advisor, and mentor, Dr. Sam Zizzi. You picked me up out of free-agency just in time for the playoffs, and we never looked back. Your guidance, wisdom, and patience have been invaluable to me throughout these four years, and particularly meaningful during my final year. I can't thank you enough for your contributions to my personal and academic development.

To Dr. Vanessa Shannon, one of the main reasons I made it to the dissertation stage of this program. Though I wish we could have finished what we started together, I truly admire the courage it took for you to follow your passion and pursue life outside of the academia bubble. Your guidance is something I will always remember and your friendship is something I will always cherish. Thanks, Doc!

Dr. Edward Etzel, the man, the myth, the legend. Thank you. A one-hour meeting with you will change the way one's views the world. I am forever grateful for our many, many, many one-hour meetings, cups of coffee, and for your contributions to this dissertation and my development as a consultant. Merci beaucoup!

To Dr. Damien Clement. Your passion for psych of injury was the main reason I chose this line of research. I am forever grateful that you introduced this area to me with such enthusiasm and energy. I am equally thankful that you so willingly shared your expertise in the conceptualization and completion of this project.

To Dr. Christine Schimmel, your expertise and input in counseling and applied work was greatly appreciated these four years. I admire your passion for teaching and to helping those under your tutelage. I've always enjoyed our conversations, regardless of the topic.

To the 494 athletic trainers who graciously and enthusiastically shared their knowledge and expertise with me, you have my lasting gratitude. Your passion for helping others (both athletes and aspiring researchers) is inspiring. Many thanks.

To my SEP family at WVU, particularly those who helped me adjust to life in Morgantown, thank you so very much. Despite constantly giving me a hard time for being Canadian (that's pretty much all of you), you made Morgantown feel like home. I'm very sad to leave you all, but grateful for all the memories I have.

À mame, pape, Tommy, Véronique, et la belle Oliva, to whom this dissertation is dedicated to. You provided me with every ounce of support a grad student could ever 
hope for. You have been a constant source of love and strength all these years and for this, I express my heart-felt gratitude to each of you. Merci infiniment!

Most importantly, none of this would have been possible without the love and support of my best friend and incredible wife, Jessalyn. Your encouragement and persistent confidence in me was invaluable in the completion of anything I have ever done. You are, without a doubt, the kindest, most supportive person I have ever met and I feel so incredibly lucky to be your husband. Nothing else matters, as long as we're together. Je t'adore. 
ATs IDENTIFYING AND REFERRING PSYCHOLOGICAL SYMPTOMS

\section{Introduction}

Certified athletic trainers (ATs) play a primary role in facilitating an athlete's rehabilitation following a sport-related injury. Understandably, the identification of physical problems and development of rehabilitation plans are viewed as being of primary importance for most sports medicine professionals when working alongside athletes. However, the importance of considering an athlete's psychological concerns during the rehabilitation process has also gained significant empirical attention since Rotella and Heyman (1986) remarked, "the future will demand that injury rehabilitation include both physical and psychological components" (p. 343). Specifically, research has reported that many psychological disturbances such as anxiety and stress (Wiese Bjornstal, Smith, Shaffer, \& Morrey, 1998), depression-like symptoms (Neal et al., 2013), and anger and frustration (Bianco, Malo, \& Orlick, 1999) have been linked to more time loss due to injury and more negative experiences during rehabilitation. In addition, research has also identified a number of psychosocial strategies shown to be advantageous to the rehabilitation process. As an example, Driediger, Hall, \& Callow (2006) revealed that injured athletes who utilized motivational imagery for goal setting and mental toughness were more likely to maintain focus, adhere to injury rehabilitation, and ultimately, return to play more quickly.

The national governing body responsible for certifying athletic trainers, the National Athletic Trainers' Association (NATA), has also recognized the value of psychosocial concerns in athletic injury by identifying a set of psychosocial competencies for entry-level athletic trainers (Neal et al., 2013). Specifically, ATs are required to demonstrate proficiencies in eight specific content areas (each with various sub- 
competencies) set forth by the NATA including, but not limited to: Evidence-Based Practice, Clinical Examination and Diagnosis, and Acute Care of Injury and Illness. One such competency, Psychosocial Strategies and Referral (PS), dictates that entry-level athletic trainers must possess basic theoretical knowledge and psychological strategies that allow them to recognize abnormal, social, and emotional behaviors exhibited by clients $^{1}$ (NATA, 2011). Specifically, PS comprises 18 of the total 228 educational subcompetencies (roughly 7\%) within the NATA guidelines. These competencies indicate that ATs must appreciate the role of mental health in injury and recovery, and be able to intervene and/or refer individuals, as necessary, to optimize rehabilitation. However, it is the Commission on Accreditation of Athletic Training Education (CAATE) that oversees the curriculum standards of all professional and post-professional institutions.

Unfortunately, as of 2014, best practice recommendations do not exist regarding how to educate athletic training students in this content area and CAATE allows flexibility in how program directors can fulfill these requirements. As a result, some accredited programs offer coursework that focuses primarily on the basic theoretical aspects of human behavior (e.g., general psychology 101) yet lack emphasis on practical applications of sport psychology techniques (e.g., imagery, relaxation training, referral) (Clement, Granquist, \& Arvinen-Barrow, 2013; Cramer Roh \& Perna, 2000). The variability in training models set to deliver these competencies, and the lack of a set of best practice guidelines, suggests that many ATs may not be receiving the training required to fulfill their responsibilities, as outlined by the NATA.

\footnotetext{
${ }^{1}$ For a comprehensive review of the NATA's Educational Competencies, including Psychosocial Strategies and Referral, please refer to: http://www.nata.org/education/education-resources.
} 
In the most recent evaluation of ATs' perceptions and experiences relating to PS, Clement and colleagues (2013) revealed from a sample of 215 certified ATs, that just over $55 \%$ of the sample $(n=119)$ had taken a formal sport psychology course at the undergraduate level and that $29 \%(n=63)$ reported taking a graduate level course in this content area, demonstrating a slight increase from previously conducted research (e.g., Larson et al., 1996). In addition, despite the increase in formal coursework related to PS, ATs in this study still expressed a clear desire to increase their current knowledge and overall understanding of PS, in order to provide the best possible care and understanding to their athletes. ATs also responded favorably to questions inquiring about the frequency of using psychosocial strategies. Specifically, ATs reported commonly using interventions such as goal setting, positive self-thoughts, motivational techniques, and stress reduction techniques. The majority also reported making referrals to mental health practitioners such as counselors, psychologists, and sport psychology consultants. However, it remains unclear whether ATs appropriately recognize various symptoms of psychological distress, pair the proper intervention with the presenting psychological concern or appropriately referred athletes requiring more specialized care. Additionally, the majority of this research relied heavily on surveys where ATs were asked to respond retrospectively regarding their experiences related to psychosocial techniques and referral practices.

Given the frequent contact and potential for strong rapport, athletes may feel more comfortable approaching ATs regarding emotional or psychological concerns, rather than mental health professionals such as counselors or sport psychology consultants (Clement \& Shannon, 2009; Maniar et al., 2001). As a result, ATs are in ideal positions to 
incorporate psychological interventions or techniques to aid athletes experiencing minor to moderate psychological distress and refer those with more severe responses. Thus, providing further support for a more structured approach to formalized training in PS.

In addition, due to the aforementioned proximity and rapport with athletes, ATs may encounter a variety of situations that warrant the referral of an injured athlete to a mental health professional. According to Ray and Wiese-Bjornstal (1999), there exist a variety of reasons for possible referral, including: psychopathology (e.g., eating disorders, mood disorders, depression, etc), adjustment difficulties, or rehabilitation setbacks. Often, signs of distress or impaired functioning may not be apparent, thus, ATs should familiarize themselves with the subtle signs commonly associated with adaptive and maladaptive rehabilitation while also securing a vast referral network. Overall, ATs reported making referrals to mental health professionals if they had access to them in their work settings (Clement et al., 2013). However, little is known regarding the specific nature or process of these referrals due to the descriptive nature of the available research. Hamson-Utley and Stiller-Ostrowski (2011) surveyed athletic training education program directors nation-wide and revealed that PS received the lowest instructional emphasis rank overall, with the majority (61\%) of the designated sub-competencies (e.g., counseling principles, referral, interventions) taught across various other athletic training core courses, rather than a designating course fulfilling these content areas. For the programs that offered psychology of sport/psychology of injury-related courses $(31 \%)$, the majority (72.6\%) relied heavily on lectures or discussions to deliver content with few programs $(21.8 \%)$ providing hands on, practical application of the content (e.g., case studies, role playing). Research implementing educational workshops and interventions 
has demonstrated that, when appropriately taught, ATs report significantly higher skill usage, overall knowledge, and positive attitudes toward this content area (e.g., Clement \& Shannon, 2009; Stiller-Ostrowski, Gould, \& Covassin, 2009). In addition, a more comprehensive education of the psychosocial factors influencing sport injury could aid ATs in effectively identifying "high-risk" athletes for intervention or referral (Cramer Roh \& Perna, 2000).

In an eight-month prospective study of 46 ballet dancers, Smith, Ptacek, and Patterson (2000) were able to attribute a considerable amount of variance in injury to psychosocial factors such as life stress and coping. Results suggested that $13-18 \%$ of the injury variance could be attributed to the interaction between daily stress and somatic anxiety. Furthermore, an earlier study conducted by Smith, Smoll, and Ptacek (1990) reported a significant relationship (22-30\% of the variance) between negative life events and injury in 424 high school varsity athletes, specifically for those who reported both low levels of social support and poor psychological copings skills. These data provide support that if ATs could be trained to identify high-risk athletes based on PS competencies, and match the appropriate intervention, they may contribute even further to improving athlete rehabilitation outcomes.

Research investigating the impact of psychological skills training during injury rehabilitation has also revealed positive results. For instance, Cupal and Brewer (2001) investigated the impact of post-surgical relaxation training, in the form of 10 individual sessions of relaxation and guided imagery, compared to placebo and control groups with similar injuries and post-surgical prognoses. Results indicated that, at 24 weeks postsurgery, those who were exposed to the psychosocial intervention reported significantly 
stronger knee strength (35\% of variance), and a significant reduction in reinjury anxiety and pain $(62 \%$ and $76 \%$ of variance in reduction, respectively). Findings such as these provide further support for the use of cognitive behavioral interventions to enhance both psychological and physical aspects of sport injury rehabilitation. The results suggest that such techniques may have an effect on recovery by accelerating physical recovery and decreasing the required visits to the AT room. Despite these findings, there remains a significant gap in the literature regarding the implementation of psychosocial strategies by ATs.

Therefore, the primary purpose of this study was to expand the literature base in the area of psychology of injury by assessing ATs skills in symptom identification, making referral decisions, and matching interventions with athletes experiencing psychological distress. These results will be compared to previously published data as well as NATA competencies to understand the current competency levels of working ATs in the area of psychosocial interventions.

\section{Method}

The purpose of this chapter is to outline the steps that will be followed in the identification and recruitment of participants, instrumentation, procedure, and data analysis.

\section{Research Questions}

Due to the exploratory nature of this study, the main research questions considered were:

1. Compared to a panel of experts, are certified athletic trainers able to correctly identify psychological symptoms and make correct referral decisions for athletes based on information presented in a case vignette? 
2. Compared to a panel of experts, are certified athletic trainers able to correctly match a psychological intervention for athletes based on psychological symptoms presented in a case vignette?

3. How do factors such as age, years of experience, perceived competency, and sport psychology coursework relate to a certified athletic trainer's ability to accurately identify psychological symptoms, make referral decisions, and identify appropriate interventions for athletes presented in case vignettes? The researcher hypothesized that athletic trainers perceived competencies, age, years of experience, and sport psychology coursework will positively predict their ability to (a) accurately identify symptoms, (b) make referral decisions, and (c) identify interventions in all three cases.

\section{Participants and Recruitment}

Following approval from the West Virginia University Institutional Review Board for the Protection of Human Subjects, potential participants were contacted via email, informed of the nature of the study, and invited to complete the web-based questionnaire (see Appendix A) posted on Qualtrics. Survey research collected via an internet site has been found to be a viable method of colleting data for scientific purposes (Dillman, 2007). Dillman also noted that there are many potential benefits of using web-based methods, such as easier access to participants, more flexibility for participants to access the survey information, less intrusion from the researcher, and greater likelihood of anonymity of participants.

As outlined by Creswell (2012) and Dillman (2007), a step-by-step procedure was used to communicate with all potential participants. These steps included (a) sending out 
an email to all randomly selected participants, including a description of the study, consent information, and link to the web-based questionnaire; (b) one week later, sending a reminder email to all ATs who did not complete the questionnaire; and (c) after one additional week, sending a final email notice to all who did not complete the survey. Each email (see Appendix B) included information regarding the study, outlining an explanation and goals of the study, and link that directed them to the web-based questionnaire. Participants gave their consent by choosing to complete the questionnaire.

Using this method of recruitment, participation was solicited from 2998 certified ATs, randomly selected from the 2014 NATA membership database. Of the 2998 emails sent, 1496 (49.8\%) were opened and viewed and of those, 494 (33\%) accepted the invitation to participate. Response rates will be indicated using the total number of ATs who opened and viewed the email and will be expressed as adjusted ratios. Thus, for those who began the web-based questionnaire, $168(11.2 \%)$ were only partially completed while 326 (21.8\%) questionnaires were entirely completed which produced an adjusted response rate of $33 \%$ (see Figure 1).

\section{Validation}

A panel of experts $(n=5)$ was assembled in order to determine the appropriate symptom identification, course of action, and intervention type for each case vignette. Experts were identified based on their experience and reputation in applied sport psychology, as well as their vast publication records in respected academic journals in the area of psychology of injury. Members of the expert panel included five members with doctoral degrees in areas related to sport and exercise psychology, four certified consultants with the Association for Applied Sport Psychology (CC-AASP), two licensed 
psychologists, two AASP Fellows, and one ATC. Each expert was given a copy of the survey and asked to respond to each question pertaining to all three case vignettes (e.g., whether they believed a particular symptom was present, their intended course of action, etc). In some cases, experts provided written feedback regarding their justification for their chosen response. Once all responses were compiled, a "correct" response was assigned when a minimum of four experts agreed on a particular response. Any question that did not reach the criteria for agreement was subjected to a second round of expert review. Only two rounds of responses were required in order for agreement to be achieved on all questions. A summary of the expert panel's responses can be found in Appendix C.

Pilot Testing. Prior to participant recruitment, extensive pilot testing of the survey materials was conducted, as suggested by Lackey and Wingate (1998). First, cognitive interviews were conducted with athletic training students (ATSs) $(n=3)$. Cognitive interviews are widely used during the pre-testing phase to detect items that are not clear to respondents as intended by the survey developers (Beatty, 2004). During this process, ATSs were instructed to complete the survey and encouraged to "think out loud." This method helped anticipate and identify potential errors made by study participants and helped understand how they might interpret and understand each question. Minor changes were made to the survey based on the responses from the three cognitive interviews. Second, a small group of experts $(n=5)$ in sport psychology, counseling psychology, athletic training, and survey design provided qualitative feedback on the content and structure of the survey. Third, a group of graduate students in sport and exercise psychology $(n=14)$ and athletic training $(n=13)$ participated in pilot 
testing the survey. This piloting process asked participants to provide specific feedback regarding the clarity of the questions, grammar, flow, completeness, ease of responding to questions, and length. Minor changes were made based on the feedback from all three phases of the piloting process.

\section{Instrumentation}

Case vignettes. Three vignettes (Appendix D) were developed, each depicting a different athlete competing at the collegiate level who is experiencing varying levels of difficulty rehabilitating from a sport injury. In each vignette, brief background information is provided regarding the athlete's age, gender, social relationships, year in college, sport type, sport and academic performance history, playing status, time of season, and previous injuries. Case vignettes were modeled (approximate length, depth of descriptive information, use of language, etc.) from previously developed vignettes in psychology of injury research (e.g., Brewer, Jeffers, Petitpas, \& Van Raalte, 1994; Maniar et al., 2001).

Following some basic background information, a description of injury was provided using appropriate language (e.g., Oscar is a soccer player who sustained a grade 3 ankle sprain while attempting to land from a header). Additionally, each vignette provided information regarding the athlete's initial response to injury (e.g., devastation, relief), timeline (e.g., how long since the injury and their projected recovery period), rehabilitation behaviors (e.g., adherence, behaviors, physical appearance), psychological factors (e.g., affect, motivation, effort), and various social factors (e.g., coach and teammate support). Each vignette varied in symptom severity: low (Stanley), moderate (Toby), and high (Oscar) in order to determine whether ATs were able to effectively able 
to identify symptoms relating to adaptive versus maladaptive responses to injury.

Vignettes were presented to ATs in random order (e.g., moderate, low, high). The description of symptoms in the case vignettes followed descriptions outlined by the fifth edition of the Diagnostic and Statistical Manual of Mental Disorders' for stress, anxiety, adjustment disorder, and depression. Symptoms included, among others, irritability, apathy, frustration, loss of motivation, social withdrawal, excessive worry, suicidal thoughts, and alcohol and drug use/abuse.

Symptom rating. Participants were asked to indicate, using a "yes" or "no" format, the presence of symptoms, depicted in each of the vignettes. The list of symptoms was created to purposefully include explicit (e.g., suicidal thoughts) and more ambiguous (e.g., difficulty adjusting to the injury) symptoms. For each case, respondents could accumulate a maximum of seven points for accuracy, when compared to responses from the panel of experts. For analysis purposes, total accuracy points were summed across all three cases and averaged (out of 7).

Recommendations for best course of action. Following the symptom identification, participants were asked to identify their intended course of action for each athlete depicted in the vignettes. Participants were given four options to choose from (a) take no action, (b) monitor closely, but make no referral, (c) consult with a supervisor, or (d) make an immediate referral. Respondents were given one point if they chose the correct course of action. Total accuracy was calculated by summing scores from all three cases, with a maximum score of three.

Recommendations for referral. If the AT chose to make a referral for the athlete, they were then asked how likely they were to choose a specific referral source. 
Specifically, participants were asked to indicate the likelihood of referring to a: (a) sport psychology professional, (b) medical supervisor (head AT, team physician), or (c) mental health professional (counselor/psychologist). These particular professionals were chosen due to their relative availability to the vast majority of certified athletic trainers and based on previous research using similar methodology (e.g., Maniar, Lewis, SommersFlanagan, \& Walsh, 2001). Results from this question were not included in the analysis due to large discrepancies in access and protocol of these professionals. Thus, what would be considered protocol in one workplace (e.g., referral to senior/supervising AT) may not be in others.

Implementing psychological interventions. Finally, participants were asked to indicate using a "yes" or "no" format, whether they believed specific psychological interventions/skills were helpful for each athlete based on the information presented in the case. Interventions were chosen based on those used in previous research (e.g., Clement et al., 2013; Larson et al., 1996; Zizzi, Blom, Watson, Downey, and Geer, 2009) and NATA educational competencies. They included: goal setting, self-talk, imagery, relaxation training, effective communication, social support, and concentration and focus skills. For each case, respondents could accumulate a maximum of 11 points for accuracy, when compared to responses from the panel of experts. For analysis purposes, calculating the average accuracy points across all three cases created an overall accuracy score out of 11 possible points.

Perceived roles of ATs. Using a "yes, no, not sure" format, participants were asked to respond to six statements regarding the roles of ATs including: (a) identifying possibly harmful responses to injury, (b) assessing and diagnosing physical injuries, (c) 
facilitating psychosocial referral, (d) explaining the best course of action to athlete and coach, (e) providing counseling to athletes for personal issues, and (f) administering psychosocial interventions to facilitate physical recovery from injury. These statements were derived from the NATA consensus agreement and represent the "minimum requirements for a student's professional education" (The NATA Training Education Competencies, 2011).

Perceived competency implementing psychosocial interventions. Participants were asked, using a 4-point likert scale from 1 (not at all competent) to 4 (very competent), to indicate their perceived level of competency for a number of basic psychosocial interventions, including: goal setting, imagery, relaxation, self-talk, communication, improving social support, focus, and pain management). These interventions were based off the NATA educational competencies as knowledge and skills that all entry-level ATs should possess and have the ability to implement. For analysis purposes, calculating the average rating across all competencies created an overall competency score with a maximum score of 4 .

Education and training relevant to PS. Using a multiple response format, participants indicated whether they received training in sport psychology and/or psychology of injury at the undergraduate and/or graduate level. Although the question specifically asked ATs to include any coursework they had taken in these areas, it is possible that many respondents interpreted this question as whether they had been exposed to each subject during their education. For analysis purposes, responses were combined into one variable, where participants received one point for taking a specialized course at any level for a maximum score of 4 . 
Referral practices. Participants were asked to indicate whether various mental health professionals (counselors, psychologists, sport psychology consultants) are accessible to them through their work as an AT. In addition, participants were asked whether they had a referral process in place and if so, to provide a brief summary of this procedure. Finally, participants were asked whether they have ever referred an athlete to a mental health professional, provided an estimation of the number of referrals made, and most common reason(s) for doing so.

Demographic information. Participants provided basic demographic information regarding their gender, age, race/ethnicity, highest academic degrees, current certifications, number of years as an AT, type of sport with which they currently work, and current employment setting as an AT (e.g., high school, university, professional, private).

\section{Data Analyses}

The quantitative analysis of the study consisted of two steps. Regarding the first and second research questions of the study, descriptive statistics were compiled to provide a summary of participants' ability to accurately diagnose, make appropriate procedural decisions, and match psychological interventions based on symptoms presented in three case vignettes. These descriptions include a summary of their responses and assessment of their relative accuracy when compared to the responses of the expert panel.

The third research question asked how factors such as age, years of experience, perceived competency, and coursework in sport psychology related to an ATs accuracy in symptom identification, intended course of action, and intervention identification. 
Stepwise regression models were used to evaluate this research question. However, preliminary regression analyses revealed variance inflation factors (VIF) above 5 and tolerance statistics below 3, indicating multicollinearity (Menard, 1995; Myers, 1990) between ATs' age $(\mathrm{VIF}=11.88$, tolerance $=.08)$ and years of experience $(\mathrm{VIF}=11.91$, tolerance $=.08)$. Given the conceptual similarity of these predictors, age was excluded from all regression analyses.

\section{Results}

\section{Demographics}

The average respondent to the web-based questionnaire was 34.7 years old $(S D=$ 10.8) and reported having an average of 11.3 years of experience in the field $(\mathrm{SD}=9.9$ years). Females comprised 191 (59\%) of the 326 respondents while $132(40.1 \%)$ were male and $3(0.9 \%)$ were undisclosed. Most ATs were employed at either the high school $(35.3 \%)$ or university settings $(33.9 \%)$. A majority of the respondents $(62.6 \%)$ reported having a master's degree, and 68\% ATs had at least taken an undergraduate course in psychological of injury. Additionally, as many as $41.3 \%$ of respondents reported taking a graduate course in sport psychology and 33\% reported taking a graduate course in psychology of injury (see Table 1).

\section{Perceptions About Psychosocial Competencies}

The results from the descriptive statistical analyses revealed that participants perceived their responsibilities as ATs to vary in importance (see Table 2). For instance, 97.3\% of respondents believed that facilitating psychological referral was a major responsibility of all ATs when the athlete exhibits personal distress. In addition, over $90 \%$ of respondents believed it is the responsibility of the AT to recognize adaptive and 
maladaptive psychological responses during injury rehabilitation. However, only $43 \%$ of respondents felt it was their responsibility to implement psychological interventions of any kind with an athlete experiencing distress.

Additionally, ATs in the sample rated their overall competencies in implementing selected psychosocial strategies as competent $(M=3.15, S D=0.74 ; 1=$ not at all competent, 4 = very competent); and perceived themselves as most competent in facilitating athlete's understanding of injury $(M=3.77, S D=0.47)$, goal setting $(M=$ $3.73, S D=0.56)$, encouraging effective communication $(M=3.70, S D=0.54)$, and using active listening $(M=3.65, S D=0.55)$. On the other hand, ATs felt least competent in teaching and implementing performance imagery $(M=2.49, S D=0.93)$ and healing imagery $(M=2.51, S D=0.97)$, developing focus cues $(M=2.59, S D=0.92)$, and teaching progressive muscle relaxation $(M=2.72, S D=0.92)$.

\section{Psychological Referrals}

Overall, ATs reported being comfortable making psychological based referrals ( $M$ $=4.76, S D=1.09 ; 1=$ not at all comfortable, $6=$ extremely comfortable $)$ despite only $61.3 \%$ of all participants reporting ever making such a referral during their careers and $50 \%$ having a referral procedure in place. Additionally, the majority (80.6\%) of ATs reported having regular access to mental health professionals such as counselors or psychologists. However, less than half $(45.8 \%)$ of all respondents described having access to sport psychology professionals at their current place of employment. Despite differences in access to professionals ATs believed that sport psychology professionals to be slightly more helpful $(M=3.21, S D=0.68)$ compared to mental health professionals 
$(M=3.15, S D=0.69 ; 1=$ not at all helpful, $4=$ extremely helpful $)$ in athlete rehabilitation.

ATs who reported making a psychological-based referral in the past two years (n $=196)$ reported anywhere between 0 to 30 referrals made $(M=3.40, S D=4.17)$. These ATs were also asked to indicate the most common reason(s) for making a psychologicalbased referral. A brief thematic content analysis of their responses revealed a total of 351 reasons for making psychological-based referrals ${ }^{2}$. More specifically, $302(86.1 \%)$ were described as referrals made as a result of psychological concerns following an injury (see Table 3). The most common reasons for injury-related referrals were depression or depression-like symptoms $(\mathrm{n}=73)$, followed by eating disorders/disordered eating $(\mathrm{n}=$ 55), suicidal ideation/self-harm $(n=38)$, and anxiety $(n=29)$. The remaining $49(13.9 \%)$ reasons for referral were described as referrals for non-injury related psychological concerns (see Table 4). These reasons for referral included family or personal issues $(\mathrm{n}=$ 20), pre-existing mental health concerns $(n=12)$, adjusting to collegiate athletics $(n=9)$, and dealing with death and grief $(n=6)$.

\section{AT Accuracy in Symptom Identification, Referral Decisions, and Intervention}

\section{Matching}

ATs in the sample demonstrated a high ability to correctly identify psychological symptoms as presented in three case vignettes. Specifically, when compared to responses established from the expert panel (maximum score $=7$ ), ATs responded well in the low $(M=5.98, S D=1.00)$, moderate $(M=6.03, S D=0.65)$, and high $(M=6.75, S D=0.82)$

\footnotetext{
${ }^{2}$ Some ATs provided several "most common" reasons for referral (e.g., depression, disordered eating, and issues with motivation) while others only provided one response (e.g., anxiety).
} 
cases (See Table 5 in Appendix ). Overall, ATs averaged a score of $6.27(S D=0.49)$ on total symptom identification across all participants and all three cases.

When asked to choose their intended course of action, from a list of four choices, most ATs chose correctly for the low (97.3\%) and high (89.7\%) cases. However, less than half of ATs $(38.3 \%)$ chose the appropriate course of action for the moderate case (see Table 6 in Appendix). For this particular case, $61 \%$ of respondents over-referred this athlete, choosing to either consult with a supervisor/mental health professional (59\%) or immediately refer to a mental health professional $(2 \%)$.

Finally, ATs appeared to have some difficulty when choosing appropriate interventions for each athlete presented in case vignettes. Specifically, compared to responses established from the expert panel (maximum score $=11$ ), ATs responded moderately well in the low $(M=8.80, S D=1.43)$ and moderate case $(M=7.91, S D=$ 1.38), yet averaged 5.42 in the high case $(S D=1.62)$ (See Table 7 in Appendix). Closer examination of the data for the high case was revealing. Specifically, the majority of ATs identified every intervention as helpful for this particular athlete, while the expert panel only identified four as helpful.

\section{Predictors of Accuracy}

The hypothesis in the current dissertation predicted that athletic trainers' perceived competency, years of experience, and sport psychology coursework would positively predict their ability to (a) accurately identify symptoms, (b) make referral decisions, and (c) identify interventions. Three separate stepwise multiple regressions were conducted to test this hypothesis. In each analysis, perceived competency, years of experience, and sport psychology coursework were entered as predictors. In the first 
regression, with symptom accuracy entered as the outcome, results revealed a significant model, $F(1,297)=9.03, p<.01$. Closer examination of the beta weights revealed that exposure to sport psychology courses was the only significant predictor of athletic trainers' accuracy in diagnosing symptoms $(\beta=.17, t=3.01, p<.01)$, accounting for $3.0 \%$ of variance in accuracy scores. This result indicates that as ATs reported specific coursework in sport psychology, they were able to more accurately identify symptoms across the three cases.

A second stepwise multiple regression included ATs' recommended course of action as the outcome variable. Results indicated a significant model, $F(1,308)=8.39, p$ $<.01$. Beta weights within the model revealed that years of experience as an AT was the only significant predictor of athletic trainers' accuracy in recommending the best course of action $(\beta=-.16, t=-2.90, p<.01)$, accounting for $2.7 \%$ of variance in accuracy scores. Contrary to hypotheses, this small effect indicates lower accuracy scores as experience increases. Follow-up stepwise regression analyses on ATs' recommended course of action for Toby (moderate) revealed a significant model, $F(1,308)=5.08, p<$ .05. This analysis was run because ATs did poorest compared to the other two case vignettes. Closer examination of the findings indicated that years of experience was the only significant predictor, $(\beta=-.13, t=-2.25, p<.05)$, accounting for $1.6 \%$ of the variance in accuracy scores. These findings demonstrate that those with more years of experience as an AT reported slightly lower accuracy scores in their intended course of action.

Results of a third stepwise multiple regression, with ATs' intervention recommendations entered as the outcome variable, indicated a nonsignificant model. Due 
to the fact that ATs did much worse choosing recommended interventions for Oscar, follow-up stepwise regression analyses on ATs' recommended intervention for Oscar (high) revealed a significant model, $F(1,305)=13.04, p<.001$. Closer examination of the model indicated that exposure to sport psychology coursework was the only significant predictor, $(\beta=-.20, t=-3.61, p<.001)$, accounting for $4.1 \%$ of the variance in intervention scores. Overall, these results indicate a negative association between sport psychology coursework and ones accuracy in identifying appropriate interventions.

\section{Discussion}

With nearly 500 ATs completing at least part of the web-based survey, these findings represent the largest sample of ATs with advanced training in PS to date. Specifically, nearly all (96\%) respondents had taken a general psychology course while an impressive portion had taken a sport psychology course at the undergraduate $(70.8 \%)$ or graduate (41.3\%) levels. Previous research evaluating ATs (e.g., Clement et al., 2013; Larson et al., 1996; Moulton et al., 1997) revealed that approximately half (55\%) of all sampled ATs had taken an undergraduate course in sport psychology and as many as $29 \%$ reported taking a graduate course in sport psychology. Additionally, a large portion of the current sample of ATs successfully completed specialized courses (i.e., psychology of injury) at the undergraduate $(68 \%)$ and graduate $(34 \%)$ levels. Unfortunately, the most recent evaluation of ATs' education (i.e., Clement et al., 2013) does not provide data regarding coursework in psychology of injury of previously surveyed ATs. The addition and continued inclusion of PS to the NATA educational guidelines and CAATE accreditation standards are most likely responsible for the increasing rates of PS coursework found in the current sample. It is possible, though, that the higher rate of ATs 
with sport psychology coursework in the current study may be due to response bias in the sample, as those with more training in PS may have been more inclined to participate than those ATs without this specialized training. However, due to the high percentage of sampled ATs having taken psychology of injury courses, it is possible that some respondents interpreted the question as whether they had received training in these areas, through workshops, seminars, or continuing education and not formal coursework.

ATs in the current sample provided mixed responses regarding their perceived competencies relating to psychological aspects of sport injury. Specifically, many ATs reported feeling "very competent" using several techniques (e.g., goal setting, active listening, providing emotional support) with athletes during injury rehabilitation, while also feeling less competent using others (e.g., imagery, focus cues, deep breathing). Overall, these findings are consistent with previous research, which indicated that ATs generally felt competent and frequently used goal setting, self-talk, and motivation, yet reported feeling unprepared to implement many of the more advanced mental skills such as imagery and relaxation training (Stiller-Ostrowski \& Hamson-Utley, 2010; StillerOstrowski \& Ostrowski, 2009). A recent evaluation of psychological skill implementation (e.g., Zizzi et al., 2009) may help interpret the observed variance in skill competency. Specifically, Zizzi and colleagues utilized the perceptions of ATs, coaches, and psychologists to establish a hierarchy of various psychological skills. Their results indicated that many of the same psychological skills that current respondents felt least competent in implementing were characterized as requiring high levels of specialized training. Given these, and previous findings, it is possible that mastering the implementation of certain psychological skills (e.g., imagery, self-talk, focus) remain 
outside the scope of a single undergraduate or graduate level course in sport psychology and therefore, may not be appropriate for entry-level ATs to use. Thus, should the NATA and CAATE decide to revise the educational guidelines of PS, they may consider adjusting the psychological skills that ATs are expected to implement by excluding the more advanced skills. Additionally, established athletic training education programs could increase active learning techniques (e.g., role playing, case studies, practical training) to supplement existing course content and improve the overall learning experience for ATSs, or perhaps offer continuing education workshops in methods of implementing more complex psychological skills.

ATs demonstrated relatively high accuracy in symptom identification for all three cases. Additionally, there was little variance in symptom identification, with respondents correctly identifying at least four of seven symptoms in all cases. These patterns of high accuracy appear to be a result of the aforementioned training in sport psychology, especially since this variable was found to be the only significant predictor in symptom identification. These findings seem to contrast with earlier research (e.g., Brewer, Petitpas, Van Raalte, Sklar, \& Ditmar, 1995; Maniar, et al., 1999) which concluded that ATs had difficulty identifying clinically meaningful emotional disturbances in injured athletes. However, these studies used correlations to compare athlete self-reports of psychological symptoms to ATs observations of behavioral indicators of distress, which makes comparison to the current findings difficult. All available research investigating this question was published prior to the NATAs implementation of the PS competency into their educational guidelines (i.e., $3^{\text {rd }}$ Edition, 1999), which suggests that previously sampled ATs had significantly fewer opportunities to take courses in sport psychology. 
One might surmise that ATs will continue to improve in these areas, given the availability of sport psychology coursework at the undergraduate and graduate levels at many institutions where accredited AT programs are housed.

Despite their accuracy in symptom identification, ATs appeared to struggle when choosing appropriate interventions for each athlete. Of particular concern was the low accuracy in choosing interventions for the high-risk case (Oscar). Many ATs believed that all 11 interventions were helpful for Oscar, despite only four being identified as the correct response by the expert panel. However, most (90\%) ATs chose the correct course of action for him (immediately refer). Thus, it is possible that ATs recognized the severity of this athlete's symptoms and simply believed that all interventions could be of some help to him. While their accuracy in choosing symptoms was low, it is encouraging that they would refer this athlete to a mental health professional, rather than attempt to intervene themselves. Furthermore, even though ATs were mostly accurate in deciding how to proceed with Stanley (low) and Oscar (high), most (61\%) over-referred Toby (moderate), choosing to either consult with a supervisor or immediately refer to a mental health professional. It is possible that, in the case of Toby, ATs were unsure how to proceed and thus, took the more conservative approach in their referral decisions in an effort to ensure that any possibly serious issues were not overlooked. In other words, ATs may have preferred not to ignore borderline symptoms at the risk of them developing into more severe concerns. While the majority chose the incorrect course of action, in the case of psychological referral, it is probably best to act conservatively.

Regression analyses also indicated interesting trends in the prediction of ATs intended course of action. Specifically, less experienced ATs were slightly more accurate 
in deciding the best course of action for all cases, particularly the moderate case. These findings are contrary to findings from research on procedural decision making in health professions (e.g., physiotherapy, nursing). Specifically, Smith and colleagues (2007) reported that, when evaluated by a supervisor, more experienced physiotherapists (PTs) adopted an approach to decision making that was more specific, refined, and ultimately, more accurate compared to those with less clinical experience. Furthermore, Phillips and colleagues, (2004) concluded that novice PTs often choose to follow protocol and guidelines derived from university-based teachings whereas experts are more likely to see a situation more broadly and critically apply rules and norms based on previous experience. It is therefore possible that more experienced ATs in this study felt limited due to the restricted options provided in the questionnaire and thus, weren't able to make more creative, yet still correct, procedural decisions. Additionally, the survey and written cases may have favored the younger ATs who were exposed to this type of evaluation in their courses more recently, whereas the older ATs may not have been exposed. Finally, it is possible that younger ATs were more likely to work in school settings rather than private clinics, where access to mental health professionals is more readily available. Future research should attempt to explore and understand this relationship more closely by asking ATs to explain the process they use to arrive to a procedural decision, or testing ATs decision making in live or video scenarios to more closely mimic real world conditions.

The absence of sport psychology coursework as a predictor in decision-making is interesting but not entirely surprising. Previous research by Stiller-Ostrowski and Ostrowski (2009) reported that even formal sport psychology courses tend to be 
predominantly theory-driven and lack practical emphasis and application of sport psychology concepts within the athletic training realm. Further, Scherzer (2004) recommended that courses should focus on educating students about referral procedures and protocols, yet few actually do. As a result, even highly trained ATs may struggle to make appropriate decisions.

Finally, understanding referral behaviors of ATs is important to ensuring that athletes are receiving the best quality of care. ATs in the current sample revealed feeling moderately comfortable making psychological-based referrals in addition to having positive attitudes regarding the helpfulness of mental health professionals and sport psychology consultants. Additionally, $61 \%$ of respondents reported making a referral, regardless of their access to any professional. These findings are consistent with previous research (e.g., Clement et al., 2013; Larson et al., 1996; Moulton et al., 1997), which indicated that that $84 \%$ of sampled ATs with access to psychological services have made at least one psychological-based referrals. Additionally, the current sample reported relatively high access to counselors/psychologists (80.6\%), as opposed to sport psychology consultants (45.8\%). This discrepancy is most likely due to the high proportion of ATs employed in high school and university settings, where access to mental health professionals or school counselors is common. Despite this difference in access, ATs perceived mental health professionals and sport psychology consultants as equally helpful to the rehabilitation process. This similarity may be due to the growing presence of mental health and sport psychology in the media and professional sports health, leading ATs to become increasingly more aware of the benefits of such resources (Schinke et al., 2006). 
ATs described a number of reasons for making psychological-based referrals, which ranged from more minor (e.g., team concerns, frustration) to clinical issues (e.g., depression, suicidal ideation). Additionally, ATs reported a number of non-injury related reasons for making referrals (e.g., family issues, pre-existing mental health concerns, death/grief). Previous research (Wiese-Bjornstal \& Shaffer, 1999; Neal et al., 2013) has indicated wide ranging psychological distress of injured athletes that often require specialized attention and referral. Specifically, Neal and colleagues described that subclinical issues can develop into a level of distress that could hinder the athlete's rehabilitation if not addressed early. Thus, current results are promising, given that ATs reported making frequent referrals when they observed signs of athlete distress. Findings from the current study also lend support to the notion of ATs as "front-line counselors" (Clement \& Shannon, 2009; Henderson \& Carroll, 1993). Specifically, ATs appeared to use their proximity and strong rapport with both injured and non-injured athletes to recognize psychological distress that may otherwise go unnoticed and appropriately refer these individuals.

The current study had a number of limitations that should be noted when interpreting the findings. First, the questionnaire was disseminated using email addresses that were provided by the NATA membership database. Thus, while email distribution may have reached more prospective participants, it may have also influence the scope of the sample who took the survey. Specifically, ATs who do not use email regularly may have been less likely to participate. However, countering this limitation is the fact that the sample of respondents represents the largest pool to date of ATs with training and interest in PS interventions. In addition, none of the recruitment emails included any information 
about sport psychology in the subject heading, thus limiting the possible response bias. Second, the responses compiled by the panel of experts may not represent actual "correct" responses to the questions relating to symptom identification, intended course of action, and intervention choice. Rather, they represent the consensus of this particular group of professionals. However, given the experience level of each member of this panel, it is conceivable that many other experts would respond similarly. Third, respondents were asked to respond to question relating to three male athletes with varying psychological symptoms. While this was intentional, ATs may have responded differently if the cases depicted female athletes. Future studies should not only explore this possibility, but also investigate the gender of the AT as a variable to fully understand this phenomenon. Finally, all responses on the questionnaire relied on ATs to self-report responses (e.g., perceived competencies, referrals behaviors, perceptions of sport psychology), which may have influenced the accuracy of the results and conclusions drawn from them.

In summary, ATs who chose to participate in this study appear to be mindful of the psychological aspects associated with sport injury and reported making frequent referrals for various psychological issues. Particularly encouraging is the fact that they appeared to have the knowledge to accurately identify the presence and absence of psychological symptoms in athletes. Additionally, ATs had a relatively strong understanding of their responsibilities and felt competent implementing many psychological techniques with athletes during rehabilitation. However, ATs struggled when asked to choose appropriate psychological interventions, which could be explained by the theoretical nature of most sport psychology courses. Therefore, a case could be 
made for the addition of practical experiences during PS coursework in order to ensure ATs are capable of navigating more applied situations with athletes.

Although the current study provided insight into ATs accuracy in symptom identification, intended course of action, and intervention identification, a number of important questions have emerged that merit further research. Specifically, while ATs did well in deciding the best course of action for athletes, the current study did not explore how ATs came to their respective decisions. Thus, future studies may use a qualitative approach to attain valuable insight into the decision-making process and supplement the current findings. Additionally, given the highly trained nature of the current sample, future research could add to the current findings by including a more diverse sample of participants. For instance, researchers may want to recruit ATs from conferences or conventions where participants could be accessed with less sport psychology coursework and training. Furthermore, due to the use of case vignettes in the current study, it is possible that some of the information within the cases were obvious (i.e., "Toby is visibly frustrated"), and thus led to high accuracy in ATs' responses. Future studies may employ other methods, such as utilizing videos, requiring ATs to pick up on more subtle behavioral cues. Finally, an assessment of injured athletes' perceptions of ATs use and knowledge of sport psychology could provide valuable insight into this area. Much of the research investigating ATs perceptions and applications of PS (this study included) fail to address the unique insights of the athletes under their care. Thus, providing the injured athlete with a voice could significantly increase our understanding of this important area of research. 


\section{References}

Bianco, T., Malo, S., \& Orlick, T. (1999). Sport injury and illness: Elite skiers describe their experiences. Research Quarterly for Sport and Exercise, 70, 157-169. doi: 10.1080/02701367.1999.10608033

Beatty, P. (2004). The dynamics of cognitive interviewing. In: S. Presser, J. M. Rothgeb, M. P. Couper, J. T. Lessler, E. Martin, J. Martin, \& E. Singer, (Eds.). Methods for testing and evaluating survey questionnaires (pp. 45-66). Hoboken, NJ: John Wiley \& Sons, Inc.

Brewer, B. W., Jeffers, K. E., Petitpas, A. J., \& Van Raalte, J. L. (1994). Perceptions of psychological interventions in the context of sport injury rehabilitation. The Sport Psychologist, 8, 176-188.

Brewer, B. W., Petipas, A. J., Van Raalte, J. L., Sklar, J. H., Ditmar, T. D. (1995). Prevalence of psychological distress among patients at a physical therapy clinic Specializing in sports medicine. Sports Medicine, Training, and Rehabilitation, 6, 138-145.

Clement, D., Granquist, M. D., \& Arvinen-Barrow, M. M. (2013). Psychosocial aspects of athletic injuries as perceived by athletic trainers. Journal of Athletic Training, 48, 512-521. doi: 10.4085/1062-6050-48.3.21

Clement, D., \& Shannon, V. R. (2009). The impact of a workshop on athletic training students' sport psychology behaviors. The Sport Psychologist, 23, 504-522.

Cramer Roh, J. L., \& Perna, F. M. (2000). Psychology/Counseling: A universal competency in athletic training. Journal of Athletic Training, 35, 458-465. 
Cupal, D. D., \& Brewer, B. W. (2001). Effects of relaxation and guided imagery on knee strength, reinjury anxiety, and pain following anterior cruciate ligament reconstruction. Rehabilitation Psychology, 46, 28-43. doi: 10.1037//00905550.46.I.28

Creswell, J. W. (2012). Qualitative inquiry and research design: Choosing among five approaches. Thousand Oaks, CA: Sage.

Dillman, D. A. (2007). Mail and internet surveys: The tailored design method (2 ${ }^{\text {nd }}$ ed.). Hoboken, NJ US: John Wiley \& Sons Inc.

Driediger, M., Hall, C., \& Callow, N. (2006). Imagery use by injured athletes: A qualitative analysis. Journal of Sports Sciences, 24, 261-271. Doi: $10.1080 / 02640410500128221$

Hamson Utley, J. J., Stiller Ostrowski, J. L. (2011). Athletic training educators' instructional methods and confidence in graduating students' abilities regarding psychosocial intervention and referral. Athletic Training Education Journal, 6, 154-162.

Lackey, N. R., \& Wingate, A. L. (1998). The pilot study: One key to research success. In P. J. Brink \& M. J. Wood (Eds.). Advanced design in nursing research (pp. 375386). Thousand Oaks, CA: Sage.

Larson, G. A., Starkey, C., \& Zaichkowsky, L. D. (1996). Psychological aspects of athletic injuries as perceived by athletic trainers. The Sport Psychologist, 10, $27-$ 37. 
Maniar, S. D., Curry, L. A., Sommers-Flanagan, J., \& Walsh, J. A. (2001). Studentathlete preferences in seeking help when confronted with sport performance problems. The Sport Psychologist, 15, 205-223.

Maniar, S., Perna, F., Newcomer, R., Cramer Roh, J., \& Stilger, V. (1999, September). Athletic trainers' recognition of psychological distress following athletic injury: Implications for referral. Symposium conducted at the annual meeting of The Association for the Advancement of Applied Sport Psychology, Banff, Alberta, Canada.

Menard, S. (1995). Applied logistic regression analysis. Sage university paper series on quantitative applications in the social sciences, 07-106. Thousand Oaks, CA: Sage.

Myers, R. (1990). Classical and modern regression with applications ( $2^{\text {nd }}$ ed.). Boston, MA: Duxbury.

National Athletic Training Association (2013). Athletic training education competencies. Fifth edition. Retrieved from: http://www.nata.org/education/competencies.

Neal, T. L., Diamond, A. B., Goldman, S., Klossner, D., Morse, E. D., Pajak, D. E., ... Welzant, V. (2013). Inter-association recommendations for developing a plan to recognize and refer student-athletes with psychological concerns at the collegiate level: An executive summary of a consensus statement. Journal of Athletic Training, 48, 716-720. 
Phillips, J. K., Klein, G., \& Sieck, W. R (2004). Expertise in judgment and decision making: A case for training intuitive decision skills. In. D. J. Koehler \& N. Harvey (Eds.). Blackwell handbook of judgment and decision making. (pp. 297315). Malden, MA: Blackwell Publishing.

Ray, R., Wiese-Bjornstal, D. M. (1999). Counseling in sports medicine. Champaign, IL: Human Kinetics.

Rotella, R. J. \& Heyman, S. R. (1986) Stress, injury and the psychological rehabilitation of athletes. In J.M. Williams (Ed.), Applied sport psychology: Personal growth to peak performance (pp. 343-364). Palo Alto, CA: Mayfield.

Seiler, B. D., Gentner, N. B., Wehring, S. P., \& Joyner, A. B. (2013). Athletic training Education program directors' and athletic trainers' perceptions of the psychosocial interventions and referral competencies. Comprehensive Journal of Educational Research, 1, 1-8.

Smith, M., Higgs, J., \& Ellis, E. (2007). Physiotherapy decision making in acute cardiorespiratory case is influenced by factors related to the physiotherapist and the nature and context of the decision: A qualitative study. Australian Journal of Physiotherapy, 53, 261-267. doi: 10.1016/S0004-9514(07)70007-7

Smith, R. E., Ptacek, J. T., \& Patterson, E. (2000). Moderator effects of cognitive and somatic trait anxiety on the relation between life stress and physical injuries. Anxiety, Stress, \& Coping: An International Journal, 13, 269-288. 
Smith, R. E., Smoll, F. L., Ptacek, J. T. (1990). Conjuctive moderator variables in vulnerability and resiliency research: Life stress, social support and coping skills, and adolescent sport injuries. Journal of Personality and Social Psychology, 58, $360-370$.

Stiller-Ostrowski, J. L., Gould, D. R., \& Covassin, T. (2009). An evaluation of an educational intervention in psychology of injury for athletic training students. Journal of Athletic Training, 44, 482-489. doi: 10.4085/1062-6050-44.5.482

Wiese Bjornstal, D. M., Smith, A. M., Shaffer, S. M., \& Morrey, M. A. (1998). An integrated model of response to sport injury: Psychological and sociological dynamics. Journal of Applied Sport Psychology, 10, 46-69.

Zizzi, S. J., Blom, L. C., Watson II, J. C., Downey, P., \& Geer, J. (2009). Establishing a hierarchy of psychological skills: Coaches', athletic trainers', and psychologists' uses and perceptions of psychological skills training. Athletic Insight, 11, 75-94. 
Table 1

Demographic Information

\begin{tabular}{|c|c|c|c|c|}
\hline Variable & $\mathbf{N}$ & $\%$ & $\mathbf{M}$ & SD \\
\hline Age & 316 & & 34.7 & 10.8 \\
\hline Ethnicity & 326 & & & \\
\hline White/Caucasian & 292 & 89.6 & & \\
\hline Hispanic/Latino & 15 & 4.6 & & \\
\hline Asian/Pacific Islander & 5 & 1.5 & & \\
\hline Multiracial & 4 & 1.2 & & \\
\hline American Indian/Alaskan Native & 2 & 0.6 & & \\
\hline Black/African American & 1 & 0.3 & & \\
\hline Gender & 325 & & & \\
\hline Female & 191 & 59 & & \\
\hline Male & 132 & 40.5 & & \\
\hline Other & 2 & 0.5 & & \\
\hline Years of Experience & 313 & & 11.3 & 9.9 \\
\hline Highest Education Level & 327 & & & \\
\hline Bachelor's Degree & 101 & 30.8 & & \\
\hline Master's Degree & 205 & 62.6 & & \\
\hline Doctorate & 17 & 5.1 & & \\
\hline Other & 4 & 1.2 & & \\
\hline PS Coursework & 380 & & & \\
\hline Sport Psychology - UG & & 70.8 & & \\
\hline Sport Psychology - Graduate & & 41.3 & & \\
\hline Psychology of Injury - UG & & 68.0 & & \\
\hline Psychology of Injury - Graduate & & 34.0 & & \\
\hline Education Field & 327 & & & \\
\hline Athletic Training & 181 & 55.4 & & \\
\hline Exercise Science & 43 & 13.1 & & \\
\hline Education/Physical Education & 34 & 10.4 & & \\
\hline Physical Therapy & 16 & 4.9 & & \\
\hline Sport and Exercise Psychology & 5 & 1.5 & & \\
\hline Psychology & 4 & 1.2 & & \\
\hline Other & 44 & 13.5 & & \\
\hline \multicolumn{5}{|l|}{ Certification } \\
\hline BOC & 318 & 98.0 & & \\
\hline ACSM & 12 & 4.0 & & \\
\hline CSCS & 41 & 13.0 & & \\
\hline Other & 45 & 14.0 & & \\
\hline Work Settings & 327 & & & \\
\hline High School & 109 & 35.3 & & \\
\hline College/University & 111 & 33.9 & & \\
\hline Sports Medicine Clinic & 26 & 8 & & \\
\hline Amateur/Professional Sport & 14 & 4.3 & & \\
\hline Private Practice & 12 & 3.7 & & \\
\hline Hospital & 9 & 2.8 & & \\
\hline None & 22 & 6.7 & & \\
\hline Other & 24 & 7.3 & & \\
\hline
\end{tabular}




\begin{tabular}{lrr} 
Sport Setting & & \\
Baseball & 153 & 51 \\
Basketball & 192 & 64 \\
XC/T\&F & 143 & 48 \\
XC/Downhill Skiing & 18 & 6 \\
Football & 160 & 53 \\
Golf & 82 & 27 \\
Gymnastics & 26 & 9 \\
Ice Hockey & 50 & 17 \\
Soccer & 163 & 54 \\
Softball & 144 & 48 \\
Swimming/Diving & 71 & 24 \\
Tennis & 109 & 36 \\
Volleyball & 148 & 49 \\
Wrestling & 101 & 34 \\
Other & 100 & 33 \\
\hline
\end{tabular}


Table 2

ATs and Sport Psychology

\begin{tabular}{|c|c|c|c|c|c|c|}
\hline Variable & $\mathbf{N}$ & $\%$ Yes & $\%$ No & \% Not Sure & $\mathbf{M}$ & SD \\
\hline AT responsibilities & 400 & & & & & \\
\hline $\begin{array}{l}\text { Incorporating treatment for physical } \\
\text { recovery }\end{array}$ & 400 & 98.3 & 0.8 & 1.0 & & \\
\hline Facilitating psychological referral & 400 & 97.3 & 0.8 & 2.0 & & \\
\hline Explaining course of action to athlete/coach & 400 & 93.0 & 4.0 & 3.0 & & \\
\hline Recognizing psychological responses & 399 & 91.2 & 2.3 & 6.5 & & \\
\hline Implementing psychological interventions & 400 & 43.0 & 41.3 & 15.8 & & \\
\hline Providing counseling to athletes & 400 & 36.0 & 46.8 & 17.3 & & \\
\hline AT perceived competencies & 384 & & & & & \\
\hline \multicolumn{7}{|l|}{ (1 Not at all -4 Very) } \\
\hline Facilitating athlete's understanding of injury & & & & & 3.77 & 0.47 \\
\hline Goal Setting & & & & & 3.73 & 0.56 \\
\hline Encouraging effective communication & & & & & 3.70 & 0.54 \\
\hline Using active listening & & & & & 3.65 & 0.55 \\
\hline Providing emotional support & & & & & 3.40 & 0.69 \\
\hline Changing self-talk & & & & & 3.33 & 0.67 \\
\hline Teaching deep breathing & & & & & 2.75 & 0.93 \\
\hline Teaching PMR & & & & & 2.72 & 0.92 \\
\hline Helping athletes develop focus cues & & & & & 2.59 & 0.92 \\
\hline Teaching healing imagery & & & & & 2.51 & 0.97 \\
\hline Teaching performance imagery & & & & & 2.49 & 0.93 \\
\hline Access to professionals & 330 & & & & & \\
\hline Counselor/Psychologist & & 80.6 & 19.4 & & & \\
\hline Sport Psychology Consultant & & 45.8 & 54.2 & & & \\
\hline Referral procedure in place? & 330 & 50.0 & 50.0 & & & \\
\hline Comfortable making referrals (1-6) & 328 & & & & 4.76 & 1.09 \\
\hline Made psychological-based referral & 326 & 61.3 & 38.7 & & & \\
\hline \multicolumn{7}{|l|}{ How helpful are } \\
\hline \multicolumn{7}{|l|}{ (1 Not at all - 4 Extremely) } \\
\hline Counselor/Psychologist & 326 & & & & 3.14 & \\
\hline Sport psychology consultant & 325 & & & & 3.21 & 0.68 \\
\hline
\end{tabular}


Table 3

Post-Injury Concerns - Qualitative Analysis

\begin{tabular}{|c|c|c|}
\hline Category & Definition & $\mathbf{N}(\%)$ \\
\hline $\begin{array}{l}\text { Depression/Depressi } \\
\text { on-like Symptoms }\end{array}$ & $\begin{array}{l}\text { Symptoms commonly associated with } \\
\text { depression (e.g., intense sadness, social } \\
\text { withdrawal, etc). }\end{array}$ & 55 (18.2) \\
\hline $\begin{array}{l}\text { Eating Disorder or } \\
\text { Disordered Eating }\end{array}$ & $\begin{array}{l}\text { Patterns of disordered eating, not necessarily } \\
\text { worthy of clinical diagnosis. }\end{array}$ & \\
\hline $\begin{array}{l}\text { Suicidal } \\
\text { Ideation/Self-Harm }\end{array}$ & $\begin{array}{l}\text { Thoughts about or behaviors consistent with } \\
\text { self-harm or suicide. }\end{array}$ & 38 (12.6) \\
\hline Anxiety & $\begin{array}{l}\text { Symptoms associated with anxiety (e.g., } \\
\text { social, return to play, performance, etc). }\end{array}$ & $29(9.6)$ \\
\hline $\begin{array}{l}\text { Motivation/Adheren } \\
\text { ce Concerns }\end{array}$ & $\begin{array}{l}\text { Difficulty becoming or staying motivated } \\
\text { during rehabilitation or does not adhere to } \\
\text { the rehabilitation plan. }\end{array}$ & $16(5.3)$ \\
\hline $\begin{array}{l}\text { Difficulty Adjusting } \\
\text { to Injury }\end{array}$ & $\begin{array}{l}\text { Difficulty adjusting to changes in life } \\
\text { associated with their injury. }\end{array}$ & $16(5.3)$ \\
\hline $\begin{array}{l}\text { Alcohol and/or Drug } \\
\text { Use/Abuse }\end{array}$ & $\begin{array}{l}\text { Use or overuse of legal or illegal substances } \\
\text { as a method to cope with injury. }\end{array}$ & $15(5.0)$ \\
\hline Stress & $\begin{array}{l}\text { Symptoms of stress associated with injury or } \\
\text { timeline }\end{array}$ & $13(4.3)$ \\
\hline Anger/Frustration & $\begin{array}{l}\text { Anger and/or frustration related to the } \\
\text { inability to fulfill rehabilitation goals }\end{array}$ & $12(4.0)$ \\
\hline Performance Issues & $\begin{array}{l}\text { Difficulty performing or returning to play } \\
\text { due to injury (e.g., trusting injured area, fear } \\
\text { of reinjury, etc.) }\end{array}$ & $8(2.6)$ \\
\hline $\begin{array}{l}\text { Post-Concussion } \\
\text { Concerns }\end{array}$ & $\begin{array}{l}\text { Issues related specifically to an athlete, } \\
\text { immediately following a concussion (e.g., } \\
\text { irritability, memory loss, etc). }\end{array}$ & $7(2.3)$ \\
\hline
\end{tabular}


Team Concerns Issues related to teammate relationships,

$6(2.0)$

problems with the coach, and communication with team.

Other

Miscellaneous behaviors that ATs felt necessitated a psychological-based referral

(e.g., sleep disturbances, season-ending injuries, pain, etc.) 
Table 4

Non-Injury-Related Concerns - Qualitative Analysis

\begin{tabular}{|c|c|c|}
\hline Category & Definition & $\mathbf{N}(\%)$ \\
\hline $\begin{array}{l}\text { Family and/or Personal } \\
\text { Issues }\end{array}$ & $\begin{array}{l}\text { Athlete openly discusses issues related to } \\
\text { his/her family or personal life (e.g., } \\
\text { parental pressure, financial concerns, } \\
\text { etc). }\end{array}$ & $20(41.0)$ \\
\hline $\begin{array}{l}\text { Pre-existing Mental Health } \\
\text { Concerns }\end{array}$ & $\begin{array}{l}\text { Athlete discusses mental health issues } \\
\text { that are not at all a result of their injury } \\
\text { (e.g., general anxiety, depression, etc). }\end{array}$ & $12(24.5)$ \\
\hline $\begin{array}{l}\text { Difficulty adjusting to } \\
\text { collegiate athletics }\end{array}$ & $\begin{array}{l}\text { Athlete struggles significantly with the } \\
\text { pressures of being a student-athlete (e.g., } \\
\text { time management, academic demands, } \\
\text { etc). }\end{array}$ & $9(18.3)$ \\
\hline Death/Grief & $\begin{array}{l}\text { Athlete has difficulty coping with the } \\
\text { loss of a family member, friend, or } \\
\text { teammate. }\end{array}$ & $6(12.2)$ \\
\hline $\begin{array}{l}\text { Motivation/Adherence } \\
\text { Concerns }\end{array}$ & $\begin{array}{l}\text { Athlete expresses having difficulty with a } \\
\text { current romantic or social relationship, } \\
\text { non-team related. }\end{array}$ & $2(4.0)$ \\
\hline
\end{tabular}


Figure 1

Study Sampling Process

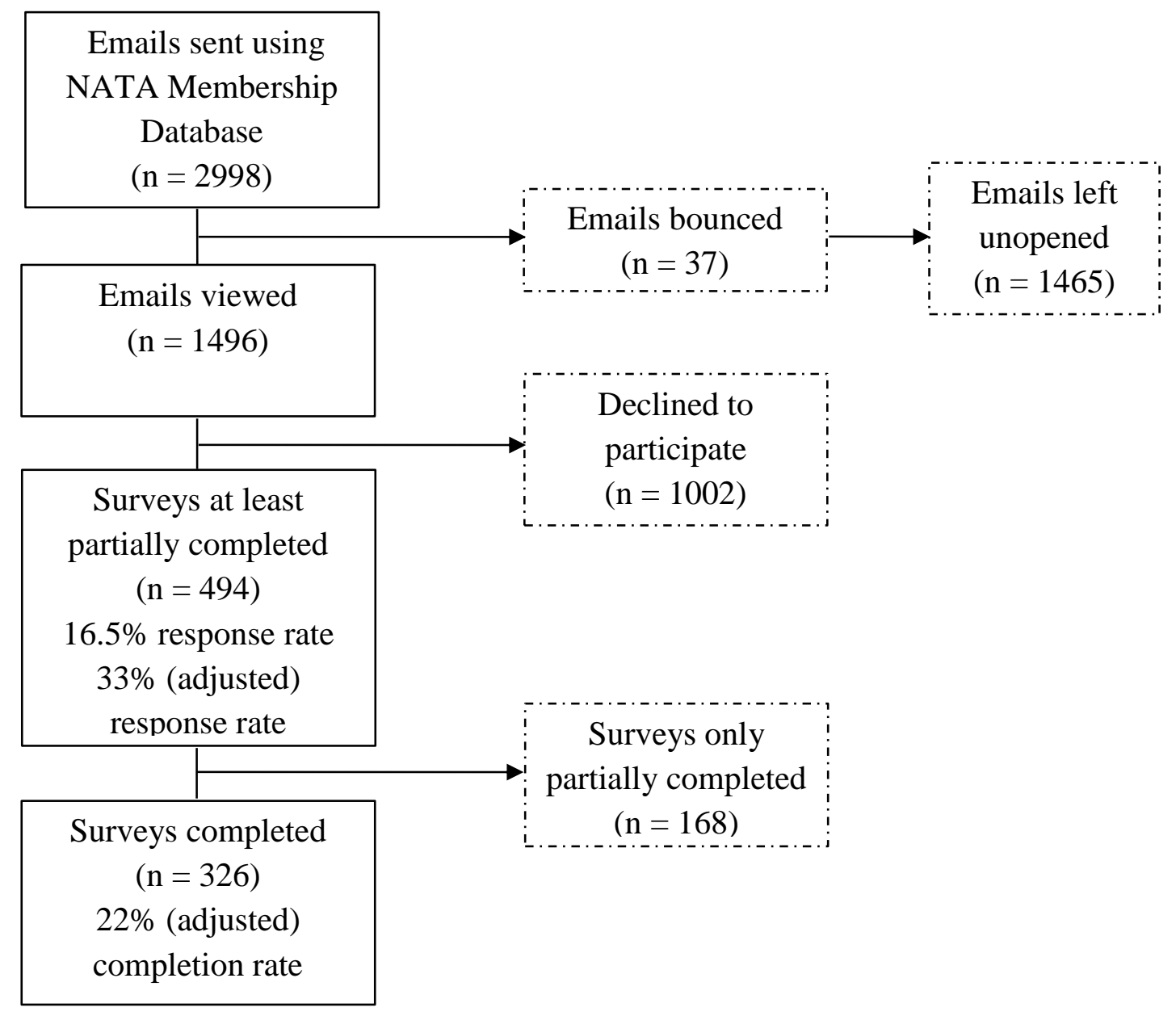

Note: The sampling process shown here is a result of three recruitment emails sent over a period of 3 weeks. Each recruitment email included an invitation to participate, information about the study, information about confidentiality, and time commitment regarding participation (Appendix B). 
Appendix A

Web-Based Questionnaire 
Dear Participant,

Thank you for your participation in this study, the purpose of which is to investigate certified athletic trainers' experiences and practices in athletic training and sport psychology. This study is being conducted in partial fulfillment of the requirements for the degree of Doctor of Philosophy for Marc L. Cormier, a Ph.D. candidate in sport and exercise psychology at West Virginia University.

The survey should take you approximately 10-15 minutes to complete, during which you will be asked to read three brief case scenarios, answer accompanying questions regarding your assessment of each scenario, and complete a short demographic questionnaire. Results could potentially help sport psychology and athletic training professionals better understand how certified athletic trainers work with, and provide services to, athletes under their care.

Your participation in this study is completely voluntary and you may discontinue your participation at any time. Please note that you will not be asked to provide any identifying information on the survey, nor will any identifying information be collected directly or indirectly through this online survey. There are no known physical or psychological risks associated with participation in this study. Results of the study will be kept on a password protected server managed by West Virginia University for a period of 5 years.

If you have any questions or would like to receive a copy of the results, please feel free to contact Marc L. Cormier, M.A. at mcormier@mix.wvu.edu or Dr. Sam Zizzi (faculty supervisor) through the Department of Sport and Exercise Psychology at West Virginia University. This study has been approved by the West Virginia University Institutional Review Board for the Protection of Human Subjects.

By clicking on the arrows, you acknowledge that you have read the above information and voluntarily agree to participate in this study. Thank you again for your participation. 
Q2 - Please indicate whether you agree or disagree with the following statements. A certified athletic trainer is responsible for:

\begin{tabular}{|c|c|c|c|}
\hline & Yes (1) & No (2) & Not Sure (3) \\
\hline $\begin{array}{l}\text { Recognizing and } \\
\text { identifying adaptive and } \\
\text { maladaptive } \\
\text { psychological responses } \\
\text { of the athlete during } \\
\text { rehabilitation (1) }\end{array}$ & 0 & O & 0 \\
\hline $\begin{array}{l}\text { Incorporating treatments } \\
\text { to facilitate physical } \\
\text { recovery from an injury } \\
\text { (2) }\end{array}$ & 0 & 0 & 0 \\
\hline $\begin{array}{l}\text { Facilitating appropriate } \\
\text { referral if the athlete } \\
\text { exhibits personal distress } \\
\text { (3) }\end{array}$ & O & 0 & $\mathrm{O}$ \\
\hline $\begin{array}{l}\text { Explaining the best } \\
\text { course of action to the } \\
\text { athlete and coach (4) }\end{array}$ & O & $\mathrm{O}$ & $\mathrm{O}$ \\
\hline $\begin{array}{l}\text { Providing counseling to } \\
\text { athletes for personal } \\
\text { issues (5) }\end{array}$ & O & O & O \\
\hline $\begin{array}{c}\text { Implementing } \\
\text { psychological } \\
\text { interventions with the } \\
\text { athlete (6) }\end{array}$ & O & O & $\mathrm{O}$ \\
\hline
\end{tabular}


Q3 - Please indicate how competent you feel in appropriately implementing each of the following psychological strategies with an injured athlete.

\begin{tabular}{|c|c|c|c|c|}
\hline & $\begin{array}{c}\text { Not at all } \\
\text { Competent (1) }\end{array}$ & (2) & (3) & $\begin{array}{c}\text { Very Competent } \\
\text { (4) }\end{array}$ \\
\hline $\begin{array}{l}\text { Setting appropriate } \\
\text { goals for } \\
\text { rehabilitation }(1)\end{array}$ & 0 & 0 & $\mathrm{O}$ & 0 \\
\hline $\begin{array}{c}\text { Encouraging } \\
\text { effective } \\
\text { communication } \\
\text { within the team (2) }\end{array}$ & 0 & 0 & 0 & $\mathrm{O}$ \\
\hline $\begin{array}{l}\text { Changing negative } \\
\text { self talk to positive } \\
\text { self talk ( } 3 \text { ) }\end{array}$ & 0 & $\mathrm{O}$ & O & $\mathrm{O}$ \\
\hline $\begin{array}{l}\text { Teaching healing } \\
\text { imagery (4) }\end{array}$ & 0 & $\mathrm{O}$ & 0 & $\mathrm{O}$ \\
\hline $\begin{array}{l}\text { Teaching deep } \\
\text { breathing } \\
\text { techniques (5) }\end{array}$ & 0 & 0 & 0 & 0 \\
\hline $\begin{array}{c}\text { Providing } \\
\text { emotional support } \\
\text { when athletes are } \\
\text { distressed (6) }\end{array}$ & $\mathrm{O}$ & 0 & 0 & 0 \\
\hline $\begin{array}{l}\text { Using active } \\
\text { listening to show } \\
\text { empathy (7) }\end{array}$ & 0 & 0 & 0 & $\mathrm{O}$ \\
\hline $\begin{array}{l}\text { Teaching } \\
\text { performance } \\
\text { imagery (8) }\end{array}$ & 0 & $\mathrm{O}$ & O & 0 \\
\hline $\begin{array}{l}\text { Helping athletes } \\
\text { develop attentional } \\
\text { (focus) cues }(9)\end{array}$ & 0 & $\mathrm{O}$ & 0 & 0 \\
\hline $\begin{array}{l}\text { Facilitating an } \\
\text { athlete's } \\
\text { understanding of } \\
\text { injury and } \\
\text { rehabilitation (10) }\end{array}$ & O & 0 & 0 & O \\
\hline $\begin{array}{c}\text { Teaching } \\
\text { progressive muscle } \\
\text { relaxation }(11)\end{array}$ & O & 0 & 0 & O \\
\hline
\end{tabular}


Q4 - For this portion of the study, you will be presented with three different cases, each describing a different injured athlete (Toby, Stanley, and Oscar). Along with each case, you will be asked to answer a series of questions based on the information provided in each case description. 


\section{Q5 - Case \#1 - Toby}

Toby is a starting junior soccer player and leading scorer at a respected NCAA Division 1 institution. After jumping up to head a ball during a pre-season match, Toby landed awkwardly and suffered a grade-3 ankle sprain on his dominant foot. After his initial evaluation, the doctors, as well as the head AT, informed Toby that he would likely be sidelined for at least 5-6 weeks but would not require surgical repair to his ankle. Since his freshman year, you have known Toby as an outgoing, cheerful, and upbeat person. However, since hearing his prognosis, Toby appears discouraged, since he worked the entire summer to become season-ready. For the first weeks following your initial assessment, you notice that Toby is often 5-10 minutes late to rehab appointments, rarely engages in small talk, and generally seems sad. He still completes all his exercises and stretches as instructed but is visibly frustrated with his rehabilitation timeline and lack of progress early on. You've also noticed that, even though he attends team practice, he normally sits on the bench and doesn't say much.

- Based on the information provided in Toby's case, please indicate whether each of the following symptoms are present.

\begin{tabular}{|c|c|c|}
\hline & Yes (1) & No (2) \\
\hline Anxiety / stress (1) & 0 & 0 \\
Difficulty adjusting to the injury & 0 & 0 \\
(2) & 0 & 0 \\
Anger (3) & 0 & 0 \\
Frustration (4) & 0 & 0 \\
Motivational issues (5) & 0 & 0 \\
Depressed mood (6) & 0 & 0 \\
\hline Suicidal thoughts (7) & & \\
\hline
\end{tabular}

Q6 - Based on the information provided in Toby's case, which of the following best describes your intended course of action?

I I would take no action. The athlete appears to be adjusting normally to the injury. (1)

I I would pay close attention and carefully monitor the athlete's mood and progress, but make no referral (2)

I would consult with a supervisor or mental health professional regarding the severity and/or duration of the athlete's symptoms (3)

O I would make an immediate referral to a mental health professional due to the severity and/or duration of the athlete's symptoms (4) 
Q7 - Case \#1 - Toby

Based upon the information provided in Toby's case, please indicate how likely you would be to refer him to each of the following individuals.

(Toby's case information - repeated)

Toby is a starting junior soccer player and leading scorer at a respected NCAA Division 1 institution. After jumping up to head a ball during a pre-season match, Toby landed awkwardly and suffered a grade-3 ankle sprain on his dominant foot. After his initial evaluation, the doctors, as well as the head AT, informed Toby that he would likely be sidelined for at least 5-6 weeks but would not require surgical repair to his ankle. Since his freshman year, you have known Toby as an outgoing, cheerful, and upbeat person.

However, since hearing his prognosis, Toby appears discouraged, since he worked the entire summer to become season-ready. For the first weeks following your initial assessment, you notice that Toby is often 510 minutes late to rehab appointments, rarely engages in small talk, and generally seems sad. He still completes all his exercises and stretches as instructed but is visibly frustrated with his rehabilitation timeline and lack of progress early on. You've also noticed that, even though he attends team practice, he normally sits on the bench and doesn't say much.

Notes:

*A sport psychology professional/mental skills coach is an individual who provides mental training services with the intention of enhancing one's personal or professional performance or well-being. These professionals educate individuals on the role of psychological factors in sport and exercise.

**A counselor or psychologist is a licensed helping professional who works with people experiencing psychological disorders and/or other mental health concerns.

\begin{tabular}{|c|c|c|}
\hline & Unlikely (1) & Likely (2) \\
\hline $\begin{array}{c}\text { Sport psychology consultant (1) } \\
\text { Medical supervisor (e.g., head } \\
\text { athletic trainer, team physician) } \\
(2)\end{array}$ & 0 & 0 \\
$\begin{array}{c}\text { Mental health professional (e.g., } \\
\text { counselor or psychologist) (3) }\end{array}$ & 0 & \\
\hline
\end{tabular}


Q8 - Case \#1 - Toby

Based upon the information provided in Toby's case, please indicate whether you believe each of the following interventions would be helpful for him.

\section{(Toby's case information - repeated)}

Toby is a starting junior soccer player and leading scorer at a respected NCAA Division 1 institution. After jumping up to head a ball during a pre-season match, Toby landed awkwardly and suffered a grade-3 ankle sprain on his dominant foot. After his initial evaluation, the doctors, as well as the head AT, informed Toby that he would likely be sidelined for at least 5-6 weeks but would not require surgical repair to his ankle. Since his freshman year, you have known Toby as an outgoing, cheerful, and upbeat person.

However, since hearing his prognosis, Toby appears discouraged, since he worked the entire summer to become season-ready. For the first weeks following your initial assessment, you notice that Toby is often 510 minutes late to rehab appointments, rarely engages in small talk, and generally seems sad. He still completes all his exercises and stretches as instructed but is visibly frustrated with his rehabilitation timeline and lack of progress early on. You've also noticed that, even though he attends team practice, he normally sits on the bench and doesn't say much.

\begin{tabular}{|c|c|c|}
\hline & Yes (1) & No (2) \\
\hline Setting appropriate goals (1) & $\mathrm{O}$ & 0 \\
\hline $\begin{array}{l}\text { Encouraging effective } \\
\text { communication within the team } \\
\text { (2) }\end{array}$ & $\mathrm{O}$ & $\mathrm{O}$ \\
\hline Teaching positive self talk (3) & O & $\mathrm{O}$ \\
\hline Teaching deep breathing (4) & $\mathrm{O}$ & O \\
\hline $\begin{array}{l}\text { Providing him with emotional } \\
\text { support (5) }\end{array}$ & $\mathrm{O}$ & O \\
\hline $\begin{array}{l}\text { Using active listening to show } \\
\text { empathy (6) }\end{array}$ & $\mathrm{O}$ & O \\
\hline Performance imagery (7) & $\mathrm{O}$ & $\mathrm{O}$ \\
\hline Anger management techniques (8) & O & O \\
\hline $\begin{array}{l}\text { Teaching progressive muscle } \\
\text { relaxation (9) }\end{array}$ & O & O \\
\hline $\begin{array}{l}\text { Facilitating an athlete's } \\
\text { understanding of injury and } \\
\text { rehabilitation (10) }\end{array}$ & $\mathrm{O}$ & $\mathrm{O}$ \\
\hline Healing imagery (11) & $\mathrm{O}$ & $\mathrm{O}$ \\
\hline
\end{tabular}


Q9 - Case \#2 - Stanley

Stanley is a starting sophomore soccer player and leading scorer at a respected NCAA Division 1 institution. While sprinting hard towards a ball, he suffered his second grade-2 hamstring strain. His first strain was during his sophomore year in high school, from which he fully recovered. After his initial evaluation, Stanley is told that he would not require surgery but would likely miss the first 4-6 weeks of the season. During the days immediately following his injury, you notice that Stanley seems somewhat discouraged but follows through with his rehabilitation protocol, as instructed. He attends each session and usually arrives on time, despite his limited mobility on campus. You have also heard from his teammates that he regularly attends practice and is fairly upbeat, despite seeming somewhat frustrated with his new role on the team. A few weeks following his injury, you explain to Stanley that he is progressing more slowly than predicted and that he should prepare himself for an extra week away from play. Though initially upset by the news, he seemed to recover quickly and become comfortable with his lack of progress and new timeline.

- Based on the information provided in Stanley's case, please indicate whether each of the following symptoms are present.

\begin{tabular}{|c|c|c|}
\hline & Yes (1) & No (2) \\
\hline Anxiety / stress (1) & 0 & 0 \\
Frustration (2) & 0 & 0 \\
Difficulty adjusting (3) & 0 & 0 \\
Anger (4) & 0 & 0 \\
Motivational issues (5) & 0 & 0 \\
Suicidal thoughts (6) & 0 & 0 \\
Depressed Mood (7) & 0 & 0 \\
\hline
\end{tabular}

Q10 - Based on the information provided in Stanley's case, which of the following best describes your intended course of action?

O I would take no action. The athlete appears to be adjusting normally to the injury. (1)

I I would pay close attention and carefully monitor the athlete's mood and progress, but make no referral (2)

O I would consult with a supervisor or mental health professional regarding the severity and/or duration of the athlete's symptoms (3)

O I would make an immediate referral to a mental health professional due to the severity and/or duration of the athlete's symptoms (4)

If I would take no action. The... Is Selected, Then Skip To Q12 
Q11 - Case \#2 - Stanley

Based upon the information provided in Stanley's case, please indicate how likely you would be to refer him to each of the following individuals.

(Stanley's case information - repeated)

Stanley is a starting sophomore soccer player and leading scorer at a respected NCAA Division 1 institution. While sprinting hard towards a ball, he suffered his second grade-2 hamstring strain. His first strain was during his sophomore year in high school, to which he fully recovered. After his initial evaluation, Stanley is told that he would not require surgery but would likely miss the first 4-6 weeks of the season. During the days immediately following his injury, you notice that Stanley seems somewhat discouraged but follows through with his rehabilitation protocol, as instructed. He attends each session and usually arrives on time, despite his limited mobility on campus. You have also heard from his teammates that he regularly attends practice and is fairly upbeat, despite seeming somewhat frustrated with his new role on the team. A few weeks following his injury, you explain to Stanley that he is progressing more slowly than predicted and that he should prepare himself for an extra week away from play. Though initially upset by the news, he seemed to recover quickly and become comfortable with his lack of progress and new timeline.

Notes:

*A sport psychology professional/mental skills coach is an individual who provides mental training services with the intention of enhancing one's personal or professional performance or well-being. These professionals educate individuals on the role of psychological factors in sport and exercise.

**A counselor or psychologist is a licensed helping professional who works with people experiencing psychological disorders and/or other mental health concerns.

\begin{tabular}{|c|c|c|}
\hline & Unlikely (1) & Likely (2) \\
\hline $\begin{array}{c}\text { Sport psychology consultant (1) } \\
\text { Medical supervisor (e.g., head } \\
\text { athletic trainer, team physician) } \\
\text { (2) }\end{array}$ & 0 & 0 \\
$\begin{array}{c}\text { Mental health professional (e.g., } \\
\text { counselor or psychologist) (3) }\end{array}$ & 0 & 0 \\
\hline
\end{tabular}


Q12 - Case \#2 - Stanley

Based upon the information provided in Stanley's case, please indicate whether you believe each of the following interventions would be helpful for him.

\section{(Stanley's case information - repeated)}

Stanley is a starting sophomore soccer player and leading scorer at a respected NCAA Division 1 institution. While sprinting hard towards a ball, he suffered his second grade-2 hamstring strain. His first strain was during his sophomore year in high school, to which he fully recovered. After his initial evaluation, Stanley is told that he would not require surgery but would likely miss the first 4-6 weeks of the season. During the days immediately following his injury, you notice that Stanley seems somewhat discouraged but follows through with his rehabilitation protocol, as instructed. He attends each session and usually arrives on time, despite his limited mobility on campus. You have also heard from his teammates that he regularly attends practice and is fairly upbeat, despite seeming somewhat frustrated with his new role on the team. A few weeks following his injury, you explain to Stanley that he is progressing more slowly than predicted and that he should prepare himself for an extra week away from play. Though initially upset by the news, he seemed to recover quickly and become comfortable with his lack of progress and new timeline.

\begin{tabular}{|c|c|c|}
\hline & Yes (1) & No (2) \\
\hline Setting appropriate goals (1) & $\mathrm{O}$ & 0 \\
\hline $\begin{array}{l}\text { Encouraging effective } \\
\text { communication within the team } \\
\text { (2) }\end{array}$ & $\mathrm{O}$ & $\mathrm{O}$ \\
\hline Teaching positive self talk ( 3 ) & $\mathrm{O}$ & O \\
\hline Teaching deep breathing (4) & $\mathrm{O}$ & $\mathrm{O}$ \\
\hline $\begin{array}{l}\text { Providing him with emotional } \\
\text { support (5) }\end{array}$ & O & O \\
\hline $\begin{array}{l}\text { Using active listening to show } \\
\text { empathy (6) }\end{array}$ & $\mathrm{O}$ & $\mathrm{O}$ \\
\hline Performance imagery (7) & $\mathrm{O}$ & $\mathrm{O}$ \\
\hline Anger management techniques (8) & $\mathrm{O}$ & $\mathrm{O}$ \\
\hline $\begin{array}{l}\text { Teaching progressive muscle } \\
\text { relaxation (9) }\end{array}$ & $\mathrm{O}$ & $\mathrm{O}$ \\
\hline $\begin{array}{l}\text { Facilitating an athlete's } \\
\text { understanding of injury and } \\
\text { rehabilitation (10) }\end{array}$ & O & $\mathrm{O}$ \\
\hline Healing imagery (11) & $\mathrm{O}$ & $\mathrm{O}$ \\
\hline
\end{tabular}




\section{Q13 - Case \#3 - Oscar}

Oscar is a starting junior soccer player and leading scorer at a respected NCAA Division 1 institution. During the first match of the season, Oscar suffered a grade-3 ankle sprain on his dominant foot while attempting to jump over an opponent. He describes hearing a "pop" when he landed. After his initial assessment, the doctors, as well as the head AT, informed Oscar that he would likely miss 5-6 weeks but would not require surgery on his ankle. After hearing the news, Oscar is visibly upset and immediately leaves the room on his crutches. For the following three weeks, Oscar misses many appointments and when he shows up, he is visibly fatigued and lacks ability to focus on his rehabilitation. You also notice that he has lost a significant amount of weight during the short period of time since his injury. He no longer shows up to practice, refuses to talk about soccer or his injury, and spends most of his time alone in his apartment. You've also heard him discuss quitting soccer all together and leaving college. His teammates have also shared with you that he frequently talks about "wishing he was not around" and "losing his purpose in life," statements that are frequently coupled with severe intoxication.

Based on the information provided in Oscar's case, please indicate whether each of the following symptoms are present.

\begin{tabular}{|c|c|c|}
\hline & Yes (1) & No (2) \\
\hline Anxiety / stress (1) & 0 & 0 \\
Difficulty adjusting (2) & 0 & 0 \\
Anger (3) & 0 & 0 \\
Frustration (4) & 0 & 0 \\
Motivational issues (5) & 0 & 0 \\
Depressed Mood (6) & 0 & 0 \\
Suicidal thoughts (7) & 0 & 0 \\
\hline
\end{tabular}

Q14 - Based on the information provided in Oscar's case, which of the following best describes your intended course of action?

I would take no action. The athlete appears to be adjusting normally to the injury. (1)

I I would pay close attention and carefully monitor the athlete's mood and progress, but make no referral (2)

I would consult with a supervisor or mental health professional regarding the severity and/or duration of the athlete's symptoms (3)

O I would make an immediate referral to a mental health professional due to the severity and/or duration of the athlete's symptoms (4) 
Q15 - Case \#3 - Oscar

Based upon the information provided in Oscar's case, please indicate how likely you would be to refer him to each of the following individuals.

(Oscar's case information - repeated)

Oscar is a starting junior soccer player and leading scorer at a respected NCAA Division 1 institution. During the first match of the season, Oscar suffered a grade-3 ankle sprain on his dominant foot while attempting to jump over an opponent. He describes hearing a "pop" when he landed. After his initial assessment, the doctors, as well as the head AT, informed Oscar that he would likely miss 5-6 weeks but would not require surgery on his ankle. After hearing the news, Oscar is visibly upset and immediately leaves the room on his crutches. For the following three weeks, Oscar misses many appointments and when he shows up, he is visibly fatigued and lacks ability to focus on his rehabilitation. You also notice that he has lost a significant amount of weight during the short period of time since his injury. He no longer shows up to practice, refuses to talk about soccer or his injury, and spends most of his time alone in his apartment. You've also heard him discuss quitting soccer all together and leaving college. His teammates have also shared with you that he frequently talks about "wishing he was not around" and "losing his purpose in life," statements that are frequently coupled with severe intoxication.

Notes:

*A sport psychology professional/mental skills coach is an individual who provides mental training services with the intention of enhancing one's personal or professional performance or well-being. These professionals educate individuals on the role of psychological factors in sport and exercise.

**A counselor or psychologist is a licensed helping professional who works with people experiencing psychological disorders and/or other mental health concerns.

\begin{tabular}{|c|c|c|}
\hline & Unlikely (1) & Likely (2) \\
\hline $\begin{array}{c}\text { Sport psychology consultant (1) } \\
\text { Medical supervisor (e.g., Head } \\
\text { athletic trainer, team physician) } \\
(2)\end{array}$ & 0 & 0 \\
$\begin{array}{c}\text { Mental health professional (e.g., } \\
\text { counselor or psychologist) (3) }\end{array}$ & 0 & 0 \\
\hline
\end{tabular}


Q16 - Case \#3 - Oscar

Based upon the information provided in Oscar's case, please indicate whether you believe each of the following interventions would be helpful for him.

\section{(Oscar's case information - repeated)}

Oscar is a starting junior soccer player and leading scorer at a respected NCAA Division 1 institution. During the first match of the season, Oscar suffered a grade-3 ankle sprain on his dominant foot while attempting to jump over an opponent. He describes hearing a "pop" when he landed. After his initial assessment, the doctors, as well as the head AT, informed Oscar that he would likely miss 5-6 weeks but would not require surgery on his ankle. After hearing the news, Oscar is visibly upset and immediately leaves the room on his crutches. For the following three weeks, Oscar misses many appointments and when he shows up, he is visibly fatigued and lacks ability to focus on his rehabilitation. You also notice that he has lost a significant amount of weight during the short period of time since his injury. He no longer shows up to practice, refuses to talk about soccer or his injury, and spends most of his time alone in his apartment. You've also heard him discuss quitting soccer all together and leaving college. His teammates have also shared with you that he frequently talks about "wishing he was not around" and "losing his purpose in life," statements that are frequently coupled with severe intoxication.

\begin{tabular}{|c|c|c|}
\hline & Yes (1) & No (2) \\
\hline Setting appropriate goals (1) & O & $\mathrm{O}$ \\
\hline $\begin{array}{l}\text { Encouraging effective } \\
\text { communication within the team } \\
\text { (2) }\end{array}$ & $\mathrm{O}$ & $\mathrm{O}$ \\
\hline Teaching positive self talk (3) & $\mathrm{O}$ & O \\
\hline Teaching deep breathing (4) & $\mathrm{O}$ & $\mathrm{O}$ \\
\hline $\begin{array}{l}\text { Providing him with emotional } \\
\text { support (5) }\end{array}$ & $\mathrm{O}$ & O \\
\hline $\begin{array}{c}\text { Using active listening to show } \\
\text { empathy (6) }\end{array}$ & $\mathrm{O}$ & $\mathrm{O}$ \\
\hline Performance imagery (7) & O & O \\
\hline Anger management techniques (8) & $\mathrm{O}$ & O \\
\hline $\begin{array}{l}\text { Teaching progressive muscle } \\
\text { relaxation (9) }\end{array}$ & $\mathrm{O}$ & $\mathrm{O}$ \\
\hline $\begin{array}{l}\text { Facilitating an athlete's } \\
\text { understanding of injury and } \\
\text { rehabilitation }(10)\end{array}$ & $\mathrm{O}$ & $\mathrm{O}$ \\
\hline Healing imagery (11) & $\mathrm{O}$ & $\mathrm{O}$ \\
\hline
\end{tabular}


Q17 - In your work as a certified athletic trainer, have you ever had or do you currently have access to any of the following professionals?

Notes:

A counselor or psychologist is a licensed helping professional who works with individuals experiencing psychological disorders and/or other mental health concerns.

A sport psychology consultant is an individual who provides mental training services with the intention of enhancing one's personal or professional performance or well-being. These professionals primarily educate individuals on the role of the psychological factors in sport and exercise.

\begin{tabular}{|c|c|c|}
\hline & Yes (1) & No (2) \\
\hline Counselor/psychologist (1) & 0 & 0 \\
Sport psychology consultant (2) & 0 & 0 \\
\hline
\end{tabular}


Q18 - In your work as a certified athletic trainer, do you currently have a referral procedure in place for psychological-based referrals?

Note: A referral should be considered when you believe an athlete's issues go beyond your own scope of experience and/or expertise. Unless indicated otherwise, please only refer to referrals made for mental health concerns throughout this study (e.g., difficulty adjusting to injury, severe anger, apathy, withdrawal).

O Yes (1)

O No (2)

If No Is Selected, Then Skip To Q20 
Q19 - Please provide a brief summary of this procedure

Q20 - How comfortable are you in making a referral for psychological concerns?

O Very Uncomfortable (1)

O (2)

○ (3)

O (4)

O (5)

Very Comfortable (6)

Q21 - In your work as a certified athletic trainer, have you ever referred an athlete to a sport psychology consultant or mental health provider (i.e., counselor or psychologist)?

O Yes (1)

O No (2)

If No Is Selected, Then Skip To Q23

Q22 - Please provide an estimation of the number of referrals you have made to a sport psychology consultant or mental health provider in the past 2 years.

Q23 - Please indicate the most common reasons why you have made (a) referral(s) for psychological concerns.

Q24 - How helpful do you believe sport psychology consultants are in the rehabilitation process?

O Not at all Helpful (1)

O (2)

O (3)

Extremely Helpful (4)

Q25 - How helpful do you believe mental health providers (counselors/psychologists) are in the rehabilitation process?

O Not at all Helpful (1)

O (2)

O (3)

O Extremely Helpful (4) 
Q26 - What is your age?

Q27 - What is your gender?

O Male (1)

O Female (2)

Other (please specify) (3)

Q28 - What is your ethnicity?

O American Indian or Alaskan Native (1)

O Asian or Pacific Islander (2)

O Black or African American (3)

O Hispanic or Latino (4)

O White/Caucasian (5)

Prefer not to answer (6)

Other (please specify) (7)

Q29 - Please indicate the number of years of experience you have working as a certified athletic trainer.

Q30 - Please indicate which of the following courses you have successfully completed at the university level, including distance/online learning, and continuing education offered through state, regional, and national organizations. (Please check all that apply).

\begin{tabular}{|c|c|c|c|}
\hline & Undergraduate (1) & Graduate (2) & $\begin{array}{c}\text { Continuing } \\
\text { Education/Professional } \\
\text { Organization (3) }\end{array}$ \\
\hline $\begin{array}{c}\text { General Psychology (1) } \\
\text { Sport and Exercise } \\
\text { Psychology (2) }\end{array}$ & $\square$ & $\square$ & $\square$ \\
$\begin{array}{c}\text { Psychology of } \\
\text { Injury/Rehabilitation (3) }\end{array}$ & $\square$ & $\square$ & $\square$ \\
\hline
\end{tabular}

Q31 - What is the highest level of education you have completed?

O Bachelor's degree (1)

O Master's degree (2)

O Ph.D. (3)

O Psy.D (4)

O Ed.D. (5)

O M.D. (6)

Other (please specify) (7) 
Q32 - Which of the following best describes the field in which you received your highest degree?

O Athletic Training (1)

O Physical Therapy (2)

O Physical Education (3)

O Kinesiology (4)

O Exercise Physiology (5)

O Education (6)

Psychology (7)

O Sport and Exercise Psychology (8)

Other (please specify) (9)

Q33 - Please indicate any relevant certifications that you currently hold (Please check all that apply).

口 $\operatorname{NATABOC~(1)~}$

a American College of Sports Medicine (2)

Association for Applied Sport Psychology (3)

Certified Strength and Conditioning Specialist (4)

- American Council on Exercise (5)

- State License or Certification (6)

Other (please specify) (7)

Q34 - In which of the following settings do you primarily work as a certified athletic trainer?

O High School (public) (1)

O High School (private) (2)

O Community College (3)

O Junior College (4)

O University (5)

O Sports Medicine Clinic (6)

O Amateur/Semi-Professional/Professional Sports Organization (7)

O Hospital (8)

O Private Practice (9)

I I do not currently work as a certified athletic trainer (10)

Other (please specify) (11) 
Q35 - In your current role as a certified athletic trainer, with which sport(s) do you primarily work? (Please check all that apply)

ㅁ Baseball (1)

B Basketball (2)

C Cross-country/Track and Field (3)

口 Cross-country/Downhill skiing (4)

F Football (5)

Golf (6)

a Gymnastics (7)

a Ice Hockey (8)

- Soccer (9)

Softball (10)

- Swimming/Diving (11)

Tennis (12)

口 Volleyball (13)

Wrestling (14)

O Other (please specify) (15)

Q36 - If you have any additional information or comments to provide regarding your answers, please include them in the box below. 
Appendix B

\section{Email History}




\section{Email Message \#1:}

Calling all Certified Athletic Trainers!

Marc Cormier and Dr. Sam Zizzi from the Department of Sport Sciences at West Virginia University invite you to test your knowledge by participating in a short research study. The purpose of the study is to learn more about how ATCs recognize and make referral decisions regarding psychological symptoms in athletes.

Your participation should not take more than 10-15 minutes of your time and will help us better understand your role in athlete rehabilitation.

All information will be kept strictly confidential and will in no way affect your professional standing or status with the NATA. This research study is being conducted to fulfill a requirement toward earning a $\mathrm{Ph}$.D, so your participation is greatly appreciated.

Should you choose to participate, please click on the link below and follow the steps as indicated on the web-based survey.

If you have any questions or would like more information regarding this study, you can contact Marc Cormier via email at mcormier@mix.wvu.edu.

Thank you for your time!

Best regards,

Marc L. Cormier, M.A.

Doctoral Candidate in Sport and Exercise Psychology

West Virginia University

mcormier@mix.wvu.edu

Follow this link to the Survey:

$\$\{1: / /$ SurveyLink?d=Click Here to Take the Survey $\}$

Or copy and paste the URL below into your internet browser:

$\$\{1: / /$ SurveyURL $\}$

Follow the link to opt out of future emails:

$\$\{1: / / O p t O u t L i n k ? d=C l i c k$ here to unsubscribe $\}$ 
Email message \#2:

Calling all Certified Athletic Trainers!

This is a friendly reminder regarding your invitation to participate in a short research study, conducted by Marc Cormier and Dr. Sam Zizzi from the Department of Sport Sciences at West Virginia University. Your expertise as a certified athletic trainer is requested and much appreciated in the completion of this study. Total participation should not exceed 10-15 minutes of your time.

The purpose of the study is to learn more about how ATCs recognize and make referral decisions regarding psychological symptoms in athletes. All information will be kept confidential and anonymous, and will in no way affect your professional standing or status with the NATA.

This research study is being conducted to fulfill a requirement toward earning a Ph.D., so your participation and expertise is greatly appreciated.

To participate, simply click on the link below and follow the steps as indicated on the web-based survey.

If you have any questions, would like more information regarding this study, or would like a copy of the results, feel free to contact Marc Cormier via email at mcormier@mix.wvu.edu.

Thank you very much for your time and willingness to share your knowledge!

Best Regards,

Marc Cormier, M.A.

Doctoral Candidate in Sport and Exercise Psychology

West Virginia University

mcormier@mix.wvu.edu

Follow this link to the Survey:

$\$\{1: / /$ SurveyLink?d=Click Here to Take the Survey $\}$

Or copy and paste the URL below into your internet browser:

$\$\{1: / /$ SurveyURL $\}$

Follow the link to opt out of future emails:

$\$\{1: / / O p t O u t L i n k ? d=C l i c k$ here to unsubscribe $\}$ 
Email message \#3:

Dear Certified Athletic Trainer,

This is your last chance to test your knowledge and participate in a short (10-15 minutes) survey! Your expertise as an AT is requested and very much appreciated in the completion of this study, conducted by Marc Cormier and Dr. Sam Zizzi from the Department of Sport Sciences at West Virginia University. The survey will be closed on Monday at 3:00pm, EST, so act fast!

As a reminder, the purpose of this study is to learn more about how ATCs recognize and make referral decisions for psychological symptoms in athletes. All responses will be kept confidential and anonymous, and will in no way affect your employment, professional standing, or status with the NATA.

To participate, simply click on the link below and follow the steps as indicated on the web-based survey.

If you have any questions, would like more information regarding this study, or would like a copy of the results, feel free to contact Marc Cormier at mcormier@mix.wvu.edu.

Thank you very much for your time and willingness to share your expertise!

Best regards,

Marc Cormier, M.A.

Doctoral Candidate in Sport and Exercise Psychology

West Virginia University

mcormier@mix.wvu.edu

Follow this link to the Survey:

$\$\{1: / /$ SurveyLink?d=Click Here to Take the Survey $\}$

Or copy and paste the URL below into your internet browser:

$\$\{1: / /$ SurveyURL $\}$

Follow the link to opt out of future emails:

$\$\{1: / / O p t O u t L i n k ? d=C l i c k$ here to unsubscribe $\}$ 
Appendix C

\section{Case Vignettes}


Stanley is a starting sophomore soccer player and leading scorer at a respected NCAA Division 1 institution. While sprinting hard towards a ball, he suffered his second grade-2 hamstring strain. His first strain was during his sophomore year in high school, from which he fully recovered. After his initial evaluation, Stanley is told that he would not require surgery but would likely miss the first 4-6 weeks of the season. During the days immediately following his injury, you notice that Stanley seems somewhat discouraged but follows through with his rehabilitation protocol, as instructed. He attends each session and usually arrives on time, despite his limited mobility on campus. You have also heard from his teammates that he regularly attends practice and is fairly upbeat, despite seeming somewhat frustrated with his new role on the team. A few weeks following his injury, you explain to Stanley that he is progressing more slowly than predicted and that he should prepare himself for an extra week away from play. Though initially upset by the news, he seemed to recover quickly and become comfortable with his lack of progress and new timeline.

Toby is a starting junior soccer player and leading scorer at a respected NCAA Division 1 institution. After jumping up to head a ball during a pre-season match, Toby landed awkwardly and suffered a grade-3 ankle sprain on his dominant foot. After his initial evaluation, the doctors, as well as the head AT, informed Toby that he would likely be sidelined for at least 5-6 weeks but would not require surgical repair to his ankle. Since his freshman year, you have known Toby as an outgoing, cheerful, and upbeat person. However, since hearing his prognosis, Toby appears discouraged, since he worked the entire summer to become season-ready. For the first weeks following your initial assessment, you notice that Toby is often 5-10 minutes late to rehab appointments, rarely engages in small talk, and generally seems sad. He still completes all his exercises and stretches as instructed but is visibly frustrated with his rehabilitation timeline and lack of progress early on. You've also noticed that, even though he attends team practice, he normally sits on the bench and doesn't say much.

Oscar is a starting junior soccer player and leading scorer at a respected NCAA Division 1 institution. During the first match of the season, Oscar suffered a grade-3 ankle sprain on his dominant foot while attempting to jump over an opponent. He describes hearing a "pop" when he landed. After his initial assessment, the doctors, as well as the head AT, informed Oscar that he would likely miss 5-6 weeks but would not require surgery on his ankle. After hearing the news, Oscar is visibly upset and immediately leaves the room on his crutches. For the following three weeks, Oscar misses many appointments and when he shows up, he is visibly fatigued and lacks ability to focus on his rehabilitation. You also notice that he has lost a significant amount of weight during the short period of time since his injury. He no longer shows up to practice, refuses to talk about soccer or his injury, and spends most of his time alone in his apartment. You've also heard him discuss quitting soccer all together and leaving college. His teammates have also shared with you that he frequently talks about "wishing he was not around" and "losing his purpose in life," statements that are frequently coupled with severe intoxication. 


\section{Appendix D}

Results From Expert Panel 


\section{Case \#1 - Toby}

Toby is a starting junior soccer player and leading scorer at a respected NCAA Division 1 institution. After jumping up to head a ball during a pre-season match, Toby landed awkwardly and suffered a grade- 3 ankle sprain on his dominant foot. After his initial evaluation, the doctors, as well as the head AT, informed Toby that he would likely be sidelined for at least 5-6 weeks but would not require surgical repair to his ankle. Since his freshman year, you have known Toby as an outgoing, cheerful, and upbeat person. However, since hearing his prognosis, Toby appears discouraged, since he worked the entire summer to become season-ready. For the first weeks following your initial assessment, you notice that Toby is often 5-10 minutes late to rehab appointments, rarely engages in small talk, and generally seems sad. He still completes all his exercises and stretches as instructed but is visibly frustrated with his rehabilitation timeline and lack of progress early on. You've also noticed that, even though he attends team practice, he normally sits on the bench and doesn't say much.

Q1 - Based on the information provided in Toby's case, please indicate whether each of the following symptom(s) is/are present.

\begin{tabular}{|c|c|c|}
\hline & Yes (1) & No (2) \\
\hline Anxiety / stress (1) & YES & \\
\hline $\begin{array}{c}\text { Difficulty adjusting to the } \\
\text { injury (2) }\end{array}$ & YES & NO \\
\hline Anger (3) & YES & \\
\hline Frustration (4) & YES & \\
\hline Motivational issues (5) & YES & NO \\
\hline Depressed mood (6) & & \\
\hline Suicidal thoughts (7) & & \\
\hline
\end{tabular}

Q2 - Based on the information provided in Toby's case, which of the following best describes your intended course of action?

O I would take no action. The athlete appears to be adjusting normally to the injury. (1)

I would pay close attention and carefully monitor the athlete's mood and progress, but make no referral (2)

I would consult with a supervisor or mental health professional regarding the severity and/or duration of the athlete's symptoms (3)

O I would make an immediate referral to a mental health professional due to the severity and/or duration of the athlete's symptoms (4) 
Q3 - Based upon the information provided in Toby's case, please indicate how likely you would be to refer him to each of the following individuals.

\section{(Toby's case information - repeated)}

Toby is a starting junior soccer player and leading scorer at a respected NCAA Division 1 institution. After jumping up to head a ball during a pre-season match, Toby landed awkwardly and suffered a grade-3 ankle sprain on his dominant foot. After his initial evaluation, the doctors, as well as the head AT, informed Toby that he would likely be sidelined for at least 5-6 weeks but would not require surgical repair to his ankle. Since his freshman year, you have known Toby as an outgoing, cheerful, and upbeat person. However, since hearing his prognosis, Toby appears discouraged, since he worked the entire summer to become season-ready. For the first weeks following your initial assessment, you notice that Toby is often 5 10 minutes late to rehab appointments, rarely engages in small talk, and generally seems sad. He still completes all his exercises and stretches as instructed but is visibly frustrated with his rehabilitation timeline and lack of progress early on. You've also noticed that, even though he attends team practice, he normally sits on the bench and doesn't say much.

Notes:

*A sport psychology professional/mental skills coach is an individual who provides mental training services with the intention of enhancing one's personal or professional performance or well-being. These professionals educate individuals on the role of psychological factors in sport and exercise.

**A counselor or psychologist is a licensed helping professional who works with people experiencing psychological disorders and/or other mental health concerns.

\begin{tabular}{|c|c|c|}
\hline $\begin{array}{c}\text { Sport psychology professional } \\
(1)\end{array}$ & Unlikely (1) & LIKELY \\
\hline $\begin{array}{c}\text { Medical supervisor (e.g., head } \\
\text { athletic trainer, team } \\
\text { physician) (2) }\end{array}$ & UNLIKELY \\
\hline $\begin{array}{c}\text { Mental health professional } \\
\text { (e.g., counselor or } \\
\text { psychologist) (3) }\end{array}$ & UNLIKELY & \\
\hline
\end{tabular}


Q4 - Based upon the information provided in Toby's case, please indicate whether you believe each of the following interventions would be helpful for him.

\section{(Toby's case information - repeated)}

Toby is a starting junior soccer player and leading scorer at a respected NCAA Division 1 institution. After jumping up to head a ball during a pre-season match, Toby landed awkwardly and suffered a grade-3 ankle sprain on his dominant foot. After his initial evaluation, the doctors, as well as the head AT, informed Toby that he would likely be sidelined for at least 5-6 weeks but would not require surgical repair to his ankle. Since his freshman year, you have known Toby as an outgoing, cheerful, and upbeat person.

However, since hearing his prognosis, Toby appears discouraged, since he worked the entire summer to become season-ready. For the first weeks following your initial assessment, you notice that Toby is often 5 10 minutes late to rehab appointments, rarely engages in small talk, and generally seems sad. He still completes all his exercises and stretches as instructed but is visibly frustrated with his rehabilitation timeline and lack of progress early on. You've also noticed that, even though he attends team practice, he normally sits on the bench and doesn't say much.

\begin{tabular}{|c|c|c|}
\hline Setting appropriate goals (1) & Yes (1) & No (2) \\
\hline $\begin{array}{c}\text { Encouraging effective } \\
\text { communication within the team } \\
(2)\end{array}$ & YES & \\
\hline Teaching positive self talk (3) & YES & NO \\
\hline $\begin{array}{c}\text { Teaching deep breathing (4) } \\
\text { support (5) }\end{array}$ & YES \\
\hline $\begin{array}{c}\text { Using active listening to show } \\
\text { empathy (6) }\end{array}$ & YES & NO \\
\hline $\begin{array}{c}\text { Performance imagery (7) } \\
\text { Anger management techniques } \\
(8)\end{array}$ & NO \\
\hline $\begin{array}{c}\text { Teaching progressive muscle } \\
\text { relaxation (9) }\end{array}$ & YES & NO \\
\hline $\begin{array}{c}\text { Facilitating an athlete's } \\
\text { understanding of injury and } \\
\text { rehabilitation (10) }\end{array}$ & YES & \\
\hline \begin{tabular}{c} 
Healing imagery (11) \\
\hline
\end{tabular} & & \\
\hline
\end{tabular}




\section{Case \#2 - Stanley}

Stanley is a starting sophomore soccer player and leading scorer at a respected NCAA Division 1 institution. While sprinting hard towards a ball, he suffered his second grade-2 hamstring strain. His first strain was during his sophomore year in high school, from which he fully recovered. After his initial evaluation, Stanley is told that he would not require surgery but would likely miss the first 4-6 weeks of the season. During the days immediately following his injury, you notice that Stanley seems somewhat discouraged but follows through with his rehabilitation protocol, as instructed. He attends each session and usually arrives on time, despite his limited mobility on campus. You have also heard from his teammates that he regularly attends practice and is fairly upbeat, despite seeming somewhat frustrated with his new role on the team. A few weeks following his injury, you explain to Stanley that he is progressing more slowly than predicted and that he should prepare himself for an extra week away from play. Though initially upset by the news, he seemed to recover quickly and become comfortable with his lack of progress and new timeline.

Q5 - Based on the information provided in Stanley's case, please indicate whether each of the following symptom(s) is/are present.

\begin{tabular}{|c|c|c|}
\hline & Yes (1) & No (2) \\
\hline Anxiety / stress (1) & & NO \\
\hline Frustration (2) & YES & NO \\
\hline Difficulty adjusting (3) & & NO \\
\hline Anger (4) & NO \\
\hline Motivational issues (5) & NO \\
\hline Suicidal thoughts (6) & NO \\
\hline Depressed Mood (7) & & \\
\hline
\end{tabular}

Q6 - Based on the information provided in Stanley's case, which of the following best describes your intended course of action?

I would take no action. The athlete appears to be adjusting normally to the injury. (1)

I would pay close attention and carefully monitor the athlete's mood and progress, but make no referral (2)

I would consult with a supervisor or mental health professional regarding the severity and/or duration of the athlete's symptoms (3)

I I would make an immediate referral to a mental health professional due to the severity and/or duration of the athlete's symptoms (4) 
Q7 - Based upon the information provided in Stanley's case, please indicate how likely you would be to refer him to each of the following individuals.

\section{(Stanley's case information - repeated)}

Stanley is a starting sophomore soccer player and leading scorer at a respected NCAA Division 1 institution. While sprinting hard towards a ball, he suffered his second grade-2 hamstring strain. His first strain was during his sophomore year in high school, to which he fully recovered. After his initial evaluation, Stanley is told that he would not require surgery but would likely miss the first 4-6 weeks of the season. During the days immediately following his injury, you notice that Stanley seems somewhat discouraged but follows through with his rehabilitation protocol, as instructed. He attends each session and usually arrives on time, despite his limited mobility on campus. You have also heard from his teammates that he regularly attends practice and is fairly upbeat, despite seeming somewhat frustrated with his new role on the team. A few weeks following his injury, you explain to Stanley that he is progressing more slowly than predicted and that he should prepare himself for an extra week away from play. Though initially upset by the news, he seemed to recover quickly and become comfortable with his lack of progress and new timeline.

Notes:

*A sport psychology professional/mental skills coach is an individual who provides mental training services with the intention of enhancing one's personal or professional performance or well-being. These professionals educate individuals on the role of psychological factors in sport and exercise.

**A counselor or psychologist is a licensed helping professional who works with people experiencing psychological disorders and/or other mental health concerns.

\begin{tabular}{|c|c|c|}
\hline $\begin{array}{c}\text { Sport psychology professional } \\
(1)\end{array}$ & Unlikely (1) & Likely (2) \\
\hline $\begin{array}{c}\text { Medical supervisor (e.g., head } \\
\text { athletic trainer, team } \\
\text { physician) (2) }\end{array}$ & UNLIKELY & \\
\hline $\begin{array}{c}\text { Mental health professional } \\
\text { (e.g., counselor or } \\
\text { psychologist) (3) }\end{array}$ & UNLIKELY & \\
\hline
\end{tabular}


Q8 - Based upon the information provided in Stanley's case, please indicate whether you believe each of the following interventions would be helpful for him.

\section{(Stanley's case information - repeated)}

Stanley is a starting sophomore soccer player and leading scorer at a respected NCAA Division 1 institution. While sprinting hard towards a ball, he suffered his second grade-2 hamstring strain. His first strain was during his sophomore year in high school, to which he fully recovered. After his initial evaluation, Stanley is told that he would not require surgery but would likely miss the first 4-6 weeks of the season. During the days immediately following his injury, you notice that Stanley seems somewhat discouraged but follows through with his rehabilitation protocol, as instructed. He attends each session and usually arrives on time, despite his limited mobility on campus. You have also heard from his teammates that he regularly attends practice and is fairly upbeat, despite seeming somewhat frustrated with his new role on the team. A few weeks following his injury, you explain to Stanley that he is progressing more slowly than predicted and that he should prepare himself for an extra week away from play. Though initially upset by the news, he seemed to recover quickly and become comfortable with his lack of progress and new timeline.

\begin{tabular}{|c|c|c|}
\hline & Yes (1) & No (2) \\
\hline $\begin{array}{c}\text { Setting appropriate goals (1) } \\
\text { Encouraging effective } \\
\text { communication within the team }\end{array}$ & YES & \\
\hline $\begin{array}{c}\text { Teaching positive self talk (3) } \\
\text { Teaching deep breathing (4) }\end{array}$ & YES & NO \\
\hline $\begin{array}{c}\text { Providing him with emotional } \\
\text { support (5) }\end{array}$ & YES & \\
\hline $\begin{array}{c}\text { Using active listening to show } \\
\text { empathy (6) }\end{array}$ & YES & \\
\hline $\begin{array}{c}\text { Performance imagery (7) } \\
\text { Anger management techniques } \\
(8)\end{array}$ & YES & NO \\
\hline $\begin{array}{c}\text { Teaching progressive muscle } \\
\text { relaxation (9) }\end{array}$ & YES & NO \\
\hline $\begin{array}{c}\text { Facilitating an athlete's } \\
\text { understanding of injury and } \\
\text { rehabilitation (10) }\end{array}$ & YES & \\
\hline \begin{tabular}{c} 
Healing imagery (11) \\
\hline
\end{tabular} & & \\
\hline
\end{tabular}




\section{Case \#3 - Oscar}

Oscar is a starting junior soccer player and leading scorer at a respected NCAA Division 1 institution. During the first match of the season, Oscar suffered a grade-3 ankle sprain on his dominant foot while attempting to jump over an opponent. He describes hearing a "pop" when he landed. After his initial assessment, the doctors, as well as the head AT, informed Oscar that he would likely miss 5-6 weeks but would not require surgery on his ankle. After hearing the news, Oscar is visibly upset and immediately leaves the room on his crutches. For the following three weeks, Oscar misses many appointments and when he shows up, he is visibly fatigued and lacks ability to focus on his rehabilitation. You also notice that he has lost a significant amount of weight during the short period of time since his injury. He no longer shows up to practice, refuses to talk about soccer or his injury, and spends most of his time alone in his apartment. You've also heard him discuss quitting soccer all together and leaving college. His teammates have also shared with you that he frequently talks about "wishing he was not around" and "losing his purpose in life," statements that are frequently coupled with severe intoxication.

Q9 - Based on the information provided in Oscar's case, please indicate whether each of the following symptom(s) is/are present.

\begin{tabular}{|c|c|c|}
\hline & Yes (1) & No (2) \\
\hline Anxiety / stress (1) & YES & \\
\hline Difficulty adjusting (2) & YES & \\
\hline Anger (3) & YES & \\
\hline Frustration (4) & YES & \\
\hline Motivational issues (5) & YES & \\
\hline Depressed Mood (6) & YES & \\
\hline Suicidal thinking (7) & YES & \\
\hline
\end{tabular}

Q10 - Based on the information provided in Oscar's case, which of the following best describes your intended course of action?

O I would take no action. The athlete appears to be adjusting normally to the injury. (1)

I I would pay close attention and carefully monitor the athlete's mood and progress, but make no referral (2)

I would consult with a supervisor or mental health professional regarding the severity and/or duration of the athlete's symptoms (3)

I would make an immediate referral to a mental health professional due to the severity and/or duration of the athlete's symptoms (4) 
Q11 - Based upon the information provided in Oscar's case, please indicate how likely you would be to refer him to each of the following individuals.

\section{(Oscar's case information - repeated)}

Oscar is a starting junior soccer player and leading scorer at a respected NCAA Division 1 institution. During the first match of the season, Oscar suffered a grade-3 ankle sprain on his dominant foot while attempting to jump over an opponent. He describes hearing a "pop" when he landed. After his initial assessment, the doctors, as well as the head AT, informed Oscar that he would likely miss 5-6 weeks but would not require surgery on his ankle. After hearing the news, Oscar is visibly upset and immediately leaves the room on his crutches. For the following three weeks, Oscar misses many appointments and when he shows up, he is visibly fatigued and lacks ability to focus on his rehabilitation. You also notice that he has lost a significant amount of weight during the short period of time since his injury. He no longer shows up to practice, refuses to talk about soccer or his injury, and spends most of his time alone in his apartment. You've also heard him discuss quitting soccer all together and leaving college. His teammates have also shared with you that he frequently talks about "wishing he was not around" and "losing his purpose in life," statements that are frequently coupled with severe intoxication.

Notes:

*A sport psychology professional/mental skills coach is an individual who provides mental training services with the intention of enhancing one's personal or professional performance or well-being. These professionals educate individuals on the role of psychological factors in sport and exercise.

**A counselor or psychologist is a licensed helping professional who works with people experiencing psychological disorders and/or other mental health concerns.

\begin{tabular}{|c|c|c|}
\hline & Unlikely (1) & Likely (2) \\
\hline $\begin{array}{c}\text { Sport psychology professional } \\
\text { (1) }\end{array}$ & UNLIKELY & \\
\hline $\begin{array}{c}\text { Medical supervisor (e.g., Head } \\
\text { athletic trainer, team } \\
\text { physician) (2) }\end{array}$ & & LIKELY \\
\hline $\begin{array}{c}\text { Mental health professional } \\
\text { (e.g., counselor or } \\
\text { psychologist) (3) }\end{array}$ & & LIKELY \\
\hline
\end{tabular}


Q12 - Based upon the information provided in Oscar's case, please indicate whether you believe each of the following interventions would be helpful for him.

\section{(Oscar's case information - repeated)}

Oscar is a starting junior soccer player and leading scorer at a respected NCAA Division 1 institution. During the first match of the season, Oscar suffered a grade-3 ankle sprain on his dominant foot while attempting to jump over an opponent. He describes hearing a "pop" when he landed. After his initial assessment, the doctors, as well as the head AT, informed Oscar that he would likely miss 5-6 weeks but would not require surgery on his ankle. After hearing the news, Oscar is visibly upset and immediately leaves the room on his crutches. For the following three weeks, Oscar misses many appointments and when he shows up, he is visibly fatigued and lacks ability to focus on his rehabilitation. You also notice that he has lost a significant amount of weight during the short period of time since his injury. He no longer shows up to practice, refuses to talk about soccer or his injury, and spends most of his time alone in his apartment. You've also heard him discuss quitting soccer all together and leaving college. His teammates have also shared with you that he frequently talks about "wishing he was not around" and "losing his purpose in life," statements that are frequently coupled with severe intoxication.

\begin{tabular}{|c|c|c|}
\hline Setting appropriate goals (1) & Yes (1) & No (2) \\
\hline $\begin{array}{c}\text { Encouraging effective } \\
\text { communication within the team } \\
(2)\end{array}$ & YES & \\
\hline Teaching positive self talk (3) & NO \\
\hline Teaching deep breathing (4) & YES & NO \\
\hline $\begin{array}{c}\text { Providing him with emotional } \\
\text { support (5) }\end{array}$ & YES & NO \\
\hline $\begin{array}{c}\text { Using active listening to show } \\
\text { empathy (6) }\end{array}$ & NO \\
\hline $\begin{array}{c}\text { Performance imagery (7) } \\
\text { Anger management techniques }\end{array}$ & & NO \\
\hline $\begin{array}{c}\text { Teaching progressive muscle } \\
\text { relaxation (9) }\end{array}$ & YES & NO \\
\hline $\begin{array}{c}\text { Facilitating an athlete's } \\
\text { understanding of injury and } \\
\text { rehabilitation (10) }\end{array}$ & & \\
\hline \begin{tabular}{c} 
Healing imagery (11) \\
\hline
\end{tabular} & & \\
\hline
\end{tabular}


Appendix E

Table 5 - Accuracy in Symptom Identification 
Table 5

Accuracy in symptom identification

\begin{tabular}{|c|c|c|c|c|c|c|c|c|}
\hline & $\begin{array}{l}\text { Anxiety/ } \\
\text { Stress }\end{array}$ & $\begin{array}{l}\text { Difficulty } \\
\text { Adjusting }\end{array}$ & Anger & Frustration & $\begin{array}{c}\text { Motivational } \\
\text { Issues }\end{array}$ & $\begin{array}{c}\text { Depressive } \\
\text { Mood }\end{array}$ & $\begin{array}{l}\text { Suicidal } \\
\text { Thoughts }\end{array}$ & Overall* \\
\hline \multicolumn{9}{|l|}{ Stanley (low) } \\
\hline $\mathrm{N}$ & 333 & 334 & 334 & 334 & 334 & 330 & 332 & 328 \\
\hline$\%$ Correct & 68.8 & 87.1 & 91.6 & 72.2 & 83.8 & 93.9 & 99.4 & \\
\hline$\%$ Incorrect & 31.2 & 12.9 & 8.4 & 27.8 & 16.2 & 6.1 & 0.6 & \\
\hline M & & & & & & & & 5.98 \\
\hline $\mathrm{SD}$ & & & & & & & & 1.00 \\
\hline \multicolumn{9}{|c|}{ Toby (moderate) } \\
\hline $\mathrm{N}$ & 364 & 365 & 363 & 365 & 364 & 366 & 361 & 358 \\
\hline$\%$ Correct & 75 & 99.2 & 32.5 & 100 & 100 & 100 & 98 & \\
\hline$\%$ Incorrect & 25 & 0.8 & 67.5 & 0 & 0 & 0 & 3 & \\
\hline $\mathrm{M}$ & & & & & & & & 6.03 \\
\hline $\mathrm{SD}$ & & & & & & & & 0.65 \\
\hline \multicolumn{9}{|l|}{ Oscar (high) } \\
\hline $\mathrm{N}$ & 328 & 330 & 328 & 329 & 330 & 329 & 330 & 324 \\
\hline$\%$ Correct & 96.0 & 98.5 & 91.8 & 98.2 & 95.8 & 98.9 & 96.1 & \\
\hline$\%$ Incorrect & 4.0 & 1.5 & 8.2 & 1.8 & 4.2 & 1.2 & 3.9 & \\
\hline $\mathrm{M}$ & & & & & & & & 6.75 \\
\hline $\mathrm{SD}$ & & & & & & & & 0.82 \\
\hline \multicolumn{9}{|l|}{ Combined } \\
\hline $\mathrm{N}$ & & & & & & & & 314 \\
\hline $\mathrm{M}$ & & & & & & & & 6.27 \\
\hline SD & & & & & & & & 0.49 \\
\hline
\end{tabular}


Appendix F

Table 6 - Accuracy in Intended Course of Action 
Table 6

Intended Course of Action

\begin{tabular}{lccccc}
\hline & $\mathrm{N}$ & \% Correct & \% Incorrect & M & SD \\
\hline Stanley (low) & 334 & 97.3 & 2.7 & & \\
Toby (moderate) & 363 & 38.3 & 61.7 & & \\
Oscar (high) & 329 & 89.7 & 10.3 & & \\
& & & & & \\
Overall & 326 & & & 2.25 & 0.55 \\
\hline
\end{tabular}




\section{Appendix G}

Table 7 - Accuracy in Choosing Appropriate Interventions 
Table 7

Accuracy in choosing appropriate interventions

\begin{tabular}{|c|c|c|c|c|c|c|}
\hline & Goal Setting & $\begin{array}{c}\text { Encouraging } \\
\text { Communication }\end{array}$ & $\begin{array}{l}\text { Positive Self } \\
\text { Talk }\end{array}$ & $\begin{array}{c}\text { Deep } \\
\text { Breathing }\end{array}$ & $\begin{array}{c}\text { Emotional } \\
\text { Support }\end{array}$ & $\begin{array}{c}\text { Active } \\
\text { Listening }\end{array}$ \\
\hline \multicolumn{7}{|l|}{ Stanley (low) } \\
\hline $\mathrm{N}$ & 331 & 332 & 332 & 331 & 331 & 332 \\
\hline$\%$ Correct & 97.6 & 85.2 & 67.2 & 73.1 & 82.2 & 89.5 \\
\hline$\%$ Incorrect & 2.4 & 14.8 & 32.8 & 26.9 & 17.8 & 10.5 \\
\hline \multicolumn{7}{|l|}{ M } \\
\hline \multicolumn{7}{|c|}{$\mathrm{SD}$} \\
\hline \multicolumn{7}{|c|}{ Toby (moderate) } \\
\hline $\mathrm{N}$ & 350 & 350 & 350 & 349 & 350 & 350 \\
\hline$\%$ Correct & 98.6 & 95.7 & 4.6 & 54.4 & 97.4 & 98.9 \\
\hline$\%$ Incorrect & 1.4 & 4.3 & 95.4 & 45.6 & 2.6 & 1.1 \\
\hline \multicolumn{7}{|l|}{ M } \\
\hline \multicolumn{7}{|l|}{$\mathrm{SD}$} \\
\hline \multicolumn{7}{|l|}{ Oscar (high) } \\
\hline $\mathrm{N}$ & 328 & 329 & 329 & 329 & 329 & 328 \\
\hline$\%$ Correct & 9.1 & 93.3 & 4.3 & 28.3 & 98.8 & 98.2 \\
\hline$\%$ Incorrect & 90.9 & 6.7 & 95.7 & 71.7 & 1.2 & 1.8 \\
\hline \multicolumn{7}{|l|}{ M } \\
\hline SD & & & & & & \\
\hline
\end{tabular}


Table 7 (continued)

\begin{tabular}{|c|c|c|c|c|c|c|}
\hline & $\begin{array}{l}\text { Performance } \\
\text { Imagery }\end{array}$ & $\begin{array}{c}\text { Anger } \\
\text { Management }\end{array}$ & $\begin{array}{c}\text { Teaching } \\
\text { PMR }\end{array}$ & $\begin{array}{c}\text { Facilitating } \\
\text { Understanding of } \\
\text { Injury }\end{array}$ & $\begin{array}{l}\text { Healing } \\
\text { Imagery }\end{array}$ & Overall \\
\hline \multicolumn{7}{|l|}{ Stanley (low) } \\
\hline $\mathrm{N}$ & 330 & 329 & 329 & 332 & 329 & 321 \\
\hline$\%$ Correct & 64.8 & 91.5 & 65.3 & 94.6 & 69.6 & \\
\hline$\%$ Incorrect & 35.2 & 8.5 & 34.7 & 5.4 & 30.4 & \\
\hline M & & & & & & 8.80 \\
\hline $\mathrm{SD}$ & & & & & & 1.43 \\
\hline \multicolumn{7}{|c|}{ Toby (moderate) } \\
\hline $\mathrm{N}$ & 349 & 348 & 346 & 350 & 349 & 345 \\
\hline$\%$ Correct & 40.1 & 60.1 & 60.7 & 99.7 & 80.5 & \\
\hline$\%$ Incorrect & 59.9 & 39.9 & 39.3 & 0.3 & 19.5 & \\
\hline M & & & & & & 7.91 \\
\hline $\mathrm{SD}$ & & & & & & 1.38 \\
\hline \multicolumn{7}{|l|}{ Oscar (high) } \\
\hline $\mathrm{N}$ & 329 & 328 & 329 & 329 & 328 & 325 \\
\hline$\%$ Correct & 43.2 & 16.5 & 33.7 & 97.6 & 18.0 & \\
\hline$\%$ Incorrect & 56.8 & 83.5 & 66.3 & 2.4 & 82.0 & \\
\hline M & & & & & & 5.42 \\
\hline $\mathrm{SD}$ & & & & & & 1.62 \\
\hline \multicolumn{7}{|l|}{ Combined } \\
\hline $\mathrm{N}$ & & & & & & 312 \\
\hline M & & & & & & 7.39 \\
\hline SD & & & & & & 0.92 \\
\hline
\end{tabular}




\section{Appendix $\mathbf{H}$}

Review of the Literature 


\section{Literature Review}

\section{Understanding Sport-Related Injuries}

The benefits of sport and exercise play an important role in promoting well-being and preventing chronic diseases such as obesity, heart disease, hypertension, and diabetes as well as increasing muscle mass and cardiovascular fitness (Berger, Pargman, \& Weinberg, 2007). As a result, athletes are often believed to be the healthiest members in our society. Yet, while sport participation may promote healthier lifestyles, competitive athletes often face unavoidable risk of injury. In many cases, these injuries occur as a result of the nature of physical competition (e.g., physical trauma, high speed collisions) or the physical and psychological demands of the sport (e.g., increased training, stress) (Yang et al., 2012). Sport-related injuries may result in significant pain, lost playing time, psychological distress, and in some severe cases, retirement from the sport all together and a loss of one's athletic identity (Pargman, 2007; Williams \& Andersen, 2007). Consequences of sport-related injury, however, often rely upon a number of factors such as the severity of the injury, competitive level, nature of the sport, culture of the sport, or one's ability to cope with change. Unfortunately, sport injuries have become very common in most sport and exercise settings. For instance, Yang and colleagues (2012) revealed that the likelihood of a collegiate athlete sustaining an injury has increased over the years. Authors were particularly interested in reporting the epidemiology of overuse injury, that is, injuries that occur as a result of prolonged stress on the body due to long training sessions or the same movement repeated numerous times. It was revealed that, from the a sample of 573 injured NCAA Division 1 athletes, nearly one third of all injuries were overuse injuries and were most commonly associated 
with low-contact sport athletes (e.g., rowing, cross-country running, track and field). Thus, it is possible that such injuries have become more common in recent years due to factors such as: more sophisticated training techniques, a greater emphasis on winning, greater risk-taking behaviors. Other recent data by Hootman, Dick, and Agel (2007) suggested that rates of concussions and anterior cruciate ligament injuries increased significantly (average annual increases of $7.0 \%$ and $1.3 \%$ respectively) over the course of a two year study. Furthermore, Burt and Overpeck (2001) indicated that sport and exercise-related injuries were responsible for as many as 3.7 million emergency room visits between 1997 and 1998 in the United States alone. Of these, athletes/exercisers between the ages of 5-24 years accounted for over $68 \%$ (2.6 million) of sport-related emergency room visits, with more than half of these injuries considered to be preventable. Similarly, Gotsch, Annest, Holmgreen, and Gilchrist (2002) reported 4.3 million emergency room visits resulting in sport/exercise participation in 2000-2001, with $25-50 \%$ of these athletes precluding from participation for at least one week. Although little longitudinal data exists on the prevalence of sport-related injuries over the years, Singh, Smith, Fields, and McKenzie (2008) described the epidemiology of gymnastics-related injuries in the United States over a period of 15 years. National estimates were calculated and revealed that injury rates continue to increase over the years and the number of injuries per year was greater for older gymnasts (12-17 years old). These results not only suggest that injuries are becoming more common as the sport continues to develop (better technologies, stronger athletes), but also that athletes become more prone to injuries as they become more and more competitive. Overall, these trends may reflect the major improvements in identification of these injuries, especially with 
technological advances (MRI, concussion testing) and increased quality of sports medicine education. Nevertheless, with higher numbers of sport-related injuries, those responsible for rehabilitation would be wise to have an understanding of all the characteristics that go along with successful rehabilitation and return to play.

However, the world of athletics is not as dominated by injuries as these data may make it appear. In most cases, participation in college athletics is relatively safe. In fact, the NCAA reported that only a small percentage of athletes sustain injuries based on the total number of athletes and the level of sport exposure. As an example, football (the most injurious sport) will see 8.1 injuries per 1000 athlete exposures (games and practices combined), with most being categorized as minor injuries, requiring minimal rehabilitation and lost playing-time (NCAA.org, January 2014). However, it is also important to consider the more publicized, yet less common, major injuries (ligament tears, concussions, bone breaks) that can lead to weeks or months in rehabilitation and away from the playing field. Injuries such as these may result in not only physical but also psychological detriments that could significantly impact an athlete's recovery and performance. Understanding the frequency, rate, and severity of sport-related injuries is an important first step for designing and carrying out effective prevention programs and treatment protocols to prevent and rehabilitate athletes. The indication of modifiable factors, if addressed through injury prevention initiatives, may contribute to lower injury rates in sports. Coaches and certified athletic trainers (ATs) are typically those who have the highest level of exposure with athletes, and should therefore have a basic understanding of all factors (including psychological ones) that influence injury and injury rehabilitation. Such close proximity with athletes enable coaches and ATs to 
recognize and possibly intervene before athletes develop more serious issues (e.g., depression). Thus, the following section will provide a brief overview of some psychological factors that may influence the likelihood of injury and the rehabilitation process. Particular focus will be placed on the role of ATs.

\section{Psychological Factors of Sport Injury}

\section{Psychological Antecedents}

In general, physical factors (e.g., high-speed collisions, overtraining, flawed biomechanics, or muscle fatigue) or situational factors (e.g., inclement weather or unsafe playing surfaces) are the primary causes of most athletic injuries (Pargman, 2007). However, there is sufficient evidence to suggest that certain psychological factors, such as life stress, also play a key contributing role in sustaining a sport-related injury (Bramwell, Masuda, Wagner, \& Holmes, 1975; Fawkner, McMurrary, \& Summers, 1999; Williams \& Andersen, 1998). As an example, Fawkner and colleagues assessed minor life events (i.e., short-lived stress), using the Daily Hassles Scale on a weekly basis to determine their relative contribution to athletic injury risk in 98 Australian athletes (field hockey, volleyball, and triathletes). Results indicated that $36 \%$ of the sample incurred an injury, with $50 \%$ of them sustaining multiple injuries across the entire season. More importantly, Fawkner and colleagues reported a significant relationship between the mean intensity of hassles scores and injury status over the course of the study. Conversely, non-injured athletes in the study showed very little fluctuation in intensity of hassles rating. The applicability of these findings rests in the ability of coaches and sports medicine professionals to identify athletes who are more at risk. To further explore 
the relationship between stress and injury, the following section will discuss the stressinjury model, along with research relating to different components of the model.

The Stress-Injury Model. Due to the theoretical basis and widespread support of the stress-injury model, this section will serve as a foundation for the basic understanding and interpretation of past and more recent findings relating the stress response to athletic injury. Briefly, according to the stress-injury model (Andersen \& Williams, 1988; Williams and Andersen, 1998) ${ }^{3}$, various psychosocial factors influencing an individual's stress response will contribute to his or her likelihood of injury or return from injury. Overall, three main factors (personality, history of stressors, and coping resources) can contribute, interactively or in isolation, to one's stress response. The central assumption of the model is that individuals with personality characteristics that intensify the stress response, a history of many stressors, and few effective coping strategies will become more likely to appraise a situation as potentially stressful. In turn, these athletes will then become more susceptible to experience narrowed visual fields, generalized muscle tension, and increased distractability. For example, an athlete who views competition as threatening and anxiety provoking may be more susceptible to negative stress (distress) which may lead the athlete to become more prone to attentional disturbances or increased muscle tension. While the stress-injury model includes factors such as personality and coping resources, research has generally provided mixed-results of these factors and their relationship with sport injury. For instance, studies have indicated that athletes exhibiting more assertive, independent, and self-assured personalities were more likely to

\footnotetext{
${ }^{3}$ The original model, published in 1988 found substantial support for the basic components and hypotheses to psychological antecedents of sport injury, but also received recommendations for minor changes. The original version of this model did not account for the bidirectional relationship between personality, history of stressors, and coping resources, found in the revised model published in 1998.
} 
experience moderate to severe injuries during performances (Van Mechelen, Twisk, Molendijk, Blom, Snel, \& Kemper, 1996; Wittig \& Schurr, 1994). Authors assumed that athletes with more dominant personalities ran a higher risk of sport injury due to their tendencies to assume more central, risky, and intense roles during practice and competition. Conversely, earlier research (e.g., Jackson et al., 1978; Valliant, 1981) revealed the opposite that more tender-minded and dependent athletes were more likely to get injured in competition due to possible increases in muscle tension caused by anxiety and nervousness. These inconsistencies point to a general problem in personality research that most personality variables, as measured by a wide variety of instruments, generally do not account for much variance in most outcomes one wishes to measure. Therefore, while athletes' personality characteristics can provide important insight in athletes' risk of injury, conclusions should not be derived from such assessments and should only be taken into consideration sparingly and in the form of valid and reliable personality assessment instruments. Thus, the following section will pay particular attention to the relationship between stress and injury due to the empirical findings supporting this link. Particular emphasis will be placed on the applicability of these findings as they relate to the work of ATs.

Stress and Injury. Prior to becoming significant in sport injury research, major life events were originally established as a strong indicator to illness (e.g., Holmes \& Rahe, 1967; Sarason, Johnson, \& Siegel, 1978). The importance of life stress is based on the assumption that the experience of major life events leads the individual to adapt, which places stress on the body and immune system, thus increasing one's risk of sustaining an injury or illness. Early research on major life events and sport injury 
evaluated high life stress using the Social Readjustment Scale (SRRS) in collegiate football players (e.g, Holmes \& Rahe, 1967). Results indicated that $50 \%$ of participants who experienced a major life event in the past 12 months reported an injury precluding them from at least three days of practice or competition. An equally noteworthy finding came from DeLongis, Coyne, Dakof, Folkman, and Lazarus (1982), who were interested in distinguishing between the impact of chronic life stress versus daily stress on individual's health status. DeLongis and colleagues evaluated 100 participants and administered a series of questionnaires evaluating constructs such as life stress, hassles, and health status. Authors were also interested in the relationship between, what they called, uplifts and somatic illness. Uplifts were described as positive experiences that are likely to occur in daily life (e.g., positive life stress). As predicted, both the frequency and perceived intensity of daily hassles showed a significant correlation relationship with overall health. However, it was revealed that more negative health outcomes occurred for those who reported high levels of negative events, and that positive events had either no influence, or a less detrimental one, to somatic illness. Such a relationship could be explained by a person's individual appraisal of an event, rather than the overall magnitude of the event disturbance. In other words, athletes who appraise stressful (positive and negative) situations negatively may be more prone to sport-related injuries.

Furthermore, Sibold and Zizzi (2012) examined the influence of othopaedic and psychosocial variables (e.g., negative life-event stress, number of previous injuries, concentration disruptions, somatic anxiety, and worry) on time-to-injury in collegiate athletes (i.e., number of days prior to sustaining an injury). Results from a sample of 125 athletes revealed that negative life-event stress, concentration disruption, and number of 
previous injuries were negatively related to days of first injury. In other words, the more frequent these variables were present in athletes' lives, the less time-to-injury the athlete experienced. These findings lend support to the stress injury model, which postulated that history of stressors (major life events, daily hassles, and previous injuries) was the strongest factor in predicting injury. Practically speaking, these findings underline the importance of psychosocial assessments in athletic health care. Although the use of valid psychometric instruments is not practical in this context, sports medicine professionals should, at the very least, possess basic screening knowledge, given its documented link to injury.

Finally, the relationship between stress and injury can also be examined in the context of injury prevention. For instance, Perna and colleagues (2003) conducted a randomized control trial that tested the efficacy of a cognitive behavioral stress management (CBSM) intervention to reduce post-intervention injury and illness among competitive collegiate rowers. Specifically, the research team was interested in determining whether a seven-week cognitive behavioral intervention aimed at teaching stress management skills would significantly reduce the number of days athletes spent either injured or ill during the course of an entire season. Results indicated that athletes assigned to the CBSM group, which consisted of 7 structured sessions containing skill acquisition and application (i.e., relaxation techniques and cognitive based strategies) components experienced significant reductions in the number of illness and injury days as compared to the control group. These results further contribute to the validity in linking various physical and health outcomes to psychological factors such as stress. However, there were a few limitations to the study. First and foremost, the documented post- 
intervention illnesses and injuries were much lower than what may accurately reflect the actual rate of injury and illness in collegiate rowers. This may have been due to actual low rates of illness and injury, incomplete documentation, or failure from ill rowers to seek medical attention for illness or injury. Regardless of the limitations, coaches, sport psychology practitioners, or ATs would benefit greatly from understanding the relationship between athlete stress (major life event, daily hassle, previous injury) and injury prevalence. Practically, this information could prove extremely useful in assessing their potential risk for injury or illness and could lead to modified training and rehabilitation programs or the development of stress management skills. Basic stress management skills are generally uncomplicated, thus, have the potential to be easily learned and implemented, particularly by those who spend significant time with injured athletes (i.e., ATs and coaches).

\section{Psychological Responses to Injury}

As expected, physical assessment and rehabilitation are the predominant concerns of sports medicine professionals when working alongside injured athletes. However, the increasing body of research focusing on the psychological responses to injury has led sports medicine professionals to also consider an athlete's psychological and emotional concerns following an injury (e.g., Cramer Roh \& Perna, 2000; Wiese Bjornstal \& Shaffer, 1999). Specifically, Wiese Bjornstal and Shaffer put forth a variety of common psychological responses to sport injury including emotional (mood disturbances), behavioral (withdrawal, malingering), and cognitive (negative self-perceptions) that play a significant role in athlete recovery. Additional research (e.g., Brewer, Petitpas, Van 
Raalte, Sklar, \& Ditmar, 1995) revealed some more extreme emotional responses, such as clinical depression, have afflicted athletes with more serious and longer lasting injuries.

The majority of psychological distress experienced by injured athletes does not meet the criteria (magnitude, duration, etc.) for clinical diagnosis (Heil, 1993). However, several studies have shown that athletes can experience clinically meaningful levels of emotional disturbance, particularly depression, during the rehabilitation process (e.g., Brewer, Linder, \& Phelps, 1995; Brewer et al., 1995). More specifically, Brewer, Petitpas and colleagues reported from a sample of 200 consecutive patients in a sports medicine clinic, that patients reported few overt signs of maladaptive psychosocial responses to injury. However, $19 \%$ of patients demonstrated clinical levels of psychological distress, mostly depression. Thus, although most injured athletes in this sample experienced no or non-clinical levels of distress while coping with their injury, some suffered more elevated, and clinically significant, levels of debilitating mood states. In addition, a recently published consensus statement written for the National Athletic Trainers' Association (Neal et al., 2013) discussed the sub-clinical changes of mental states that impact the student-athlete population and require further attention from the sports medicine team. Neal and colleagues argued that sub-clinical concerns could possibly develop into a level of distress that moves the athlete further away from his or her baseline state of well-being and require further attention by the sports primary and secondary rehabilitation team. The presence of psychological concerns, whether clinical or not, in injured athletes poses the question of whether coaches and/or ATs have the ability to recognize if an athlete is experiencing levels of distress pre- or post-injury. 
Along these lines, within the area of psychological response to injury, two broad categories of theoretical models have provided the basis for understanding and investigating responses to sport injury: stage models and cognitive appraisal models. Stage models have been adapted from research on psychological responses to terminal illness and other such forms of grief and loss (Brewer, 2001). For instance, the KüblerRoss model of death and dying has been applied to the sport injury context (e.g., Lynch, 1988; Rotella, 1985), suggesting that athletes pass sequentially through a series of emotional stages following their injury (e.g., denial, anger, bargaining, depression, and finally, acceptance of their injury). Despite the best efforts to successfully tailor stage models to the sporting context, the individualistic nature of injury-response still exists. In other words, while it has been shown that sport injury can elicit reactions congruent with a grief response, the notion that athletes respond to injury in a predictable stage-like manner has not been empirically supported (Brewer, 1994; 2001). Therefore, while ATs might benefit from understanding different processes of stage models of psychological response to injury, they should exercise caution and refrain from placing athletes into general categories without considering their individual differences.

On the other hand, considerable support has been given to cognitive appraisal models (CAM) of sport injury. These models give cognition a central role in determining the athletes' behavioral and emotional response to their injuries (Daly, Brewer, Van Raalte, Petitpas, \& Sklar, 1995). Similar to the theories explaining sport injury risk, CAMs are rooted in the theories of stress and coping (Walker \& Heaney, 2013). According to these models, importance is placed on how the injury is perceived and interpreted by the athlete (i.e., their cognitive appraisal). As a result, emotional and 
behavioral responses are largely determined by the individual athlete's appraisal of the injury (Wiese Bjornstal, Smith, Shaffer, \& Morrey, 1998).

Research investigating cognitive appraisal have clearly demonstrated that athletes appraise their injuries as stressful, which may influence emotional and behavioral outcomes (rehabilitation) (e.g., Albinson \& Petrie, 2003; Bianco, Malo, \& Orlick, 1999; Daly et al., 1995). Specifically, Daly and colleagues investigated the relationship between cognitive appraisals and rehabilitation behaviors such as adherence and total mood disturbances. Results of the study revealed that cognitive appraisal, as measured by a single item scale, was correlated with emotional disturbances, and in turn, was correlated with adherence behaviors (i.e., attendance to rehabilitation sessions and AT/PT ratings of athlete behaviors). Despite the correlational nature of the study, findings provided initial support for the relationship between emotional disturbance and attendance to rehabilitation sessions. In other words, athletes experiencing symptoms of psychological distress were less likely to attend sessions; or athletes who missed appointments may have also been struggling to adjust to their injury. Practically, these results recommend that ATs have the ability to identify athletes who are not adjusting well to an injury. The ability to do this may lead ATs to develop an intervention designed to enhance the rehabilitation goals (i.e., providing social support, creating variety in the rehabilitation sessions).

Other research investigating the emotional responses to sport injury have revealed that negative emotions such as depression, confusion, anger, frustration, and fear are among the most common throughout the rehabilitation process (Bianco et al., 1999; Morrey, Stuart, Smith, \& Wiese-Bjornstal, 1999; Udry, Gould, Bridges, \& Beck, 1997). 
More specifically, Morrey and colleagues reported that athletes experience changes in their mood almost immediately post-injury. For example, frustration showed a "U" shape pattern for most athletes as rehabilitation progressed. In other words, athletes showed initial motivation/positive mood which dwindled over time, only to recover as they neared their rehabilitation goals. Perhaps this fluctuation is explained by the different phases of the rehabilitation process (e.g., the injury-illness phase, the rehabilitation recovery phase, and the return to full activity phase). Furthermore, Bianco and colleagues revealed, from a sample of skiers, that significant stressors were present throughout the entirety of the recovery process. For example, during the middle and final stages, depression and frustration continued to be prominent as athletes dealt with rehabilitation concerns (e.g., physical setbacks) and fear of reinjury.

Overall, it is evident that athletes have psychological responses to their injuries and these differ greatly, depending on the individual athlete. Cognitively, athletes appear to develop attributions for the causes of their injuries, which could lead to the development of negative mood. For instance, Brewer and colleagues (2007) examined changes in pain and negative mood over the first six weeks of rehabilitation for ACL surgical reconstruction. Results from 91 athletes revealed a significant correlation between level of pain and frequency in negative moods. But more importantly, Brewer and colleagues revealed that all participants experienced some form of negative mood fluctuation throughout the rehabilitation process and that personality variables (e.g., neuroticism) accounted for up to $19 \%$ of the variability in negative mood. In addition, authors reported a relationship between time since surgery and negative mood, but indicated that many variables influenced this variability, such as athletic identity and 
optimism. For example, people with a lower athletic identity had a less pronounced decrease in negative mood as time progressed post-surgery. While it would be advantageous for ATs to know how many injured athletes experience negative moods and how long these moods last, individual differences make it extremely difficult to make such predictions. Overall, these findings highlight the importance for allied sports medicine professionals (e.g., ATs, physicians) to be better prepared to respond appropriately, given the psychological symptoms demonstrated by the injured athlete. This response could take the form of: recognizing the issue and intervening themselves, or referring the athlete to the proper mental health professional

Now that we have examined the different psychological factors involved with sport injury (both pre- and post-injury), the following sections will examine ATs. Specifically, an overview of the accreditation and certification process, the role of the AT, ATs' perceptions of the psychosocial aspects of sport injury, and the educational model currently in place to ensure that ATs are adequately trained in this area.

\section{Certified Athletic Trainers}

\section{Accreditation and Certification.}

The National Athletic Training Association (NATA), established in 1950, serves as a professional membership association for ATs in the United States and some Canadian provinces. The development of the NATA was initiated based on the identification and need for a set of professional standards and appropriate professional recognition. In short, the NATA has been a driving force behind the recognition of athletic training as a profession by setting the standard for professionalism, education, certification, research, and practice (www.nata.org). As an NATA subset, the Board of 
Certification (BOC) was established as a part of the NATA in the 1970's, as a program certifying entry-level athletic trainers based on standards set forth by the NATA. Since its inception, the NATA has provided guidelines for the training of athletic training students (ATSs) in order to properly prepare them for certification and effective fieldwork. However, it is the Commission on Accreditation of Athletic Training Education (CAATE) that oversees the curriculum standards of all professional and postprofessional institutions. In other words, while the NATA is responsible for setting the certification standards for all entry-level athletic trainers, CAATE is responsible for ensuring that Athletic Training Education Programs (ATEPs) meet these standards, while the BOC is responsible for certifying individual athletic trainers, who graduate from CAATE accredited programs, via written and practical examination.

However, it was not until 2004 that the NATA replaced the internship route to athletic training certification, and required that all ATSs seeking certification enroll in CAATE accredited ATEPs in order to be eligible for the BOC national examination in its place (www.nata.org). In order to achieve certification standards, ATEPs are required to implement eight educational competencies and proficiencies within the required coursework. The implementation of standardized competencies within ATEPs has drastically changed the face of athletic training education by ensuring that entry-level ATs are given a consistent education that effectively prepare them for their work with athletes. For instance, among the list of competencies, ATs must demonstrate proficiency in the strategies and referral process of the psychosocial aspects of injury (competency six - Psychosocial Strategies and Referral) (Athletic Training Educational Competencies, $5^{\text {th }}$ Edition, 2011). Specifically, this competency (PS) emphasizes ATs 
ability to recognize patients exhibiting maladaptive responses to injury, based on social, emotional, and mental behaviors. In addition, ATs must possess communication skills, motivation and adherence strategies, social support, basic counseling skills (e.g., reflective listening), mental skills training (e.g., imagery, relaxation), coupled with the ability to intervene and refer these individuals as necessary.

Despite these regulations and standards outlined by the NATA and enforced by CAATE and the BOC, a debate exists as to whether ATs receive adequate levels of training in the psychosocial competencies (e.g., Clement, et al., 2013; Hamson Utley, Martin, \& Walters, 2008; Stiller-Ostrowski \& Ostrowski, 2009). While the NATA requires that students receive coursework that satisfies the basic requirements of PS, not all candidates who sit for and gain certification have taken a course in psychology of injury, psychopathology, counseling, or even foundational sport psychology (Cramer Roh \& Perna, 2000). In fact, an internet search will reveal that some accredited ATEPs require no more than a general psychology course (i.e., psych 101) as part of the required coursework in order to fulfill this certification competency. Furthermore, Stiller Ostrowski and Ostrowski (2009) revealed that, even ATs who received sport specific coursework (i.e., psychology of injury/rehabilitation), reported lacking proficiency in handling communication, interpersonal, and motivational issues, while also feeling inadequate at recognizing and addressing psychosocial issues in athletes. ATs in this study also reported learning very little about counseling, social support, mental skills training, and psychosocial referral over the course of their accredited education. Findings from Stiller-Ostrowski and Ostrowski lend support to Larson and colleagues (1996) who reported that even formal sport psychology courses tend to focus predominately on the 
theoretical aspects of sport psychology and lack practical emphasis and application within the athletic training realm. Further, Scherzer (2004) recommended that courses should focus on educating ATSs about specific sport psychology interventions and referral, yet few actually do. As a result, ATs receive very inconsistent training in the psychosocial aspects of sport-injury, despite the best efforts of the NATA, CAATE, and BOC. Given these findings, the following sections will provide a more comprehensive overview of the specific roles of ATs, particularly in relating to the psychosocial aspects of sport injury, and provide a rationale for a strong foundation in PS.

\section{Athletic Trainers' Roles}

Returning athletes to competition following athletic injury is a key role of ATs. Naturally, a major responsibility of ATs is to evaluate and rehabilitate injured athletes' physical status and readiness. This may include the assessment and diagnosis of physical symptoms and rehabilitation of the physical ailment. However, in order to ensure a more holistic recovery, research has highlighted the importance of also addressing the psychosocial implications that injured athletes commonly experience (Booher \& Thibodeau, 2000; Stiller-Ostrowski \& Hamson-Utley, 2010). Specifically, athletes can benefit from sport psychology in a number of ways. As far as its role in injury, mental skills training can be advantageous in preventing injuries (e.g., stress management techniques), or as a way to assist athletes as they navigate the rehabilitation process and attempt to return to competition (e.g., imagery, goal setting) (Naylor, 2009).

Given the diverse factors influencing recovery and rehabilitation, a multidisciplinary approach to injury rehabilitation, which includes working with athletes on a day-to-day basis on both physical and psychological components is recommended 
(Clement \& Arvinen-Barrow, 2013; Kolt, 2000). For instance, Kolt (2000) stated that it was typical for a team of sport medicine professionals (sport psychology professionals, clinical psychologists, strength and conditioning coaches, nutritionists) to work alongside ATs and PTs to supplement and even accelerate the rehabilitation process. While Kolt's approach of providing athletes with as many resources as possible for successful recovery seems ideal, perhaps this approach is only realistic in high-budget professional or Olympic settings. Athletes and ATs in lower ranking levels may only have limited access to a fraction of these professionals. Thus, a more conservative and realistic model is required to fit this more populous group. For instance, Clement and Arvinen-Barrow have provided such a model, by differentiating between primary and secondary rehabilitation teams. Specifically, the primary team generally involves those with close working relationships with the athlete at the onset of the injury and throughout the rehabilitation process. In general, these team members include primary treatment providers with frequent and direct access to the athlete (e.g., athletic trainers, physical therapists, team physicians, and/or surgeons). As such, it has been suggested that primary team members, particularly ATs, are in an ideal position to inform, educate, and support with both physical and psychological processes of injury rehabilitation (Clement \& Shannon, 2009; Larson, Starkey, \& Zaichkowsky, 1996; Tunick, Clement, \& Etzel, 2009). For instance, given that injury rehabilitation typically occurs in the athletic training room under the direction of an AT, significant time is spent directly with the athlete. Similarly, it is also common for ATs to attend daily practices and travel with the team to away locations. Although ATs typically deal with athletes on a physical level (e.g., prescribing rehabilitation activities, taping ankles, stretching), they have frequent 
opportunities to get to know athletes on a personal level. The nearly daily contact ATs have with athletes during periods of health and injury provide them with frequent opportunities to develop rapport and thus, recognize when they are having difficulties managing athletes' injuries or everyday concerns (Gordon, Potter, \& Ford, 1998; Kolt, 2000; Wiese-Bjornstal \& Smith, 1993). As a result, athletes may feel more comfortable seeking help from ATs than they are from mental health professionals, given the frequency and duration of their interactions (Clement \& Shannon, 2009).

The secondary rehabilitation team, on the other hand, is ideally consisted of individuals who are not in direct daily contact with the athlete, yet also play a significant role in assisting the athlete achieve successful recovery. The secondary team typically consists of a wide range of sport medicine professionals with varying degrees of specialty areas that have intermittent interaction with the rehabilitating athlete. Individuals in this team include, but are not limited to: sport psychology professionals, clinical/counseling psychologists, sport nutritionists, strength and conditioning specialists, exercise physiologists, coaches, massage therapists, and/or personal support systems (friends, family, teammates). Of particular interest for this study, is the importance of the sport psychology professional (SPP). Evidence exists to support the inclusion of these professionals (sport psychology consultants, counseling psychologists, clinical psychologists) as part of a successful rehabilitation program, but is rarely used (Brewer, 1998; Clement, Granquist, \& Arvinen Barrow, 2013). Ideally, sport psychology professionals would be able to identify and intervene at the sight of a potentially stressful situation, thereby decreasing the likelihood of injury or maladjustment. Unfortunately, sport psychology professionals are rarely in positions where these symptoms may be 
observed or discussed openly or are not an available resource for athletes (i.e., youth and high school sport). However, frequent contact between athletes and ATs enables ATs to develop rapport with athletes that can assist them in understanding each athlete's personality and intervene when athletes' responses to injury are maladaptive (Misasi, Davis, Morin, \& Stockman, 1996). Therefore, recognition of the psychological factors associated with sport injury becomes increasingly more important for primary rehabilitation team members, such as ATs. In this instance, ATs often serve as front-line counselors, and can play a significant role in motivating the athlete toward adherence and recovery, both physically and psychologically (Clement \& Shannon, 2009; Henderson \& Carroll, 1993). As front-line counselors, ATs should be proficient in all areas of PS or at least be able to recognize behaviors consistent with maladjustment to injury and make proper referral to SPPs. However, as we will see, ATs are typically not fully trained nor do they perceive themselves to be adequately equipped to deal with some of the psychological aspects of recovery from injury (Clement, Arvinen-Barrow, \& Granquist, 2013; Larson et al., 1996). One solution to this problem is to train rehabilitation personnel to properly deliver sport psychology rehabilitation interventions or making proper referrals. However, let us first examine the specific areas in which ATs believe further training is required.

\section{Educating Athletic Trainers}

As discussed, newly certified athletic trainers must be able to navigate both physical and psychological aspects of injury to fully rehabilitate the athlete. It is not uncommon for ATs to be viewed as counselors by the athletes they work with and as such, some training in this area may be necessary. However, it has been suggested that 
ATEPs may not effectively prepare students to apply basic counseling skills and/or psychological interventions that can improve the rehabilitation process (e.g., Cramer-Roh \& Perna, 2000; Larson et al., 1996; Stiller-Ostrowski \& Ostrowski, 2009). What's more, studies evaluating the effectiveness of ATEPs revealed that only $25 \%$ of those who graduated from CAATE accredited programs reported being taught about mental imagery and other such mental skills with athletes (Stiller-Ostrowski \& Hamson-Utley, 2010). Furthermore, Stiller-Ostrowski and Ostrowski revealed through focus groups of a small sample of recently certified ATs, that while ATEPs are doing an adequate job of preparing ATs for many communication and interpersonal issues, most felt underprepared to manage other athlete-related issues in the areas of adherence, motivation, social support, mental skills training, and psychological referral. Of the few ATs that reported feeling prepared in these areas, a small portion reported actually using these techniques in their clinical practice. This raises an important question concerning the specific methods in which these techniques are being taught within ATEPS.

Other research has also examined issues regarding ATs clinical use and confidence in using PS-related skills and the overall satisfaction of students in their PS educational preparation (e.g., Hamson-Utley \& Stiller-Ostrowski, 2011; StillerOstrowski, Gould, \& Covassin, 2009). These studies were interested in the way in which the PS content was instructed and whether it was sufficient to build one's efficacy in employing such techniques in clinical settings. In a nation-wide survey, Hamson-Utley and Stiller-Ostrowski gathered data from 128 ATEP program directors (PDs) in order to determine how the PS (formerly PIR) competencies were taught in CAATE accredited programs. Results indicated that the majority of ATEPs had no designated course for the 
PS competencies and implemented this content into a variety of other athletic training core curriculum courses. The remainder of programs reported several courses such as: sport and exercise psychology, psychology of injury, introduction to psychology, and general education courses. More specifically, results from this study revealed that much of the instructional methods relied heavily on lecture and/or discussion formats to deliver PS content, while role-playing and other methods (e.g., guest speakers, case studies, supplemental readings) were used less often. Overall, results from this study revealed major inconsistencies in the method of instruction in PS across CAATE accredited programs in the United States. Perhaps these inconsistencies contribute to why ATs perceive their training in PS to be inadequate or incomplete.

In a related study, Stiller-Ostrowski, Gould, and Covassin (2009) evaluated the effectiveness of an educational intervention in increasing psychology of injury knowledge and skill usage in ATSs. Here, authors designed an educational intervention that consisted of two-hour classroom sessions once a week for three weeks, followed by 30-minute seminars once a week for three weeks. The intervention was evidence-based and allowed ATSs to be active participants, through case studies, case presentations, class discussions, and clinical practice. The intervention took place in lieu of whatever course was intended to fulfill the PS requirement. Control groups, on the other hand, were exposed to regular coursework intended to fulfill PS. Results revealed a significant increase in psychology of injury knowledge and skill usage by week three, with continued increase throughout the remainder of the intervention. Although retention tests at week seven and week 14 indicated that participants forgot some of the content they 
initially gained, the retained knowledge and skill usage was still significantly higher than baseline levels and compared to control outcomes.

Similarly, Clement and Shannon (2009) also implemented a psycho-educational workshop aimed at determining what effects it would have on ATSs' sport psychology behaviors (viz. speaking to an athlete about sport psychology, seeking additional information about sport psychology, talking to an SPC about an athlete, referring an athlete to an SPC, and using basic applied techniques with athletes). Results indicated that ATSs who received the educational intervention reported a significant increase in all sport psychology behaviors at a six-week follow-up compared to the control group, with the exception of referral behaviors. Based on these results, Clement and Shannon concluded that increased exposure to sport psychology education clearly increases sport psychology knowledge within the ATS population. Findings also echoed previous recommendations (e.g., Granitz, 2001; Siegel, 2000; Scherzer, 2004) that a practical (i.e., case studies and practice) versus a theoretical (i.e., lecture and assigned readings) educational format is most effective since it helps to develop important skills such as critical thinking and problem solving skills, which can be used once ATSs mature into ATs.

Overall, research has indicated the importance of both knowledge and usage of psychological skills in sport injury rehabilitation (Stiller-Ostrowski \& Ostrowski, 2009; Moulton et al., 1997). Findings generally indicated that ATs value the inclusion of mental skills within the rehabilitation process and in most cases, are interested in expanding this knowledge base in this area (Clement et al., 2013; Larson et al., 1996; Cramer Roh \& Perna, 2000). Research implementing educational workshops and 
interventions has shown significant improvements in short- and long-term behaviors, relating to the psychological aspects of injury (e.g., Clement and Shannon, 2009), thus, lending support for the inclusion of practical, sport-specific training related to PS within the athletic training educational curriculum. Yet, despite the best efforts of CAATE, the NATA, and NATABOC, ATs perceive their education (or method of instruction) in PS to be inadequate or incomplete (Clement et al., 2013; Cramer Roh \& Perna, 2000). To help injured athletes, Wiese and Weiss (1987) recommended that ATs should possess effective communication skills and be aware of motivational techniques such as goal setting, relaxation, and imagery. Wiese and Weiss describe effective communication within the rehabilitation realm as encompassing both proper content (e.g., correct information) and delivery (e.g., positive, encouraging approach) of the message. The different skills that may benefit the injured athlete's overall rehabilitation experience will be described in more detail in the sections that follow. Particular emphasis will be placed on their applicability to the rehabilitation process.

\section{Athletic Trainers Attitudes and Use of Sport Psychology}

An early investigation (e.g., Moulton, Molstad, \& Turner, 1997) revealed that ATs believe their roles go beyond the prevention and care of athletic injuries. In fact, many ATs reported they took on the role of counselor and problem solver, as necessary, with athletes during their post-injury rehabilitation. However, the majority of these very same ATs did not report feeling adequately trained to assist athletes with their personal or behavioral issues. In a similar study, Larson and colleagues (1996) revealed from a national sample of ATs that 54\% had taken a formal sport psychology course and as many as $76 \%$ had never referred an athlete for counseling as a result of their injury. The 
lack of referral is concerning given that many participants reported symptoms of anxiety (71\%) and anger (53\%) affecting their athletes, perceived to be a direct result of their injuries. However, given the absence of formal coursework in sport psychology and/or psychology of injury, it is possible that ATs in this study may be misinterpreting or overestimating the degree to which athletes present with certain psychological symptoms. In other words, it is possible (and likely) that $71 \%$ of athletes did not, in fact, show symptoms of anxiety following their injury. Or perhaps, these athletes simply showed very minor signs associated with anxiety. In addition, these studies relied heavily on ATs ability to remember previous experiences with injured athletes and report estimations based on those experiences. Therefore, it is difficult to ascertain how accurate these diagnoses were. However, despite these limitations, results from both of these investigations highlight several important points. First, ATs reported that they frequently encountered and were able to identify psychological maladjustment/distress in athletes, which is consistent with above-discussed literature. Second, despite the frequency and severity of athlete distress, most ATs reported lacking the ability to intervene competently or make a referral to appropriate professionals. This either indicates that ATs intervene without possessing the necessary skills or do nothing, leaving the athlete to deal with his or her distress alone.

It is worth noting that much advancement in athletic training education has been made since these seminal studies were published. Specifically, in the third edition of the NATA training competencies (now in its fifth edition), published in 1999, specific competency areas were required of ATEPs to achieve accreditation. Prior to this edition, ATs were not required to demonstrate competencies in areas related to PS. Therefore, it 
should be no surprise that earlier studies (i.e., studies published prior to the introduction of educational competencies) revealed lower attitudes towards handling psychological areas of injury than more recent studies. It is therefore conceivable that these gaps in knowledge were not attributable to poor training, but absence of training all together. In an effort to examine the impact of the NATA's educational competencies, Clement and colleagues (2013) were interested in extending the work of Larson and colleagues (1996) by surveying the psychosocial aspects of athletic injuries as perceived by more recently trained ATs. Results indicated that over $50 \%$ of recently trained ATs had taken a formal sport psychology course at the undergraduate level and $64 \%$ reported taking a graduate course related to sport psychology. It can be assumed that the remainder of the participants either had little to no formal training in PS perhaps due to the fact that they received BOC certification prior to the NATA revisions. In addition, survey results demonstrated that ATs perceived injured athletes to experience psychological responses to injury (e.g., stress/anxiety, anger, adherence issues, depression, etc) similar to those from the Larson and colleagues study. This finding was not surprising since it can be assumed that collegiate athletes experience similar stressors as those from years ago (e.g., increased academic and athletic pressures and competitive demands). In terms of referral behaviors, Clement and colleagues reported that despite only $20 \%$ of surveyed ATs had access to sport psychology services, most (84\%) reported making referrals to these services in the past. Conversely, only $27 \%$ of ATs made referrals to counseling services. These findings suggest that providing ATs with access to sport-specific counseling services may increase the likelihood of referral as compared to those with only general college counseling resources. Finally, despite the fact that 
only slight differences in the proportion of ATs from both studies (e.g., Clement et al., 2013; Larson et al., 1996) had been formally educated in sport psychology, higher proportions of recently trained ATs revealed that they had made referrals to both sport psychology and counseling professionals. It can be assumed, at least to some degree, that the NATA revisions have led ATs to demonstrate more awareness and overall competency in the area of psychological intervention and referrals. It is also possible that the increasing visibility and access to sport psychology practitioners, particularly in collegiate athletics, has contributed to this increase in referral behaviors.

Overall, while these results are useful in informing perceptions of ATs, they provide only descriptive data. Specifically, little is known regarding the severity of athlete distress and whether or not ATs' identification of symptoms were accurate. In other words, due to the descriptive nature of these studies, and the fact that they are selfreport questionnaires, we are unable to determine whether the ATs perceptions of stress/anxiety are representative of genuine symptoms. Additionally, even though both studies revealed identical "top 5" psychosocial intervention techniques (goal setting, keeping athletes involved with team, encouraging positive self-talk, creative variety in rehabilitation exercises, and encouraging effective communication), little is known on the effectiveness of these strategies, as used by ATs. What's more, little is known about whether ATs implemented the appropriate intervention techniques, given the athlete's symptoms. The following sections explore some of the more commonly implemented psychosocial strategies and their documented relationships within the sport-injury realm.

Sport psychology interventions. Although it is practical to have insight into the identification of maladaptive behaviors and psychological distress, it is equally useful to 
have a grasp of some of the basic sport psychology interventions, as well as basic guidelines for implementing such interventions. This section serves as a brief review for commonly used psychosocial interventions, as perceived by ATs. While the following list is by no means comprehensive, it seeks to address some of the more common techniques likely to be employed by professionals working with injured athletes. Recently, Zizzi, Blom, Watson, Downey, and Geer (2009) established a hierarchy of psychological skills by using the perceptions of coaches, ATs, and psychologists. Interestingly, ATs rated their qualifications to teach psychological techniques significantly higher than they were rated by the other groups. This finding may suggest that ATs report a level of over-confidence in their ability to teach these skills to athletes or perhaps ATs hold a higher degree of familiarity within sport psychology than expected by other professionals. Results also indicated, across professionals, a fairly consistent hierarchy of training required to teach various psychological skills. Specifically, skills were divided into three categories (requiring low, moderate, and high levels of training) for successful implementation with athletes. Low-level skills included time management, goal setting, and focus, whereas moderate skills included team building, communication, and energy management. The more complex skills, such as those involving a deeper understanding of human cognition (e.g., hypnosis, imagery and visualization, and selftalk) were consistently rated as requiring high training yet commonly used with athletes. Overall, an increased understanding of such a hierarchy could lead to a first step in establishing a level of professional boundaries of practice. 
In other words, having a clear understanding of the degree of training required to use these skills, could help differentiate between skills that can be implemented alone versus those that require professional referral.

The specific strategies discussed in this section are those most commonly used by ATs, as described in past and recent research (i.e., Clement et al., 2013; Larson et al., 1996) and those commonly addressed in many basic sport psychology courses and textbooks. Additionally, these particular interventions are among those that do not require certification or licensure, thus can be implemented by both primary and secondary rehabilitation teams with basic training in sport psychology (i.e., undergraduate or graduate courses in sport psychology). However, it should be noted that effective implementation of these strategies require some training and supervision.

Goal setting. Goal setting has been reported as being an extremely beneficial technique for any athlete in the rehabilitation setting, regardless of the level of competition, severity of injury, or duration of the recovery process (Brown, 2005; Williams \& Scherzer, 2006). More specifically, although goals are easily set in every day life (i.e., study more, lose weight, work harder), many factors must be taken into consideration when setting goals. For instance, research has identified three types of goals; (1) outcome, (2) performance, and (3) process goals (Hardy, Jones, \& Gould, 1996). Briefly, outcome goals are those focused on the outcome of an event and usually involve some sort of interpersonal comparison (i.e., recover faster than one's teammate). Performance goals often involve intrapersonal assessment, as they are usually focused on reaching a particular level of performance, as compared to a previously reached level (i.e., improving one's range of motion compared to last week). Finally, process goals are 
focused on the specific actions and tasks in which an individual must engage to reach a desired level of performance (i.e., complete all exercises properly, each day). According to Weinberg and Gould (2010), when outcome, performance, and process goals are used together, athletes are more likely to experience higher levels of performance and more positive psychological development, compared to when used alone.

The positive effects of goal setting in the rehabilitation environment can be linked to the above-mentioned integrated model. Specifically, a behavioral strategy such as setting a goal(s) can impact one's cognitive appraisal of the injury (e.g., being in control of a perceived timeline), which in turn, can impact the emotional response to injury (e.g., decreasing feelings of frustration) (Arvinen Barrow \& Hemmings, 2013). Other ways in which goal setting can help facilitate the rehabilitation process include increasing selfefficacy (Evans \& Hardy, 2002), motivation (Latham \& Locke, 1985), and adherence (Arvinen Barrow, Penny, Hemmings, \& Corr, 2010; Evans \& Hardy, 2002). For instance, the relationship between goal setting and adherence has been well documented (e.g., Arvinen Barrow et al., 2010; Fisher, Scriber, Matheny, Alderman, \& Bitting, 1993; Scherzer, Brewer, \& Cornelius, 2001). Over time, the implementation of goal setting has been shown to increase levels of motivation, communication, and self-efficacy, which are thought to be key determinants to overall levels of adherence (Evans \& Hardy, 2002). Finally, in order for goals to be most effective, it is imperative that the ATC or sport psychology professional make athletes an active participant in the conceptualization of goals (Williams \& Scherzer, 2006). Athlete participation is thought to increase one's investment and commitment to achieving the set goals. Practitioners should also encourage positively-framed and realistic goals (Ford \& Gordon, 1998), while also 
ensuring that they provide the athlete with the ability to modify goals as progress persists (Brown, 2005).

Imagery. Mental imagery is not a new skill for most athletes. In fact, many athletes use imagery without necessarily knowing it when they focus on a new sport skill or are asked by the coach to "close your eyes and see the playing surface" before a big match. Similar to goal setting, imagery focused interventions are commonly used techniques that can lead athletes to experience enhanced motivation, more developed skills, and increased adherence during injury rehabilitation (Brown, 2005). Mental imagery is a skill that involves the creation or recreation of an object, scene, or sensation as though it was actually occurring (Driediger, Hall, \& Callow, 2006). In the context of injury rehabilitation, imagery can be helpful in decreasing negative thoughts, pain, and/or frustration that are common during the early weeks of rehabilitation (Bowering et al., 2013; Hare, Evans, \& Callow, 2008). Specifically focusing on a peaceful or relaxing image can distract the athlete during painful exercising in rehabilitation. Athletes can also use imagery to imagine their rehabilitation exercises before actually performing them. Using this technique may improve concentration and can lead to an increase in effort throughout the rehabilitation process (Cupal \& Brewer, 2001; Driediger et al., 2006). More specifically, Driediger and colleagues qualitatively assessed 10 injured athletes and found that cognitive imagery was used to learn and properly perform the rehabilitation exercises prior to physically attempting them. In addition, participants made use of motivational imagery for goal setting, enhancing mental toughness, helping maintain concentration, and fostering a positive attitude. Overall, athletes believed that imagery, if used effectively and along with physical rehabilitation, should enhance the 
rehabilitation experience and thus, facilitate recovery rates. Additionally, Cupal and Brewer (2001) revealed that 10 guided relaxation imagery sessions, as opposed to no sessions, coupled with regular rehabilitation, resulted in significantly greater knee strength and significantly less reinjury anxiety and pain in athletes 24 weeks post-ACL reconstruction.

Similar research by Dickstein and Deutsch (2007) found that, while imagery is a helpful tool during injury rehabilitation, rehearsing the imagery script with the athlete had an even greater effect on the rehabilitation outcome. Specifically, for athletes to most effectively use imagery in their rehabilitation, they must be taught the proper skills and encouraged to practice the image as often as possible. Thus, in the absence of an SPC, ATs should possess the necessary knowledge to guide athletes in the use of imagery.

Relaxation training. Relaxation training has been shown to decrease overall stress and recovery time, as well as pain (Brewer \& Van Raalte, 1991; Viljanen, Malmivaara, Uitti, \& Rinne, 2003). Because tension increases pain and decreases blood flow and range of motion, it is commonly coupled with undesirable recovery outcomes (e.g., increased length of recovery, increased pain) (Williams \& Scherzer, 2006). Since relaxation exercises are often used as a method to decrease tension in the body, relaxation training can be used both as a method to decrease the initial risk of injury by relieving muscle tension, as well as during the rehabilitation phase. Evidence supporting the inclusion of relaxation training during rehabilitation is well documented (e.g., Ahern \& Lohr, 1997; Brewer \& Van Raalte, 1991; Cupal \& Brewer, 2001; Perna, Antoni, \& Baum, Gordon, \& Schneiderman, 2003). Specifically, Cupal and Brewer examined the effects of an intervention containing relaxation and guided imagery on several outcomes 
in ACL reconstruction surgery patients. Results indicated that patients receiving the intervention, compared to those in the control condition, experienced significantly less reinjury anxiety and pain and significantly greater knee strength in participants, accounting for $62 \%, 76 \%$, and $35 \%$ of the variance, respectively. Research has offered many explanations as to why imagery and relaxation produce positive outcomes on knee strength and pain measures. On possibility is that interventions such as this promoted the belief that the athletes' rate and success in recovery is within their control (Laubach, Brewer, Van Raalte, \& Petitpas, 1996). It is also possible that the reduction in pain and anxiety resulted in further relaxation and become more fully engaged in the rehabilitation process (Cupal \& Brewer, 2001).

Equally convincing is the documented importance of relaxation training in areas indirectly linked to sport-injury rehabilitation, such as reducing treatment-related symptoms in non-surgical cancer treatments. Specifically, Luebbert, Dahe, and Hasenbring (2001) conducted a meta-analytical review to determine how effective relaxation training has been in recent years for 742 individual cancer patients undergoing medical treatment. A total of 15 randomized controlled studies using relaxation training as the main intervention were included in the review. Results indicated significant (moderate) effect size on depression (.54) and small yet significant effect sizes on other variables such as anxiety (.45), mood (.44), pain (.43), and hostility (.34). In general, patients receiving relaxation training were found to be less depressive and anxious while also experiencing significantly less pain associated with their diagnosis and treatment. These findings, though not directly related to sport-injury rehabilitation, provide further 
support to the various benefits of relaxation-focused interventions in overall well-being, pain management, and similar outcomes common in athletes rehabilitating from injury. Mental Health Referrals

After reviewing much of the literature regarding psychosocial factors associated both pre- and post-injury in athletes, and the role of ATs in the recognition and application of these factors, it is apparent that the need exists ATs to make referrals to proper mental health professionals when necessary or when the symptoms exceed the scope of practice of ATs. Referrals, in theory, are consistent with the guiding principle of enhancing the overall wellbeing of an injured athlete, by focusing on his or her psychological health as well as physical health. But more importantly, it is the ethical, professional, and in some cases, legal responsibility of the AT to provide a referral (Tunick et al., 2009).

Sports medicine professionals may encounter a variety of situations that warrant a referral of an injured athlete to a mental health professional. Specifically, Ray and WieseBjornstal (1999) outlined a number of reasons for possible referral, including: psychopathology, adjustment difficulties, or rehabilitation setbacks. Often, signs of distress or impaired functioning may not be direct, thus ATs should be aware of various subtle signs adjusting to rehabilitation (over-adherence, excessive preoccupation with return to sport) and have an established referral network, including individuals able to meet the psychological needs of their injured athletes.

Overall ATs are expected to demonstrate competency in navigating through the referral process (Athletic Training Educational Competencies, $5^{\text {th }}$ Edition, 2011). Recently, ATs have reported utilizing mental health professionals as referral networks if 
they had access to them in their work setting (Clement et al., 2013). For instance, Clement and colleagues reported that of the $21 \%$ of AT who had access to sport psychology professionals, over $84 \%$ of ATs reported making a referral of some kind. However, due to the descriptive nature of the findings, little is known regarding the nature of these referrals, how they were made, how many were made, and whether they were made appropriately to the right mental health professional. Thus, much is left unanswered regarding the referral practices of ATs.

\section{Summary}

While physical factors are the primary concern for ATs during injury rehabilitation, increasing evidence has supported the importance of considering an athlete's psychological concerns during the rehabilitation process. Aside from coaches, ATs are the individuals with the highest degree of contact with both injured and noninjured athletes. This high level of contact allows ATs the opportunity to develop strong rapport with athletes. Thus, ATs have the ability to play a primary role in facilitating athletes' rehabilitation be it physically or psychologically. ATs are generally responsible and expected to provide basic counseling and psychological interventions to athletes experiencing minimal to moderate psychological distress, as well as screening for more serious psychological problems and making appropriate referrals. Unfortunately, it has been suggested that ATs do not feel comfortable in the area of psychosocial strategies and referral (Clement et al., 2013; Cramer Roh \& Perna, 2000) and in turn, may not intervene in the most effective way possible. As a result, rehabilitation goals may be prolonged and/or the injured athlete's symptoms may intensify and manifest into a more serious diagnosis. 
To date, no studies have examined ATs' abilities to diagnose an athlete and select an appropriate course of action based upon their direct observation of an athlete's psychological distress. Rather, the few studies conducted in the area of psychological intervention and referral (e.g., Clement et al., 2013; Larson et al., 1996; Moulton et al., 1997) have utilized surveys where ATs were asked to respond retrospectively regarding their experiences related to psychological techniques and referral practices.

Thus, the primary purpose of this study was to expand the literature base in the area of psychology of sport injury by assessing certified athletic trainers' abilities to correctly identify psychological symptoms, and choose appropriate interventions for athletes experiencing varying degrees of psychological distress. In addition, this study examined whether these responses are influenced by the education level and years of experience, and perceived competencies in sport psychology.. 


\section{References}

Ahern, D. K., \& Lohr, B. A. (1997). Psychosocial factors in sports injury rehabilitation. Clinics in Sports Medicine, 16, 755-768. doi: 10.1016/S0278-5919(05)70052-1

Albinson, C. B., \& Petrie, T. A. (2003). Cognitive appraisal, stress, and coping: Preinjury and postinjury factors influencing psychological adjustment to sport injury. Journal of Sport Rehabilitation, 12, 306-322.

Anderson, M. B., \& Williams, J. M. (1988). A model of stress and athletic injury: Prediction and prevention. Journal of Sport and Exercise Psychology, 10, 294306.

Arvinen-Barrow, M., \& Hemmings, B. (2013). Goal setting in sport injury rehabilitation. In M. Arvinen-Barrow \& N. Walker (Eds.). The psychology of sport injury and rehabilitation. New York, NY: Routledge.

Arvinen-Barrow, M., Penny, G., Hemmings, B., \& Corr, S. (2010). UK chartered physiotherapists' personal experiences in using psychological interventions with injured athletes: An interpretative phenomenological analysis. Psychology of Sport and Exercise, 11, 58-66.

Berger, B. G., Pargman, D., \& Weinberg, R. S. (2007). Foundations of exercise psychology. Morgantown, WV: Fitness Information Technology.

Bianco, T., Malo, S., \& Orlick, T. (1999). Sport injury and illness: Elite skiers describe their experiences. Research Quarterly for Sport and Exercise, 70, 157-169. doi: $10.1080 / 02701367.1999 .10608033$

Booher, J.M., \& Thibodeau, G.A. (2000). Athletic injury assessment, fourth edition. United States: McGraw-Hill Companies, Inc. 
Bowering, K. J., O’Connell, N. E., Tabor, A., Catley, M. J., Leake, H. B., Moseley, G. L., \& Stanton, T. R. (2013). The effects of graded motor imagery and its components on chronic pain: A systematic review and meta-analysis. The Journal of Pain, 14, 3-13. doi: 10.1016/j.jpain.2012.09.007

Bramwell, S. T., Masuda, M., Wagner, N. H., \& Holmes, T. H. (1975). Psychological factors in athletic injuries: Development and application of the Social and Athletic Readjustment Rating Scale (SARRS). Journal of Human Stress, 1, 6-20.

Brewer, B. W. (1994). Review and critique of models of psychological adjustment to athletic injury. Journal of Applied Sport Psychology, 6, 87-100. doi:10.1080/10413209408406467

Brewer, B. W. (1998). Introduction to the special issue: Theoretical, empirical, and applied issues in the psychology of sport injury. Journal of Applied Sport Psychology, 10, 1-4. doi: 10.1080/10413209808406374

Brewer, B. W. (2001). Psychology of sport injury rehabilitation. In G. Tenenbaum \& R. Eklund (Eds.). Handbook of sport psychology, third edition. Hoboken, NJ: John Wiley \& Sons, Inc.

Brewer, B. W., Cornelius, A. E., Sklar, J. H., Van Raalte, J. L., Tennen, H., Armeli, S., Corsetti, J. R., \& Brickner, J. C. (2007). Pain and negative mood during rehabilitation after anterior cruciate ligament reconstruction: A daily process analysis. Scandinavian Journal of Medicine and Science in Sports, 17, 520-529. doi: 10.1111/j.1600-0838.2006.00601 
Brewer, B. W., Jeffers, K. E., Petitpas, A. J., \& Van Raalte, J. L. (1994). Perceptions of psychological interventions in the context of sport injury rehabilitation. The Sport Psychologist, 8, 176-188.

Brewer, B. W., Linder, D. E., \& Phelps, C. M. (1995). Situational correlates of emotional adjustment to athletic injury. Clinical Journal of Sport Medicine, 5, 241-245.

Brewer, B. W., Petitpas, A. J., Van Raalte, J. L., Sklar, J. H., \& Ditmar, T. D. (1995). Prevalence of psychological distress among patients at a physical therapy clinic specializing in sports medicine. Sports Medicine, Training and Rehabilitation, 6, 139-145. doi: 10.1080/15438629509512045

Brewer, B. W., Van Raalte, J. L. (1991). Peak performance and the perils of retrospective introspection. Journal of Sport and Exercise Psychology, 13, 227-238.

Brown, C. (2005). Injuries: The psychology of recovery and rehabilitation. In S. Murphy (Ed.) The sport psych handbook (pp. 215-237). Champaign, IL: Human Kinetics.

Burt, C. W., \& Overpeck, M. D. (2001). Emergency visits for sport-related injuries. Annals of Emergency Medicine, 37, 301-308.

Clement, D., \& Arvinen-Barrow, M. (2013). Sport medicine team influences in psychological rehabilitation. In. M. Arvinen-Barrow \& N. Walker (Eds.). The psychology of sport injury and rehabilitation (pp. 156-170). New York, NY: Routledge.

Clement, D., Granquist, M. D., \& Arvinen-Barrow, M. M. (2013). Psychosocial aspects of athletic injuries as perceived by athletic trainers. Journal of Athletic Training, 48, 512-521. doi: 10.4085/1062-6050-48.3.21 
Clement, D., \& Shannon, V. R. (2009). The impact of a workshop on athletic training students' sport psychology behaviors. The Sport Psychologist, 23, 504-522.

Cramer Roh, J. L., \& Perna, F. M. (2000). Psychology/Counseling: A universal competency in athletic training. Journal of Athletic Training, 35, 458-465.

Cupal, D. D., \& Brewer, B. W. (2001). Effects of relaxation and guided imagery on knee strength, reinjury anxiety, and pain following anterior cruciate ligament reconstruction. Rehabilitation Psychology, 46, 28-43. doi: 10.1037//00905550.46.I.28

Daly, J. M., Brewer, B. W., Van Raalte, J. L., Petitpas, A. J., \& Sklar, J. H. (1995). Cognitive appraisal, emotional adjustment and adherence to rehabilitation following knee surgery. Journal of Sport Rehabilitation, 4, 23-30.

Dickstein, R., \& Deutsch, J. E. (2007). Motor imagery in physical therapist practice. Physical Therapy, 87, 942-953. doi: 10.2522/ptj.20060331

DeLongis, A., Coyne, J. C., Dakof, G., Folkman, S., \& Lazarus, R. S. (1982). Relationship of daily hassles, uplifts, and major life events to health status. Health Psychology, 1, 119-136.

Driediger, M., Hall, C., \& Callow, N. (2006). Imagery use by injured athletes: A qualitative analysis. Journal of Sports Sciences, 24, 261-271. doi: $10.1080 / 02640410500128221$

Evans, L., \& Hardy, L. (2002). Injury rehabilitation: A goal-setting intervention study. Research Quarterly for Exercise and Sport, 73, 310-319. doi: 10.1080/02701367.2002.10609025 
Fawkner, H. J., McMurray, N. E., \& Summers, J. J. (1999). Athletic injury and minor life events: A prospective study. Journal of Science and Medicine in Sport, 2, 117124.

Fisher, C. A., Scriber, K. C., Matheny, M. L., Alderman, M. H., \& Bitting, L. A. (1993). Enhancing athletic injury rehabilitation adherence. Journal of Athletic Training, 28, 312-318.

Ford, I., \& Gordon, S., (1998). Perspectives of sports trainers and athletic therapists on the psychological content of their practice and training. Journal of Sport Rehabilitation, 7, 79-94.

Gordon, S., Potter, M., \& Ford, I. W. (1998). Toward a psychoeducational curriculum for training sport-injury rehabilitation personnel. Journal of Applied Sport Psychology, 10, 140-156.

Gotsch, K., Annest, J. L., Holmgreen, P., \& Gilchrist, J. (2002). Nonfatal sports - and recreation-related injuries treated in emergency departments - United States, July 2000-June 2001. Morbitiy and Mortality Weekly Report, 51, 736-740.

Hamson Utley, J. J., Martin, S., \& Walters, J. (2008). Athletic trainers' and physical therapists' perceptions of the effectiveness of psychological skills within sport injury rehabilitation programs. Journal of Athletic Training, 43, 258-264.

Hamson Utley, J. J., Stiller Ostrowski, J. L. (2010). Athletic training educators' instructional methods and confidence in graduating students' abilities regarding psychosocial intervention and referral. Athletic Training Education Journal, 6, $154-162$. 
Hardy, L., Jones, J. G., \& Gould, D. (1996). Understanding psychological preparations for sport: Theory and practice of elite performers. Hoboken, NJ: John Wiley \& Sons Inc.

Hare, R., Evans, L., \& Callow, N. (2008). Imagery use during rehabilitation from injury: A case study of an elite athlete. The Sport Psychologist, 22, 405-422.

Heil, J., Bowman, J. J., \& Bean, B. (1993). Patient management and the sports medicine team. In J. Heil (Ed.), Psychology of sport injury (pp. 237-249). Champaign, IL: Human Kinetics.

Henderson, J., \& Carroll, W. (1993). The athletic trainer's role in preventing sport injury and rehabilitating injured athletes: A psychological perspective. In D. Pargman (Ed.). Psychological bases of sport injuries (pp. 15-31). Morgantown, WV: Fitness Information Technology.

Holmes, T. H., \& Rahe, R. H. (1967). The social readjustment scale. Journal of Psychosomtic Research, 11, 213-218.

Hootman, J. M., Dick, R., \& Agel, J. (2007). Epidemiology of collegiate injuries for 15 sports: Summary and recommendations for injury prevention initiatives. Journal of Athletic Training, 42, 311-319.

Jackson, D. W., Jarrett, H., Bailey, D., Kausek, J., Swanson, M. J., \& Powell, J. W. (1978). Injury prediction in the young athlete: A preliminary report. American Jornal of Sports Medicine, 6, 6-12.

Kolt, G. S. (2000). Doing sport psychology with injured athletes. In M. Andersen (Ed.). Doing sport psychology (pp. 223-236). Champaign, IL: Human Kinetics. 
Lackey, N. R., \& Wingate, A. L. (1998). The pilot study: One key to research success. In P. J. Brink \& M. J. Wood (Eds.). Advanced design in nursing research (pp. 375386). Thousand Oaks, CA: Sage.

Larson, G. A., Starkey, C., \& Zaichkowsky, L. D. (1996). Psychological aspects of athletic injuries as perceived by athletic trainers. The Sport Psychologist, 10, 2737.

Latham, G. P., \& Locke, E. A. (1985). The application of goal setting to sports. Journal of Sport Psychology, 7, 205-222.

Laubach, W. J., Brewer, B. W., Van Raalte, J. L., \& Petitpas, A. J. (1996). Attributions for recovery and adherence to sport injury rehabilitation. Australian Journal of Science and Medicine in Sport, 28, 30-34.

Luebbert, K., Dahme, B., \& Hasenbring, M. (2001). The effectiveness of relaxation training in reducing treatment-related symptoms and improving emotional adjustment in acute non-surgical cancer treatment: A meta-analysis. PsychoOncology, 10, 490-502. doi: 10.1002/pon.537

Lynch, G. P. (1988). Athletic injuries and the practicing sport psychologist: Practical guidelines for assisting athletes. The Sport Psychologist, 2, 161-167.

Misasi, S. P., Davis, C. F., Morin, G. E., \& Stockman, D. (1996). Academic preparation of athletic trainers as counselors. Journal of Athletic Training, 31, 39-42.

Morrey, M. A., Stuart, M. J., Smith, A. M., \& Wiese-Bjornstal, D. M. (1999). A longitudinal examination of athletes' emotional and cognitive responses to anterior cruciate ligament injury. Clinical Journal of Sport Medicine, 9, 63-69. 
Moulton, M. A., Molstad, S., \& Turner, A. (1997). The role of athletic trainers in counseling collegiate athletes. Journal of Athletic Training, 32, 148-150.

National Athletic Training Association (2013). Athletic training education competencies. Fifth edition. Retrieved from: http://www.nata.org/education/competencies.

NCAA Sports Science Institute (2014, January 17). Retrieved from http://www.ncaa.org/health-and-safety/medical-conditions/sports-injuries

Naylor, A. H. (2009). The role of mental training in injury prevention. Athletic Therapy Today, 14, 27-29.

Neal, T. L., Diamond, A. B., Goldman, S., Klossner, D., Morse, E. D., Pajak, D. E., ... Welzant, V. (2013). Inter-association recommendations for developing a plan to recognize and refer student-athletes with psychological concerns at the collegiate level: An executive summary of a consensus statement. Journal of Athletic Training, 48, 716-720.

Pargman, D. (2007). Sport injury: An introduction and overview of related psychological issues. In D. Pargman (Ed.). Psychological Bases of Sport Injuries ( $3^{\text {rd }}$ ed) (p. xvii-xxvii). Fitness Information Technology: Morgantown, WV.

Perna, F. M., Antoni, M. H., Baum, A., Gordon, P., \& Schneiderman, N. (2003). Cognitive behavioral stress management effects on injury and illness among competitive athletes: A randomized control trial. Annals of Behavioral Medicine, 25, 66-73. doi: 10.1207/S15324796ABM2501_09 
Rotella, R. J. (1985). The psychological care of the injured athlete. In K. Bunker, R.J. Rotella, \& S. Reilly (Eds.). Sport psychology: psychological considerations in maximizing sport performance (pp. 273-287). Ann Arbor, MI: McNaughton \& Gunn.

Scherzer, C. B. (2004) Training athletic trainers in the delivery of sport psychology rehabilitation interventions. (Doctoral dissertation). Retrieved from ProQuest Information and Learning Company. (3145124)

Scherzer, C. B., Brewer, B. W., \& Cornelius, A. G., (2001). Psychological skills and adherence to rehabilitation after reconstruction of the anterior cruciate ligament. Journal of Sport Rehabilitation, 10, 165-172.

Seiler, B. D., Gentner, N. B., Wehring, S. P., \& Joyner, A. B. (2013). Athletic training Education program directors' and athletic trainers' perceptions of the psychosocial interventions and referral competencies. Comprehensive Journal of Educational Research, 1, 1-8.

Sibold, J., \& Zizzi, S. (2012). Psychosocial variables and time to injury onset: A hurdle regression analysis model. Journal of Athletic Training, 47, 537-540.

Siegel, C. F. (2000). Introducing marketing students to business intelligence using project-based learning on the world wide web. Journal of Marketing Education, $22,90 \_98$.

Singh, S., Smith, G. A., Fields, S. K., \& McKenzie, L. B. (2008). Gymnastics-related injuries to children treated in the emergency departments in the United States, 1990-2005. Pediatrics, 121, 954-960. 
Smith, R. E., Ptacek, J. T., \& Patterson, E. (2000). Moderator effects of cognitive and somatic trait anxiety on the relation between life stress and physical injuries. Anxiety, Stress, \& Coping: An International Journal, 13, 269-288.

Smith, R. E., Smoll, F. L., Ptacek, J. T. (1990). Conjuctive moderator variables in vulnerability and resiliency research: Life stress, social support and coping skills, and adolescent sport injuries. Journal of Personality and Social Psychology, 58, 360-370.

Stiller-Ostrowski, J. L., Gould, D. R., \& Covassin, T. (2009). An evaluation of an educational intervention in psychology of injury for athletic training students. Journal of Athletic Training, 44, 482-489. doi: 10.4085/1062-6050-44.5.482

Stiller-Ostrowski, J. L., \& Hamson-Utley, J. J. (2010). Athletic trainers' educational satisfaction and technique use within the psychosocial intervention and referral content area. Athletic Training Education Journal, 5, 4-11.

Stiller-Ostrowski, J. L. \& Ostrowski, J. A. (2009). Recently certified athletic trainers' undergraduate educational preparation in psychosocial intervention and referral. Journal of Athletic Training, 44, 67-75.

Tunick, R., Clement, D., \& Etzel, E. F. (2009). Counseling injured and disabled student athletes: A guide for understanding intervention. In E. Etzel ( Ed.). Counseling and psychological services for college student-athletes (pp.403-450).

Morgantown, WV: Fitness Information Technology.

Udry, E., Gould, D., Bridges, D., \& Beck, L. (1997). Down but not out: Athletes’ responses to season-ending injuries. Journal of Sport \& Exercise Psychology, 19, 229-248. 
Valliant, P. M. (1981). Personality and injury in competitive runners. Perceptual and Motor Skills, 53, 251-253.

Van Mechelen, W., Twisk, J., Molendijk, A., Blom, B., Snel, J., \& Kemper, H. C. (1996). Subject-related risk factors for sport injuries: A 1-yr prospective study in young adults. Medicine and Science in Sports and Exercise, 28, 1171-1179. doi: 10.1097/00005768-199609000-00014

Viljanen, M., Malmivaara, A., Uitti, J., Rinne, M., Palmroos, P., \& Laippala, P. (2003). Effectiveness of dynamic muscle training, relaxation training, or ordinary activity for chronic neck pain: Randomized controlled trial. $B M J, 327,475-480$. doi: $\underline{10.1136 / \mathrm{bmj} .327 .7413 .475}$

Walker, N., \& Heaney, C. (2013). Psychological response to injury. In M. ArvinenBarrow \& N. Walker (Eds.). The psychology of sport injury and rehabilitation (pp. 23-39). New York, NY: Routledge.

Weinberg, R. S., \& Gould, D. (2010). Foundations of sport and exercise psychology $\left(5^{\text {th }}\right.$ ed.). Champaign IL: Human Kinetics.

Wiese, D. M., \& Weiss, M. R. (1987). Psychological rehabilitation and physical injury: Implications for the sports medicine team. The Sport Psychologist, 1, 318-330.

Wiese Bjornstal, D. M. \& Shaffer, S. M. (1999). Psychosocial dimensions of sport injury. In R. Ray \& D. Wiese Bjornstal (Eds.). Counseling in sports medicine (pp. 23-40). Champaign, IL: Human Kinetics.

Wiese Bjornstal, D. M., Smith, A. M., Shaffer, S. M., \& Morrey, M. A. (1998). An integrated model of response to sport injury: Psychological and sociological dynamics. Journal of Applied Sport Psychology, 10, 46-69. 
Williams, J. M., Anderson, M. B. (1998). Psychosocial antecedents of sport injury: Review and critique of the stress and injury model. Journal of Applied Sport Psychology, 10, 5-25.

Williams, J. M., \& Andersen, M. B. (2007). Psychosocial antecedents of sport injury and interventions for risk reduction. In G. Tenenbaum \& R. Eklund (Eds.). Handbook of sport psychology ( $3^{\text {rd }}$ ed. pp. 379-403). Hoboken, NJ: Wiley.

Williams, J. M., \& Scherzer, C. B. (2006) Injury risk and rehabilitation: Psychological considerations. In J.M. Williams (Ed.). Applied sport psychology: Personal growth for peak performance ( $3^{\text {rd }}$ ed) (pp. 565-594). New York, NY: McGrawHill.

Wittig, A. F., \& Schurr, K. T. (1994). Psychological characteristics of women volleyball players: Relationships with injuries, rehabilitation, and team success. Personality and Social Psychology Bulletin, 20, 322-330. doi: 10.1177/0146167294203010

Yang, J., Tibbetts, A. S., Covassin, T., Cheng, G., Nayar, S., \& Heiden, E. (2012). Epidemiology of overuse and acute injuries among competitive collegiate athletes. Journal of Athletic Training, 47, 198-204.

Zizzi, S. J., Blom, L. C., Watson II, J. C., Downey, P., \& Geer, J. (2009). Establishing a hierarchy of psychological skills: Coaches', athletic trainers', and psychologists' uses and perceptions of psychological skills training. Athletic Insight, 11, 75-94. 
